\title{
Albumin Binder-Conjugated Fibroblast Activation Protein Inhibitor Radiopharmaceuticals for Cancer Therapy
}

\author{
Mengxin $\mathrm{Xu}^{* 1}, \mathrm{Pu}$ Zhang $^{* 1}$, Jie Ding ${ }^{2}$, Junyi Chen ${ }^{1}$, Li Huo ${ }^{3}$, Zhibo Liu ${ }^{1,3}$
}

\begin{abstract}
${ }^{1}$ Radiochemistry and Radiation Chemistry Key Laboratory of Fundamental Science, Beijing National Laboratory for Molecular Sciences, College of Chemistry and Molecular Engineering, Peking University, Beijing 100871, China;

${ }^{2}$ Department of Nuclear Medicine, Peking Union Medical College Hospital, Chinese Academy of Medical Science \& Peking Union Medical College, Beijing, 100730, China. ${ }^{3}$ Peking University-Tsinghua University Center for Life Sciences, Beijing 100871, China; *Contributed equally to this work.
\end{abstract}

\section{Corresponding author}

Zhibo Liu

Radiochemistry and Radiation Chemistry Key Laboratory of Fundamental Science, Beijing National Laboratory for Molecular Sciences, College of Chemistry and Molecular Engineering, Peking University

Beijing, 100871, China.

Email: zbliu@pku.edu.cn

Phone: +86-15711362486

Fax: +86-01062751715 


\section{First author}

Mengxin $\mathrm{Xu}$

College of Chemistry and Molecular Engineering, Peking University

Beijing, 100871, China.

Email: xumengxinbest@pku.edu.cn

Phone: +86-18810991871

Fax: +86-01062751715

Pu Zhang

College of Chemistry and Molecular Engineering, Peking University

Beijing, 100871, China.

Email: zpwawj@pku.edu.cn

Phone: $+86-15860752259$

Fax: $+86-01062751715$

Word count: 4840

Running title: Radiotherapy ligands for FAP

Key Words: Albumin binder, FAP inhibitor, Radionuclide therapy

Immediate Open Access: Creative Commons Attribution 4.0 International License (CC BY) allows users to share and adapt with attribution, excluding materials credited to previous publications.

License: https://creativecommons.org/licenses/by/4.0/.

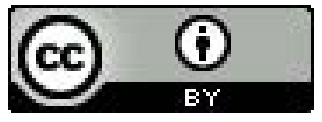

Details: https://jnm.snmjournals.org/page/permissions. 


\section{ABSTRACT}

Fibroblast activation protein (FAP) has become an attractive target for diagnosis and therapy, and a series of FAP inhibitor (FAPI) based radiotracers have been developed and performed excellent diagnosis outcomes in clinical applications. Yet, their fast clearance and insufficient tumor retention have hampered their further clinical applications for cancer treatment. In this study, we developed two albumin binder-conjugated FAPI radiotracers, TEFAPI-06 and TEFAPI-07. They are derived from FAPI-04, and optimized by conjugating two types of well-studied albumin binders, 4-(p-iodophenyl) butyric acid moiety (TEFAPI-06) and truncated Evans blue moiety (TEFAPI-07), to try to overcome the above limitations at the expense of prolonging the blood circulation.

Methods: TEFAPI-06 and TEFAPI-07 were synthesized and labeled with ${ }^{68} \mathrm{Ga},{ }^{86} \mathrm{Y}$ and ${ }^{177} \mathrm{Lu}$ successfully. A series of cell assays were performed to identify the binding affinity and FAP specificity in vitro. PET imaging, SPECT imaging and biodistribution study were performed to evaluate the pharmacokinetics in the pancreatic cancer patient-derived xenografts (PDX) animal models. The cancer treatment efficacy of ${ }^{177}$ Lu-TEFAPI-06 and ${ }^{177}$ Lu-TEFAPI-07 have been evaluated in pancreatic cancer PDX-bearing mice.

Results: The binding affinity $\left(\mathrm{K}_{\mathrm{d}}\right)$ to FAP of ${ }^{68} \mathrm{Ga}$-TEFAPI-06 and ${ }^{68} \mathrm{Ga}-\mathrm{TEFAPI}-07$ is $10.16 \pm 2.56 \mathrm{nM}$ and $7.81 \pm 2.28 \mathrm{nM}$, respectively, which were comparable with that of ${ }^{68}$ Ga-FAPI-04. Comparative PET imaging of HT-1080-FAP and HT-1080 tumor-bearing 
mice and blocking study showed the FAP targeting ability in vivo of these two tracers. Compared with ${ }^{177}$ Lu-FAPI-04, PET imaging, SPECT imaging and biodistribution studies of TEFAPI-06 and TEFAPI-07 have demonstrated their remarkably enhanced tumor accumulation and retention, respectively. Notable tumor growth inhibitions of ${ }^{177} \mathrm{Lu}-$ TEFAPI-06 and ${ }^{177}$ Lu-TEFAPI-07 have been observed, while the control groups and the group treated by ${ }^{177} \mathrm{Lu}$-FAPI-04.

Conclusion: Two albumin binder-conjugated FAPI radiopharmaceuticals have been developed and evaluated in vitro and in vivo. Significantly improved tumor uptake and retention have been observed compared to the original FAPI tracer. Both ${ }^{177} \mathrm{Lu}$-TEFAPI06 and ${ }^{177}$ Lu-TEFAPI-07 showed remarkable growth inhibition to PDX tumors while the side effect is almost negligible, showing that they are promising for further clinical translational studies. 


\section{INTRODUCTION}

Fibroblast activation protein (FAP) is overexpressed in cancer-associated fibroblasts (CAFs), which is one of the main tumor stroma components and constitutes a major proportion of cells within the tumor $(1,2)$. Though they are not malignant, the growth factor and chemokine produced by stromal cells especially CAFs can lead to the direct stimulation of tumor cell growth, migration and progression (3). Considering the vital role in tumor survival and cancer growth, CAFs-targeted diagnosis and therapy via the biomarker FAP have become an attractive strategy for tumor treatment (4,5). FAP-targeted radiopharmaceutical therapy could deliver therapeutic radioisotopes to the CAFs. It damages the stromal cells and the neighboring tumor cells through the "crossfire" effect of the $\beta$ or $\alpha$-emitting radionuclides, which may achieve the augmented therapeutic efficacy (6).

Recently, a variety of quinolone-based fibroblast activation protein inhibitors (FAPI) radiopharmaceuticals have been developed and demonstrated excellent uptake in different FAP-positive tumors of cancer patients (7-9). For FAP-targeted radiotherapy, an emerging strategy is to directly modify the inhibitor structure for the purpose to enhance the tumor uptake and retention, meanwhile, make the accumulation in non-target tissues remain unchanged or decreased (10-12). A series of FAPI probes including FAPI-04, FAPI-21 and FAPI-46 have been successfully developed, their improved pharmacokinetic properties 
make them promising candidates for therapeutic outcome improvement (13-16). Though this is one of the optimal ways for developing therapeutic radiopharmaceuticals, the relatively rapid washout from the tumor is still a considerable limitation. Besides, it may be challenging to achieve notable enhancement of pharmacokinetic properties by subtle structure modification.

Several studies have shown that prolonging the blood circulation of drug molecules by using albumin-binder moieties could remarkably improve the therapeutic dose (17). 4-(piodophenyl) butyric acid and truncated Evans blue moieties are the most widely used albumin binders. The previous studies suggest that they can enhance the tumor uptake and retention of radiopharmaceuticals, resulting in improved therapeutic efficacy (18-23). Further clinical translation studies also validate the promising of this strategy to be a platform technology for radiopharmaceutical development (24-26). Therefore, we are curious if attaching an albumin-binder moiety to the FAPI molecules would improve the FAP targeted radiotherapy efficacy at the expense of increased retention in blood.

In this study, two albumin binder-FAPI conjugates, TEFAPI-06 and TEFAPI-07, are developed by logistical fabrication of three functional components: a quinoline-based FAP inhibitor originated from FAPI-04; a chelator (i.e., DOTA group) that allows radionuclide labeling for imaging $\left({ }^{68} \mathrm{Ga}\right.$ or $\left.{ }^{86} \mathrm{Y}\right)$ or therapy $\left({ }^{177} \mathrm{Lu}\right)$; an albumin binder, 4-(p-iodophenyl) butyric acid moiety (TEFAPI-06) or truncated Evans blue moiety (TEFAPI-07). The 
purpose of the study is to evaluate whether the modification improves tumor retention in vivo, and which albumin binder matches FAPI molecules better. A series of detailed experiments and comparisons including cell binding assay, PET imaging, biodistribution and radiotherapy study have been performed. And the results demonstrated the high FAP binding affinity and specificity, the enhanced tumor retention and the improved radiotherapy efficacy of these two albumin binders conjugated FAPI radiotracers.

\section{MATERIALS AND METHODS}

\section{Ligands and Radionuclides}

The synthesis route and chemical characterization of TEFAPI-06 and TEFAPI-07 were described in the supplemental information (supplemental Fig. $1-20$ ). ${ }^{68} \mathrm{GaCl}_{3}$ was eluted with a solution of $0.6 \mathrm{M}$ hydrochloride from the ${ }^{68} \mathrm{Ge}^{6}{ }^{68} \mathrm{Ga}$ generator (iThemba LABS, South Africa). ${ }^{86} \mathrm{YCl}_{3}$ was produced with a $14.6-\mathrm{MeV}$ cyclotron, the target design follows our previous report (27) and the purification procedure follows the previous protocol (28).

${ }^{177} \mathrm{LuCl}_{3}$ in a solution of $0.1 \mathrm{M}$ hydrochloride was purchased from ITG (Germany).

\section{Radiolabeling and Stability in vitro}

The radiolabeling of ${ }^{68} \mathrm{Ga},{ }^{86} \mathrm{Y}$ and ${ }^{177} \mathrm{Lu}$ is performed by incubating with $50 \mathrm{nmol}$ precursor at $\mathrm{pH}=4.5-5.0$ at $90{ }^{\circ} \mathrm{C}$ for $10 \mathrm{~min}$. The product is purified by $\mathrm{C} 18$ column extraction and the radiochemical purity is determined by high performance liquid chromatography 
equipped with radioactivity detector (radio-HPLC). Stability of ${ }^{177} \mathrm{Lu}$-TEFAPI-06 and

${ }^{177} \mathrm{Lu}$-TEFAPI-07 in saline and human serum were monitored from $2 \mathrm{~h}$ to $168 \mathrm{~h}$ by using radio-HPLC (13). More details about radiochemistry, quality control and stability assay can be found in supplemental information (Section 3).

\section{Cell Culture and Assay}

The human fibrosarcoma cell line (HT-1080) and HT-1080 cell line transfected with human FAP gene (HT-1080-FAP, from WuXi AppTec) were cultivated in Eagle's minimum essential medium containing $10 \%$ fetal bovine serum, $1 \%$ antibiotic-antimycotic, $4 \mu \mathrm{g} / \mathrm{mL}$ Blasticidin $\mathrm{S}$ at $37^{\circ} \mathrm{C} / 5 \%$ carbon dioxide condition. For competition assays, HT-1080-FAP cells were seeded in 6 -well plates and cultivated until they reached about $1.2 \times 10^{6}$ cells per well. The cells were incubated simultaneously with unlabeled FAPI-04, TEFAPI-06 or TEFAPI-07 $\left(10^{-5}-10^{-9} \mathrm{M}\right)$ with ${ }^{68} \mathrm{Ga}-\mathrm{FAPI}-04$ in $1 \mathrm{~mL}$ fresh medium without FBS for one hour. Removed the medium and washed the cells for twice with PBS. Subsequently, the cells were lysed with $0.5 \mathrm{~mL} 1 \mathrm{M} \mathrm{NaOH}$ and washed with $0.5 \mathrm{~mL}$ PBS twice, collected the solution of $\mathrm{NaOH}(0.5 \mathrm{~mL})$ and $\mathrm{PBS}(0.5 \mathrm{~mL} \times 2)$ to determine the uptake counts. For saturation binding assays, HT-1080-FAP and HT-1080 cells were seeded in 24-well plates and cultivated until they reached about $2 \times 10^{5}$ cells per well. ${ }^{68} \mathrm{Ga}$-FAPI- $04,{ }^{68} \mathrm{Ga}$-TEFAPI06 or ${ }^{68} \mathrm{Ga}$-TEFAPI-07 diluted to the concentration $0.01-200 \mathrm{nM}$ in fresh medium without FBS. The cells were incubated in the above solution for one hour and then washed twice 
with PBS. The lysed cells and washing PBS were collected to be determined the counts.

\section{Tumor-Bearing Animal Models}

All animal care and experimental procedure were performed by following the animal protocols (CCME-LiuZB-2) approved by the ethics committee of Peking University, and the mice were from Beijing Vital River Laboratory Animal Technology Co., Ltd. For cellline-derived xenograft (CDX) models, $5 \times 10^{6}$ HT-1080-FAP or HT-1080 cells were subcutaneously inoculated into the right shoulder of 6 weeks old female nu/nu mice. For patient-derived xenograft (PDX) model establishment, the tumor specimens were obtained from patients who underwent presurgical ${ }^{68} \mathrm{Ga}-\mathrm{FAPI}-04 \mathrm{PET} / \mathrm{CT}$ imaging to confirm the tumor was FAP positive. After surgical resection, the tumor specimens were immediately placed in ready to use fresh tissue preservation solution (TM2701-100) and transported under refrigerated condition within two hours. Research protocol was approved by the Institutional Ethics Committee of Peking Union Medical College Hospital (JS-2628). Six weeks old female nonobese diabetic/severe combined immunodeficiency (NOD/SCID) mice were used to establish the PDX models. After being taken out from the preservation solution, the tumor specimens were immediately immersed in sterile phosphate buffer saline solution, and minced with scissors, then the fragments were implanted subcutaneously into the left and right shoulder of the mice which were anesthetized with isoflurane in advance. Engraftment efficiency was determined by ${ }^{68} \mathrm{Ga}-\mathrm{FAPI}-04$ PET/CT 
imaging (Supplemental Fig. 21A). The IHC staining (Supplemental Fig. 21B) demonstrated that the pancreatic cancer PDX model used in this study was indeed FAP overexpressed.

\section{Small Animal PET Imaging}

All PET scans were performed on Mediso nanoScan ${ }^{\circledR}$ PET 122S small animal PET/CT imaging system. For the 60-min dynamic PET imaging, 29.6-37.0 MBq of ${ }^{68} \mathrm{Ga}-\mathrm{TEFAPI}-$ 06 or ${ }^{68} \mathrm{Ga}$-TEFAPI-07 were given to healthy NOD/SCID mice through tail-vein injection. The rest PET imaging was performed on pancreatic cancer PDX tumor-bearing mice, HT1080-FAP and HT-1080 tumor-bearing mice at the indicated time points after intravenous injection of 7.4-11.1 MBq ${ }^{86}$ Y-FAPI-04, ${ }^{86}$ Y-TEFAPI-06 or ${ }^{86}$ Y-TEFAPI-07.

\section{Small Animal SPECT Imaging}

SPECT scans were performed on Mediso nanoSPECT/CT imaging system. The ${ }^{177} \mathrm{Lu}-$ TEFAPI-06 and ${ }^{177} \mathrm{Lu}$-TEFAPI-07 SPECT imaging were performed on the pancreatic cancer PDX-bearing mice at the indicated time points after intravenous injection of 37 MBq ${ }^{177} \mathrm{Lu}$-TEFAPI-06 or ${ }^{177} \mathrm{Lu}$-TEFAPI-07, respectively.

\section{Biodistribution Study}

PDX-bearing mice were injected with $925.0 \mathrm{kBq}{ }^{177} \mathrm{Lu}$-TEFAPI-06 or ${ }^{177} \mathrm{Lu}$-TEFAPI-07 for ex biodistribution. The mice were sacrificed at $24 \mathrm{~h}$ and $96 \mathrm{~h}$ after injection, the counts of different organs were measured with $\gamma$-counter and the data was normalized to ID $\% / g$ 
using the $1 \%$ of total counts.

\section{Radiotherapy Study}

${ }^{68} \mathrm{Ga}$-FAPI-04 PET imaging was performed to evaluate the tumor volume, and the mice were treated when their average tumor volume reaches $35 \mathrm{~mm}^{3}$. The PDX-bearing mice (six groups, 7-9 mice/group) were treated by saline, $3.7 \mathrm{MBq}{ }^{177} \mathrm{Lu}-\mathrm{FAPI}-04,1.85 \mathrm{MBq}$ ${ }^{177} \mathrm{Lu}$-TEFAPI-06, 3.7 MBq ${ }^{177}$ Lu-TEFAPI-06, 1.85 MBq ${ }^{177}$ Lu-TEFAPI-07 and 1.85 MBq ${ }^{177}$ Lu-TEFAPI-07, respectively. The tumor volume and body weight were monitored every two or three days, were euthanized when the tumor volume reached above $1000 \mathrm{~mm}^{3}$. Histopathologic Staining was performed with an anti-human FAP mAb (ab207178, Abcam), and the Hematoxylin and eosin (H\&E) staining were performed by following the previous study (29).

\section{RESULTS}

\section{Radiochemistry and Stability in Vitro}

The radiolabeling yield of TEFAPI-06 and TEFAPI-07 (structures as in Fig. 1A) were over $90 \%$ and the radiochemical purity were over $99 \%(n>20)$. The specific activity of ${ }^{68} \mathrm{Ga}-$ FAPI-04, ${ }^{68} \mathrm{Ga}$-TEFAPI-06 and ${ }^{68} \mathrm{Ga}$-TEFAPI-07 were 5.2-6.7 GBq/ $\mu \mathrm{mol}$. The specific activity of ${ }^{86}$ Y-TEFAPI-06 and ${ }^{86}$ Y-TEFAPI-07 were $2.2-3.4 \mathrm{GBq} / \mu \mathrm{mol}$. The specific activity of ${ }^{177}$ Lu-FAPI-04, ${ }^{177}$ Lu-TEFAPI-06 and ${ }^{177}$ Lu-TEFAPI-07 were 2.9-4.4 
$\mathrm{GBq} / \mu \mathrm{mol}$. Stability of ${ }^{177} \mathrm{Lu}-\mathrm{TEFAPI}-06$ and ${ }^{177} \mathrm{Lu}-\mathrm{TEFAPI}-07$ in saline and human serum were analyzed using radio-HPLC, as shown in Supplemental Fig. 22, the radiochemistry purity of ${ }^{177}$ Lu-TEFAPI-06 and ${ }^{177} \mathrm{Lu}$-TEFAPI-07 were both still over $90 \%$ after incubated in saline and human serum for 7 days.

\section{Binding Assay}

As shown in Fig. 1B and Supplemental Fig. 23A, the cellular uptake of ${ }^{68} \mathrm{Ga}-\mathrm{FAPI}-04$ can be significantly inhibited by treating with cold TEFAPI-06 and TEFAPI-07. The ligand concentration required for $50 \%$ inhibition $\left(\mathrm{IC}_{50}\right)$ of TEFAPI-06, TEFAPI-07 is $12.24 \pm 0.65$ $\mathrm{nM}$ and $17.02 \pm 1.43 \mathrm{nM}$, respectively. The dissociation constant $\mathrm{K}_{\mathrm{d}}$ of ${ }^{68} \mathrm{Ga}$-TEFAPI-06 and ${ }^{68} \mathrm{Ga}$-TEFAPI-07 were $10.16 \pm 2.56 \mathrm{nM}$ and $7.81 \pm 2.28 \mathrm{nM}$ (Fig. 1C), respectively, which is comparable to that of ${ }^{68} \mathrm{Ga}-\mathrm{FAPI}-04(1.91 \pm 0.62 \mathrm{nM}$, Supplemental Fig. 23B). As shown in Fig. 1D, both of ${ }^{68}$ Ga-TEFAPI-06 and ${ }^{68}$ Ga-TEFAPI-07 exhibit almost negligible uptake in HT-1080 cells, but have significant uptake in HT-1080-FAP cells. We have also performed the above binding assays in $0.05 \%$ human serum albumin (20). The results are as following: the IC50 of TEFAPI-06 and TEFAPI-07 is $11.39 \pm 1.15 \mathrm{nM}$ and $27.68 \pm 5.00$ $\mathrm{nM}$ in the presence of albumin, respectively; The $\mathrm{K}_{\mathrm{d}}$ of TEFAPI-06 and TEFAPI-07 was $4.37 \pm 0.81 \mathrm{nM}$ and $19.12 \pm 5.54$ in the absence of albumin, respectively. The IC50 and $\mathrm{K}_{\mathrm{d}}$ of TEFAPI-07 are slightly impacted in the presence of albumin which may be the reason why the blood clearance is faster than TEFAPI-06. 


\section{Small Animal PET Imaging}

To evaluate the in vivo pharmacokinetics of these two radiotracers, dynamic PET imaging of ${ }^{68} \mathrm{Ga}$-TEFAPI-06 and ${ }^{68} \mathrm{Ga}$-TEFAPI-07 were performed in healthy NOD-SCID mice. The signal in heart peaked rapidly at about 2 min after injection and then declined gradually. For ${ }^{68} \mathrm{Ga}$-TEFAPI-06, it was decreased by $35.70 \pm 4.74 \%$ from 10 to 60 min after injection, which was higher than that of ${ }^{68} \mathrm{Ga}$-TEFAPI-07 with the value of $23.15 \pm 2.16 \%$, while from 60 to 240 min after injection, the signal of heart was decreased by $31.80 \pm 1.15 \%$ and $40.56 \pm 5.25 \%$ for ${ }^{68} \mathrm{Ga}$-TEFAPI-06 and ${ }^{68} \mathrm{Ga}$-TEFAPI-07 respectively, resulting in the similar decrease proportion of these two radiotracers from 10 to $240 \mathrm{~min}$ with the values of $56.18 \pm 2.50 \%$ and $54.28 \pm 4.98 \%$ for ${ }^{68} \mathrm{Ga}$-TEFAPI-06 and ${ }^{68} \mathrm{Ga}$-TEFAPI-07 respectively. As shown in Fig. 2, for both ${ }^{68}$ Ga-TEFAPI-06 and ${ }^{68}$ Ga-TEFAPI-07, most of the radioactivity is retained in the blood circulation during the monitoring period and the uptake in other organs such as liver, spleen and kidney were lower compared with the heart and main blood vessels.

To identify the tumor-targeting ability and monitor the in vivo pharmacokinetics quantitatively over a longer period. TEFAPI-06, TEFAPI-07 and FAPI-04 were labeled with the radionuclide ${ }^{86} \mathrm{Y}$ which has a half-life $14.7 \mathrm{~h}$ and the PET imaging was performed using pancreatic cancer PDX-bearing mice. As shown in Fig. 3 and Supplemental Fig. 24, for both ${ }^{86}$ Y-TEFAPI-06 and ${ }^{86}$ Y-TEFAPI-07, tumor could be completely visible at $2 \mathrm{~h}$ after 
injection. The tumor uptake of ${ }^{86} \mathrm{Y}-\mathrm{TEFAPI}-06$ peaked at 0.73 (SUV mean) at $18 \mathrm{~h}$ after injection and that of ${ }^{86}$ Y-TEFAPI-07 peaked at 0.81 (SUV mean) at $8 \mathrm{~h}$ after injection. Then the tumor uptake decreased slowly but still remained high uptake until $36 \mathrm{~h}$ after injection with the value of 0.602 and 0.606 for ${ }^{86}$ Y-TEFAPI-06 and ${ }^{86}$ Y-TEFAPI-07 respectively. While the tumor uptake of ${ }^{86} \mathrm{Y}$-FAPI-04 peaked at 0.35 (SUV mean) at $0.2 \mathrm{~h}$ after injection, and then decreased rapidly. And the area under the curve (AUC) of TEFAPI-07 and TEFAPI-06 is 35.5 folds and 37.9 folds of the AUC of FAPI-04.

To further confirm the FAP specificity in vivo of these two radiotracers, PET imaging of HT-1080-FAP and HT-1080 tumor-bearing mice were performed. As shown in Fig. 4, Supplemental Fig. 25 and Supplemental Fig. 26, the uptake of ${ }^{86}$ Y-TEFAPI-06 and ${ }^{86} \mathrm{Y}$ TEFAPI-07 in HT-1080-FAP tumors was consistently 2-6 folds higher than that of in HT1080 tumors, respectively. Blocking study was also performed, as shown in Supplemental Fig. 27, the tumor uptake decreased at $12 \mathrm{~h}$ and $24 \mathrm{~h}$ after treated with cold TEFAPI-06 and TEFAPI-07.

\section{Small Animal SPECT Imaging}

To further explore the characterization of these two molecules, SPECT imaging was conducted in PDX tumor models in a longer time. As shown in Supplemental Fig. 28, high tumor to non-targeted tissue signal ratios were observed for both ${ }^{177} \mathrm{Lu}$-TEFAPI-06 and

${ }^{177} \mathrm{Lu}$-TEFAPI-07 until $144 \mathrm{~h}$ after injection, The blood circulation properties of these two 
molecules are very similar to the previous PET study.

\section{Biodistribution Study}

To further evaluate the metabolic properties in vivo, biodistribution studies using the pancreatic cancer PDX-bearing mice were performed. As shown in Fig. 5 and Table 1, the tumor uptake of ${ }^{177}$ Lu-TEFAPI-06 and ${ }^{177}$ Lu-TEFAPI-07 were respectively $8.68 \pm 0.73$ and $7.87 \pm 2.08 \% \mathrm{ID} / \mathrm{g}$ at $24 \mathrm{~h}$ after injection, and the tumor to liver ratio were 2.91 and 2.45 . The tumor uptake remained high until $96 \mathrm{~h}$ after injection, which was $7.33 \pm 2.28$ and 7.57 $\pm 2.68 \% \mathrm{ID} / \mathrm{g}$ for ${ }^{177} \mathrm{Lu}$-TEFAPI-06 and ${ }^{177} \mathrm{Lu}$-TEFAPI-07, and the tumor to liver ratio increased to 4.21 and 3.28, respectively. As consistent with the results of PET and SPECT imaging, the kidney uptake of ${ }^{177} \mathrm{Lu}$-TEFAPI-07 retained high at both 24 and $96 \mathrm{~h}$ after injection, with the values of $8.67 \pm 2.30$ and $10.16 \pm 3.28 \% \mathrm{ID} / \mathrm{g}$, while the kidney uptake of ${ }^{177} \mathrm{Lu}$-TEFAPI-06 was much lower, with the value of $2.66 \pm 0.54 \% \mathrm{ID} / \mathrm{g}$ for $96 \mathrm{~h}$ after injection. By comparison, the blood clearance of ${ }^{177}$ Lu-TEFAPI-06 (24 h, $13.32 \pm$ $1.33 \% \mathrm{ID} / \mathrm{g} ; 96 \mathrm{~h}, 2.25 \pm 0.68 \% \mathrm{ID} / \mathrm{g})$ was slower than that of ${ }^{177} \mathrm{Lu}-\mathrm{TEFAPI}-07$ (24 h, 5.64 $\pm 1.50 \% \mathrm{ID} / \mathrm{g} ; 96 \mathrm{~h}, 0.51 \pm 0.24 \% \mathrm{ID} / \mathrm{g})$.

\section{Radiotherapy Study}

To make the assessment of therapeutic efficacy more relevant to the clinical setting, pancreatic cancer PDX-bearing mice were used for the indicated radiotherapy study (Fig. 6A). Comparing to the group treated by saline or $3.7 \mathrm{MBq}{ }^{177} \mathrm{Lu}-\mathrm{FAPI}-04$, the groups 
treated by $1.85 \mathrm{MBq}$ or $3.7 \mathrm{MBq}$ of ${ }^{177} \mathrm{Lu}$-TEFAPI-06 and ${ }^{177} \mathrm{Lu}-\mathrm{TEFAPI}-07$ showed remarkable suppression of tumor growth (Fig. 6B). No statistical difference was observed in treatment efficacy between ${ }^{177} \mathrm{Lu}$-TEFAPI-06 and ${ }^{177} \mathrm{Lu}$-TEFAPI-07. This result is corroborative to the PET imaging and biodistribution study, as they have equally high uptake in the tumors. Except for the control group treated with only saline, transient weight loss was observed for all treatment groups, including ${ }^{177} \mathrm{Lu}-\mathrm{FAPI}-04$, but then return to the healthy level after $7 \mathrm{~d}$ post the initial treatment. H\&E staining of main organs revealed that the side effect from the treatment of ${ }^{177} \mathrm{Lu}$-TEFAPI-06 and ${ }^{177} \mathrm{Lu}$-TEFAPI-07 is almost negligible (Supplemental Fig. 29).

\section{DISCUSSION}

The purpose of this study is to develop FAPI-based radiopharmaceuticals that are more effective than the existing candidates for FAP targeted radiotherapy. Two different albumin binders, 4-(p-iodophenyl) butyric acid and truncated Evans blue moieties, were chosen to be attached with FAPI-04. The resulted TEFAPI-06 and TEFAPI-07 were synthesized and radiolabeled with ${ }^{68} \mathrm{Ga},{ }^{86} \mathrm{Y}$ and ${ }^{177} \mathrm{Lu}$. The radiolabeled TEFAPIs exhibit good stability in saline and human serum, and exhibit high FAP binding affinity in vitro. In addition, SPECT imaging and biodistribution study of ${ }^{177}$ Lu-TEFAPI-06 and ${ }^{177}$ Lu-TEFAPI-07 showed that notable tumor uptake can still be observed even at $6 \mathrm{~d}$ post the injection. Meanwhile, almost 
no radioactive signal could be detected for ${ }^{177} \mathrm{Lu}$-FAPI-04 at $24 \mathrm{~h}$ after injection. We also wondered whether further modifications on the structure may elongate the blood circulation, thus increase the tumor accumulation. Nevertheless, it can be a challenge to balance the treatment efficacy and the potential side effect from blood circulation.

In regards to the clearance pathway, there was no significant difference of uptake between ${ }^{177} \mathrm{Lu}$-TEFAPI-06 and ${ }^{177} \mathrm{Lu}$-TEFAPI-07 in tumor and main organs, except for the kidney. For TEFAPI-07, both the PET and SPECT imaging results showed the significantly higher kidney uptake than that of TEFAPI-06. Of note, imaging indicated that there is no obvious clearance of TEFAPI-07 from kidney over time, which was consistent with the results of biodistribution study. Besides, as both TEFAPI-06 and ${ }^{177}$ Lu-TEFAPI-07 has relatively long blood circulation than the classical radiopharmaceuticals, the side effect may not be negligible. Therefore, a comprehensive $\mathrm{H} \& \mathrm{E}$ staining study of major organs have been performed, and no observable tissue damage were found (Supplemental Fig. 29).

As reported in previous studies, the radiolabeled albumin binder may target the tumor due to enhanced permeability and retention of albumin $(30,31)$. Thus, we are curious that whether the enhanced tumor uptake and retention of ${ }^{177} \mathrm{Lu}$-TEFAPI-06 and ${ }^{177} \mathrm{Lu}$-TEFAPI07 are FAP-dependent. PET imaging results of FAP-positive (HT-1080-FAP) and FAPnegative (HT-1080) tumor-bearing mice showed the much higher uptake of FAP-positive tumor than that of FAP-negative tumor, which demonstrated that the higher tumor uptake 
was dependent on the FAP targeting ability in vivo. For blocking study, the tumor uptake of ${ }^{68} \mathrm{Ga}-\mathrm{FAPI}-04$ decreased significantly when the mice were treated with cold TEFAPI-06 and TEFAPI-07 until $24 \mathrm{~h}$ after injection, which supported that the prolonged tumor retention of these two radiotracers were also mainly dependent on their excellent FAP targeting ability in vivo.

\section{CONCLUSION}

In this study, two albumin binder-conjugated FAPIs, denoted as TEFAPI-06 and TEFAPI $=07$, were developed to optimize the pharmacokinetics of current FAPI radiopharmaceuticals for cancer radiotherapy. Compared with ${ }^{177} \mathrm{Lu}$-FAPI-04, both ${ }^{177} \mathrm{Lu}-$ TEFAPI-06 and ${ }^{177}$ Lu-TEFAPI-07 showed enhanced uptake and retention in tumors. The tumor accumulations are highly FAP-selective and result in remarkable growth inhibition to PDX tumors while the side effect is negligible. Their promising pharmacokinetics warrant further investigations toward a clinical translation for the treatment of FAPpositive cancers. 


\section{DISCLOSURE}

M. X., P. Z., J. C. and Z. L. are consultants for Borui Biotech. J. D. and L. H. have nothing to disclose. No other potential conflicts of interest relevant to this article exist.

\section{ACKNOWLEDGMENTS}

The measurements of NMR were performed at the Analytical Instrumentation Center of Peking University. This work was funded by Beijing Municipal Natural Science Foundation (Z200018), the Special Foundation of Beijing Municipal Education Commission (Grant No. 3500-12020123), the National Natural Science Foundation of China (Grants U1867209 and 21778003) and the Ministry of Science and Technology of the People's Republic of China (2017YFA0506300) and Li Ge-Zhao Ning Life Science Youth Research Foundation (LGZNQN202004). 


\section{KEY POINTS}

QUESTION: Would albumin binder-conjugated FAPI radiopharmaceuticals have high FAP specificity and give enhanced tumor retention and improved radiotherapy efficiency? PERTINENT FINDINGS: Albumin binder-conjugated FAPI radiopharmaceuticals exhibited notably improved tumor uptake and retention compared to the original FAPI tracers, and showed remarkable growth inhibition to PDX tumors while the side effect is negligible.

IMPLICATIONS FOR PATIENT CARE: The conjugation of albumin binder is a promising strategy to develop FAP-targeted radiopharmaceuticals for treating cancers. 


\section{REFERENCES}

1. Hamson EJ, Keane FM, Tholen S, Schilling O, Gorrell MD. Understanding fibroblast activation protein (FAP): Substrates, activities, expression and targeting for cancer therapy. Proteomics Clin Appl. 2014;8:454463.

2. Park JE, Lenter MC, Zimmermann RN, Garin-Chesa P, Old LJ, Rettig WJ. Fibroblast activation protein, a dual specificity serine protease expressed in reactive human tumor stromal fibroblasts*. $J$ Biol Chem. 1999;274:36505-36512.

3. Li H, Fan X, Houghton J. Tumor microenvironment: The role of the tumor stroma in cancer. JCell Biochem. 2007;101:805-815.

4. Calais J. FAP: The next billion dollar nuclear theranostics target? J Nucl Med. 2020;61:163-165.

5. Lo A, Wang L-CS, Scholler J, et al. Tumor-promoting desmoplasia is disrupted by depleting FAPexpressing stromal cells. Cancer Res. 2015;75:2800-2810.

6. Fischer E, Chaitanya K, Wüest T, et al. Radioimmunotherapy of fibroblast activation protein positive tumors by rapidly internalizing antibodies. Clin Cancer Res. 2012;18:6208-6218.

7. Jansen K, Heirbaut L, Verkerk R, et al. Extended structure-activity relationship and pharmacokinetic investigation of (4-quinolinoyl)glycyl-2-cyanopyrrolidine inhibitors of fibroblast activation protein (FAP). $J$ Med Chem. 2014;57:3053-3074.

8. Loktev A, Lindner T, Mier W, et al. A tumor-imaging method targeting cancer-associated fibroblasts. $J$ Nucl Med. 2018;59:1423-1429. 
9. Lindner T, Altmann A, Krämer S, et al. Design and development of ${ }^{99 \mathrm{~m}} \mathrm{Tc}-$ labeled FAPI Tracers for SPECT imaging and ${ }^{188}$ Re Therapy. $J$ Nucl Med. 2020;61:1507-1513.

10. Giesel FL, Adeberg S, Syed M, et al. FAPI-74 PET/CT using either ${ }^{18} \mathrm{~F}-\mathrm{AlF}$ or cold-kit ${ }^{68} \mathrm{Ga}$ labeling: biodistribution, radiation dosimetry, and tumor delineation in lung cancer patients. J Nucl Med. 2021;62:201207.

11. Kratochwil C, Flechsig P, Lindner T, et al. ${ }^{68}$ Ga-FAPI PET/CT: Tracer uptake in 28 different kinds of cancer. J Nucl Med. 2019;60:801-805.

12. Windisch P, Zwahlen DR, Koerber SA, et al. Clinical results of fibroblast activation protein (FAP) specific PET and implications for radiotherapy planning: systematic review. Cancers (Basel). 2020;12:2629.

13. Lindner T, Loktev A, Altmann A, et al. Development of quinoline-based theranostic ligands for the targeting of fibroblast activation protein. J Nucl Med. 2018;59:1415-1422.

14. Loktev A, Lindner T, Burger E-M, et al. Development of fibroblast activation protein-targeted radiotracers with improved tumor retention. J Nucl Med. 2019;60:1421-1429.

15. Watabe T, Liu Y, Kaneda-Nakashima K, et al. Theranostics targeting fibroblast activation protein in the tumor stroma: ${ }^{64} \mathrm{Cu}$ - and ${ }^{225} \mathrm{Ac}$-labeled FAPI-04 in pancreatic cancer xenograft mouse models. $J$ Nucl Med. 2020;61:563-569.

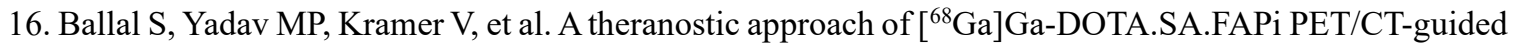
$\left[{ }^{177} \mathrm{Lu}\right] \mathrm{Lu}$-DOTA.SA.FAPi radionuclide therapy in an end-stage breast cancer patient: new frontier in targeted radionuclide therapy. Eur J Nucl Med Mol Imaging. 2021;48:942-944. 
17. Liu Z, Chen X. Simple bioconjugate chemistry serves great clinical advances: albumin as a versatile platform for diagnosis and precision therapy. Chem Soc Rev. 2016;45:1432-1456.

18. Müller C, Farkas R, Borgna F, Schmid RM, Benešová M, Schibli R. Synthesis, radiolabeling, and characterization of plasma protein-binding ligands: potential tools for modulation of the pharmacokinetic properties of (radio)pharmaceuticals. Bioconjug Chem. 2017;28:2372-2383.

19. Benešová M, Umbricht CA, Schibli R, Müller C. Albumin-binding PSMA ligands: optimization of the tissue distribution profile. Mol Pharm. 2018;15:934-946.

20. Kelly JM, Jeitner TM, Ponnala S, et al. A Trifunctional Theranostic Ligand Targeting Fibroblast Activation Protein- $\alpha$ (FAP $\alpha$ ) [published online ahead of print, 2021 Mar 15]. Mol Imaging Biol. 2021;10.1007/s11307-021-01593-1.

21. Kelly, J. M., Amor-Coarasa, A., Nikolopoulou, A, et al. Dual-Target Binding Ligands with Modulated Pharmacokinetics for Endoradiotherapy of Prostate Cancer. J. Nucl. Med. 2017;58:1442-1449..

22. Lau J, Jacobson O, Niu G, Lin KS, Bénard F, Chen X. Bench to bedside: albumin binders for improved cancer radioligand therapies. Bioconjug Chem. 2019;30:487-502.

23. Kuo HT, Lin KS, Zhang Z, et al. Novel ${ }^{177}$ Lu-labeled albumin-binder-conjugated PSMA-targeting agents with extremely high tumor uptake and enhanced tumor-to-kidney absorbed dose ratio. $J$ Nucl Med. $2021 ; 62: 521-527$.

24. Kramer V, Fernández R, Lehnert W, et al. Biodistribution and dosimetry of a single dose of albuminbinding ligand $\left[{ }^{177} \mathrm{Lu}\right] \mathrm{Lu}-\mathrm{PSMA}-\mathrm{ALB}-56$ in patients with mCRPC. Eur J Nucl Med Mol Imaging. 
2021;48:893-903.

25. Zhang J, Hao W, Weiss O J, Cheng Y, Chen X. Safety, pharmacokinetics and dosimetry of a long-acting radiolabeled somatostatin analogue ${ }^{177}$ Lu-DOTA-EB-TATE in patients with advanced metastatic neuroendocrine tumors. $J$ Nucl Med. 2018;59:1699-1705.

26. Hao W, Cheng Y, Zhang J, Jie Z, Chen X. Response to single low-dose ${ }^{177}$ Lu-DOTA-EB-TATE treatment in patients with advanced neuroendocrine neoplasm: a prospective pilot study. Theranostics. 2018;8:33083316.

27. Wang Q, Wang Y, Ding J, et al. A bioorthogonal system reveals antitumour immune function of pyroptosis. Nature. 2020;579(7799):421-426.

28. Avila-Rodriguez MA, Nye JA, Nickles RJ. Production and separation of non-carrier-added ${ }^{86} \mathrm{Y}$ from enriched ${ }^{86}$ Sr targets. Appl Radi Isot. 2008;66:9-13.

29. Ren $\mathrm{J}, \mathrm{Xu} \mathrm{M}$, Chen $\mathrm{J}$, et al. PET imaging facilitates antibody screening for synergistic radioimmunotherapy with a ${ }^{177} \mathrm{Lu}$-labeled $\alpha \mathrm{PD}-\mathrm{L} 1$ antibody. Theranostics. 2021;11(1):304-315.

30. Kelly JM, Amor-Coarasa A, Ponnala S, et al. Trifunctional PSMA-targeting constructs for prostate cancer with unprecedented localization to LNCaP tumors. Eur J Nucl Med Mol Imaging. 2018;45(11):1841-1851.

31. Kelly JM, Amor-Coarasa A, Ponnala S, et al. Albumin-Binding PSMA Ligands: Implications for Expanding the Therapeutic Window. J Nucl Med. 2019;60:656-663. 


\section{Figures}
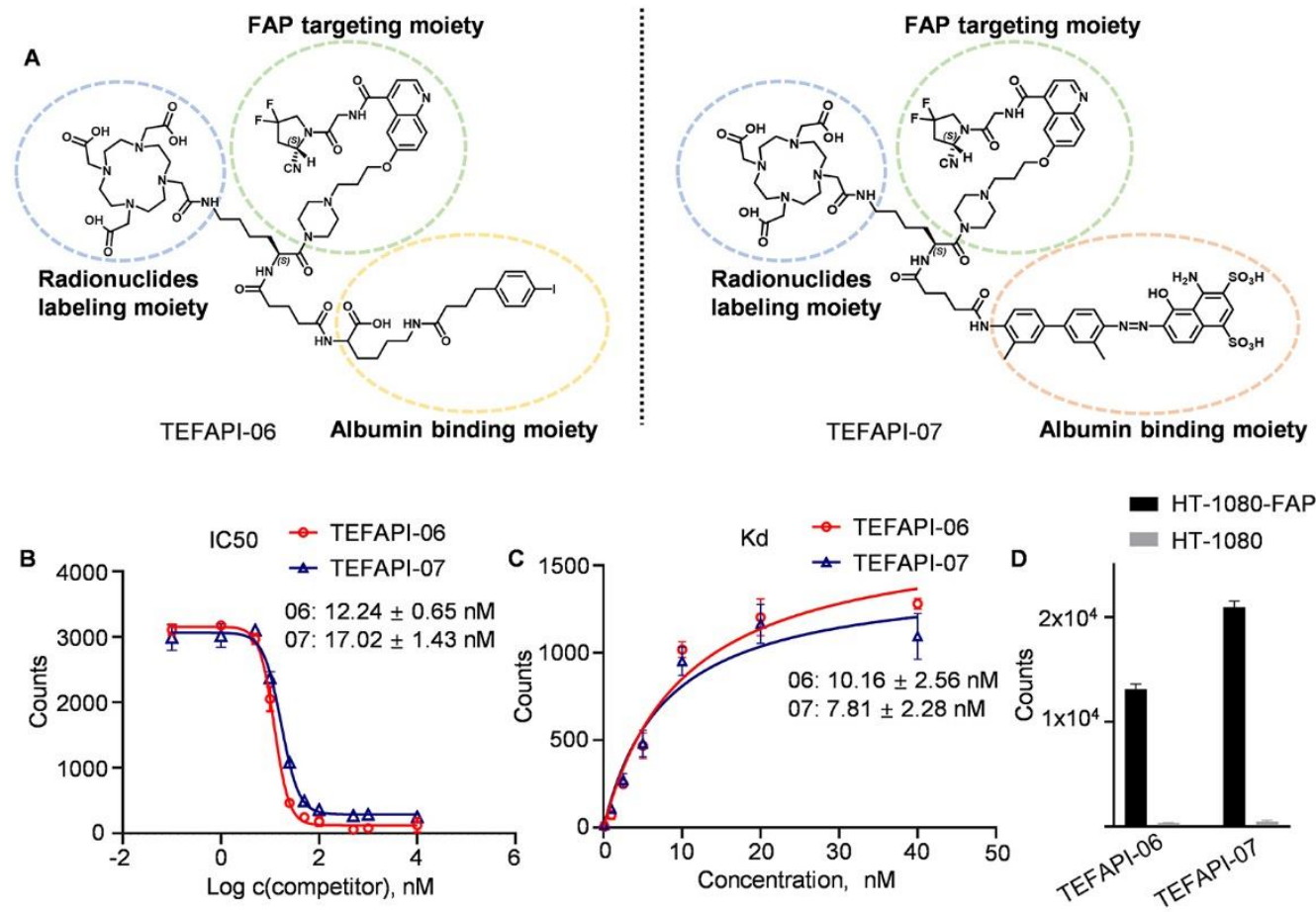

FIGURE 1. (A) Chemical structures of TEFAPI-06 and TEFAPI-07. (B) Competition assays of TEFAPI-06 and TEFAPI-07; (C) Saturation binding assays of radiolabeled TEFAPI-06 and TEFAPI-07; (D) Cellular uptake assays of ${ }^{68} \mathrm{Ga}$-TEFAPI-06 and ${ }^{68} \mathrm{Ga}-$ TEFAPI-07 in HT-1080-FAP and HT-1080 cells. 

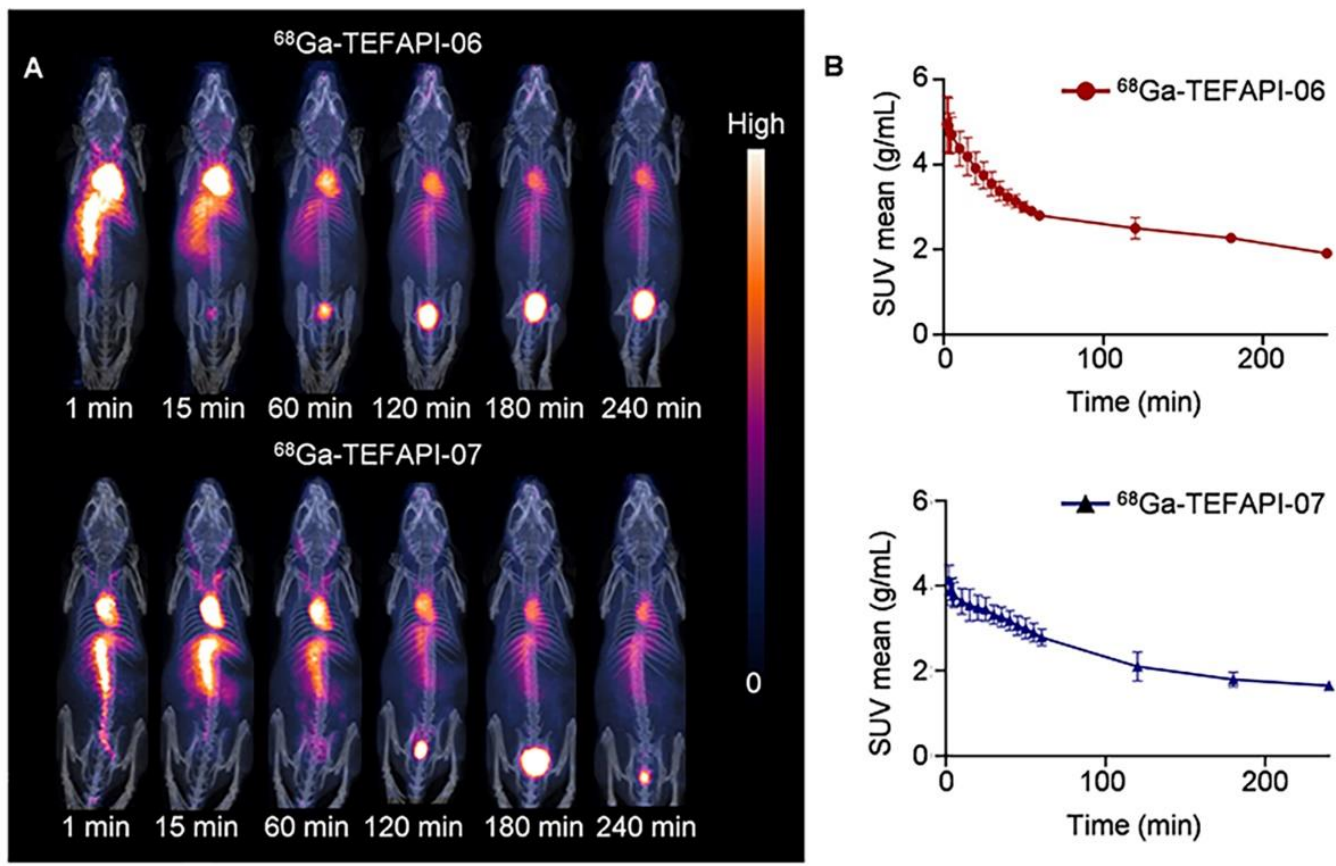

FIGURE 2. (A) Dynamic PET imaging of ${ }^{68} \mathrm{Ga}$-TEFAPI-06 and ${ }^{68} \mathrm{Ga}-\mathrm{TEFAPI}-07$ in healthy NOD/SCID mice. (B) Corresponding blood time-activity curves of ${ }^{68}$ Ga-TEFAPI06 and ${ }^{68} \mathrm{Ga}$-TEFAPI-07. 

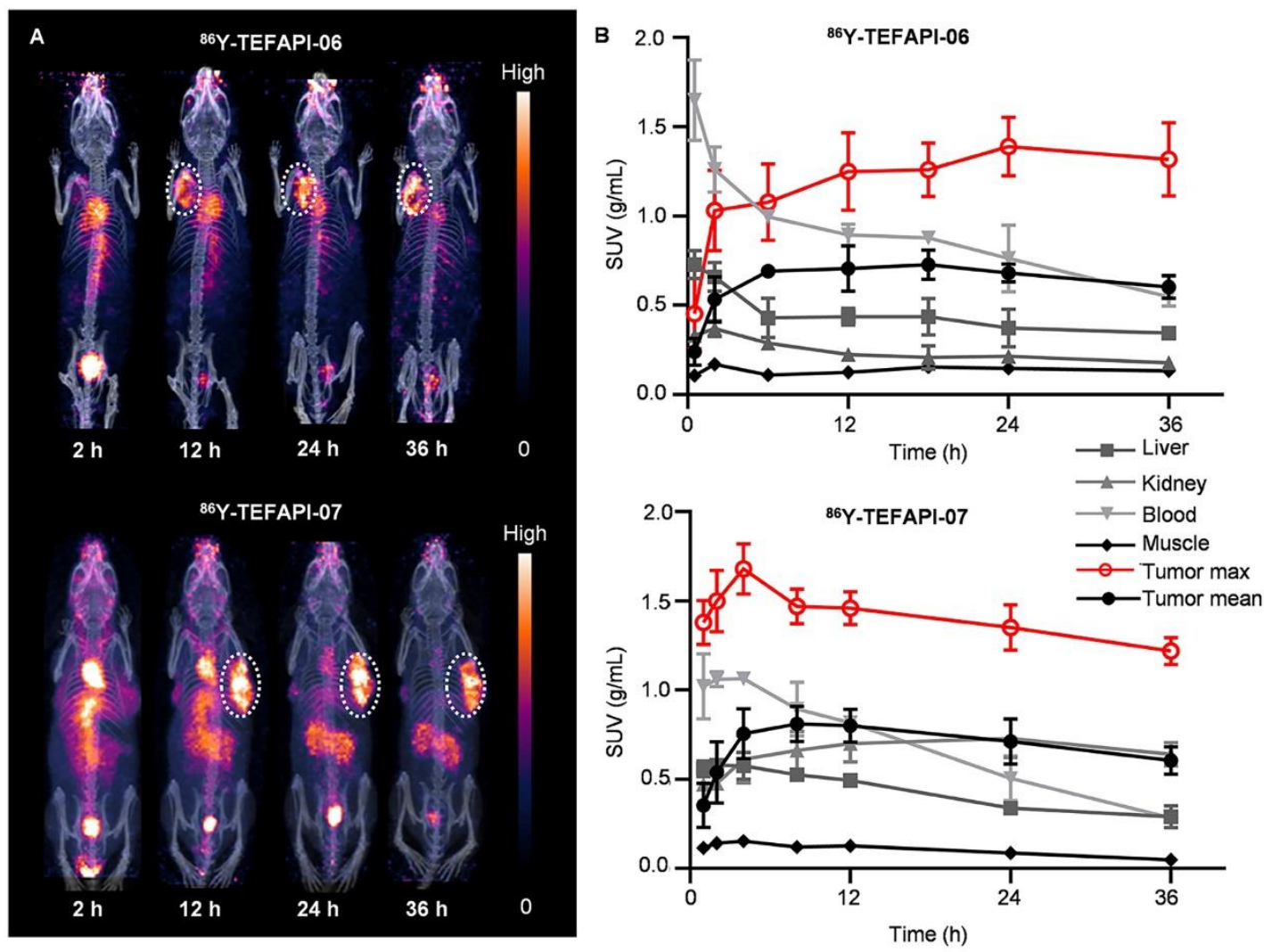

FIGURE 3. (A) PET imaging of ${ }^{86}$ Y-TEFAPI-06 and ${ }^{86}$ Y-TEFAPI-07 in PDX-bearing mice; (B)The time-activity curves for tumor and major organs of ${ }^{86} \mathrm{Y}-\mathrm{TEFAPI}-06$ and ${ }^{86} \mathrm{Y}-$ TEFAPI-07. 

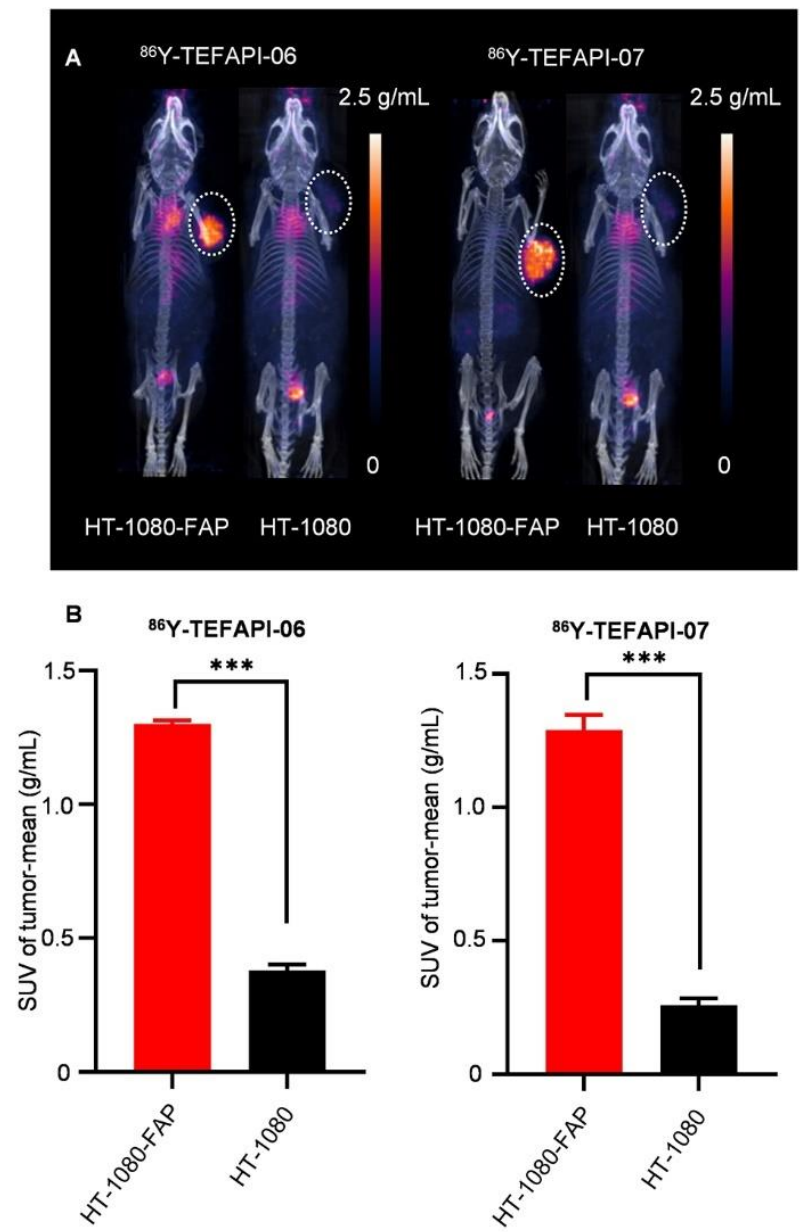

FIGURE 4. (A) PET imaging of ${ }^{86}$ Y-TEFAPI-06 and ${ }^{86}$ Y-TEFAPI-07 in HT-1080-FAP and HT-1080 tumor bearing mice at $24 \mathrm{~h}$ post injection; (B) The uptake of ${ }^{86}$ Y-TEFAPI-06 and ${ }^{86}$ Y-TEFAPI-07 in HT-1080-FAP and HT-1080 tumors at $24 \mathrm{~h}$ post injection $(* * * \mathrm{P}<0.001)$. 


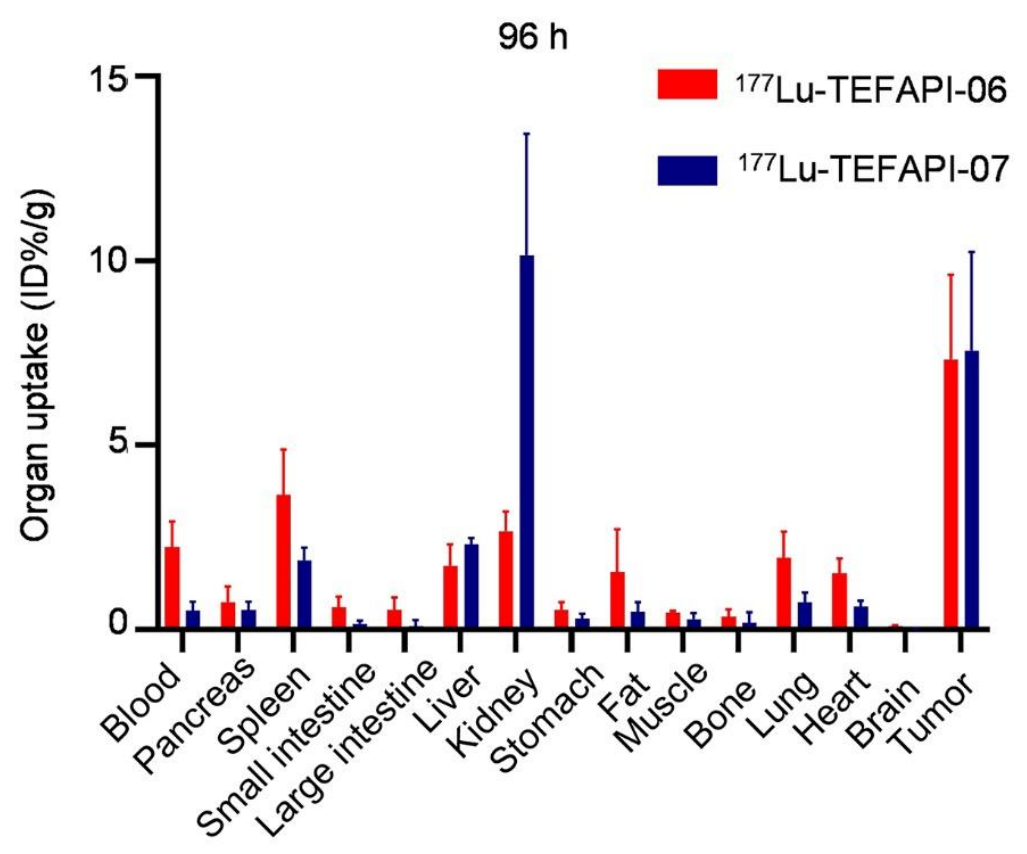

FIGURE 5. Biodistribution study of ${ }^{177}$ Lu-TEFAPI-06 (red bars) and ${ }^{177}$ Lu-TEFAPI-07 (blue bars) in pancreatic cancer PDX-bearing mice at $96 \mathrm{~h}$ after injection $(\mathrm{n}=5)$. 
A

- Control

$\because \quad{ }^{177}$ Lu-FAPI-04 3.7 MBq

$\simeq \quad{ }^{177}$ Lu-TEFAPI-07 1.85 MBq

$\multimap \quad{ }^{177}$ Lu-TEFAPI-06 1.85 MBq

$\leftarrow \quad{ }^{177 L u-T E F A P I-07 ~} 3.7 \mathrm{MBq}$

Tumor implant

$\because \quad$ 177Lu-TEFAPI-06 $3.7 \mathrm{MBq}$

B

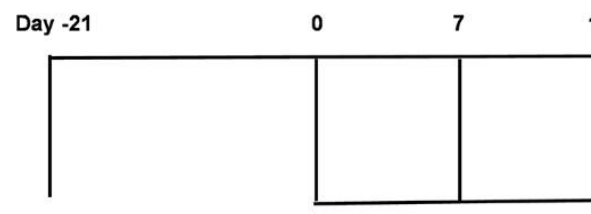

${ }^{177}$ Lu-TEFAPI radiotherapy 3 cycles

$14 \quad 61$

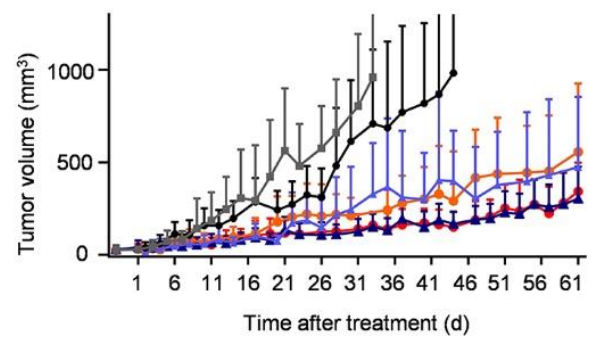

C

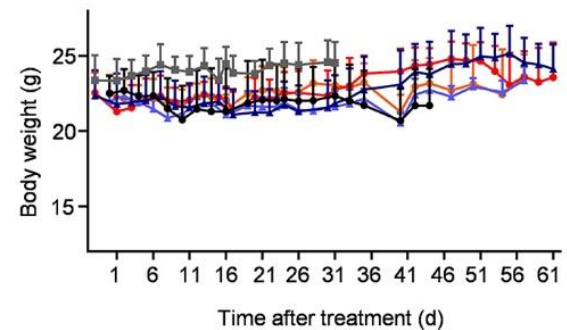

FIGURE 6. Treatment assay of ${ }^{177} \mathrm{Lu}$-TEFAPI-06 and ${ }^{177} \mathrm{Lu}-\mathrm{TEFAPI}-07$ in pancreatic cancer PDX-bearing mice. (A) Design of therapy protocols and treatment scheme; (B) The tumor growth curve after treatment ( $\mathrm{n}=7-9$ mice for each group); (C) Body weight change after treatment. 
TABLE 1. Biodistribution results of ${ }^{177} \mathrm{Lu}$-TEFAPI-06 and ${ }^{177} \mathrm{Lu}$-TEFAPI-07.

\begin{tabular}{|c|c|c|c|c|c|c|c|c|}
\hline \multirow{3}{*}{ Organs } & \multicolumn{4}{|c|}{${ }^{177} \mathrm{Lu}$-TEFAPI-06 } & \multicolumn{4}{|c|}{${ }^{177} \mathrm{Lu}$-TEFAPI-07 } \\
\hline & \multicolumn{2}{|c|}{$24 \mathrm{~h}$} & \multicolumn{2}{|c|}{$96 \mathrm{~h}$} & \multicolumn{2}{|c|}{$24 \mathrm{~h}$} & \multicolumn{2}{|c|}{$96 \mathrm{~h}$} \\
\hline & Mean(\%ID/g) & $\mathrm{SD}(\% \mathrm{ID} / \mathrm{g})$ & Mean(\%ID/g) & $\mathrm{SD}(\% \mathrm{ID} / \mathrm{g})$ & Mean(\%ID/g) & $\mathrm{SD}(\% \mathrm{ID} / \mathrm{g})$ & Mean(\%ID/g) & $\mathrm{SD}(\% \mathrm{ID} / \mathrm{g})$ \\
\hline Blood & 12.32 & 1.33 & 2.25 & 0.68 & 5.64 & 1.49 & 0.51 & 0.24 \\
\hline Pancreas & 2.01 & 0.26 & 0.75 & 0.42 & 2.16 & 0.69 & 0.53 & 0.22 \\
\hline Spleen & 3.00 & 0.66 & 3.66 & 1.22 & 2.69 & 0.87 & 1.88 & 0.34 \\
\hline $\begin{array}{l}\text { Small } \\
\text { Intestine }\end{array}$ & 2.55 & 0.64 & 0.61 & 0.28 & 1.19 & 0.26 & 0.16 & 0.09 \\
\hline $\begin{array}{l}\text { Large } \\
\text { Intestine }\end{array}$ & 1.66 & 0.27 & 0.53 & 0.35 & 1.15 & 0.33 & 0.10 & 0.15 \\
\hline Liver & 2.98 & 0.64 & 1.74 & 0.57 & 3.21 & 0.81 & 2.31 & 0.17 \\
\hline Kidney & 3.20 & 0.84 & 2.66 & 0.54 & 8.67 & 2.30 & 10.16 & 3.28 \\
\hline Stomach & 1.75 & 0.17 & 0.54 & 0.21 & 1.20 & 0.45 & 0.29 & 0.14 \\
\hline Fat & 1.86 & 0.90 & 1.55 & 1.17 & 1.82 & 1.18 & 0.48 & 0.25 \\
\hline Muscle & 1.09 & 0.18 & 0.45 & 0.05 & 1.00 & 0.37 & 0.28 & 0.16 \\
\hline Bone & 1.32 & 0.30 & 0.35 & 0.20 & 1.71 & 0.63 & 0.18 & 0.28 \\
\hline Lung & 4.33 & 1.44 & 1.95 & 0.70 & 2.58 & 0.75 & 0.73 & 0.28 \\
\hline Heart & 3.70 & 1.59 & 1.51 & 0.42 & 2.53 & 1.19 & 0.62 & 0.17 \\
\hline Brain & 0.37 & 0.08 & 0.09 & 0.03 & 0.23 & 0.09 & -0.01 & 0.04 \\
\hline Tumor & 8.68 & 0.73 & 7.33 & 2.28 & 7.87 & 2.08 & 7.57 & 2.68 \\
\hline
\end{tabular}




\section{GRAPHICAL ABSTRACT}
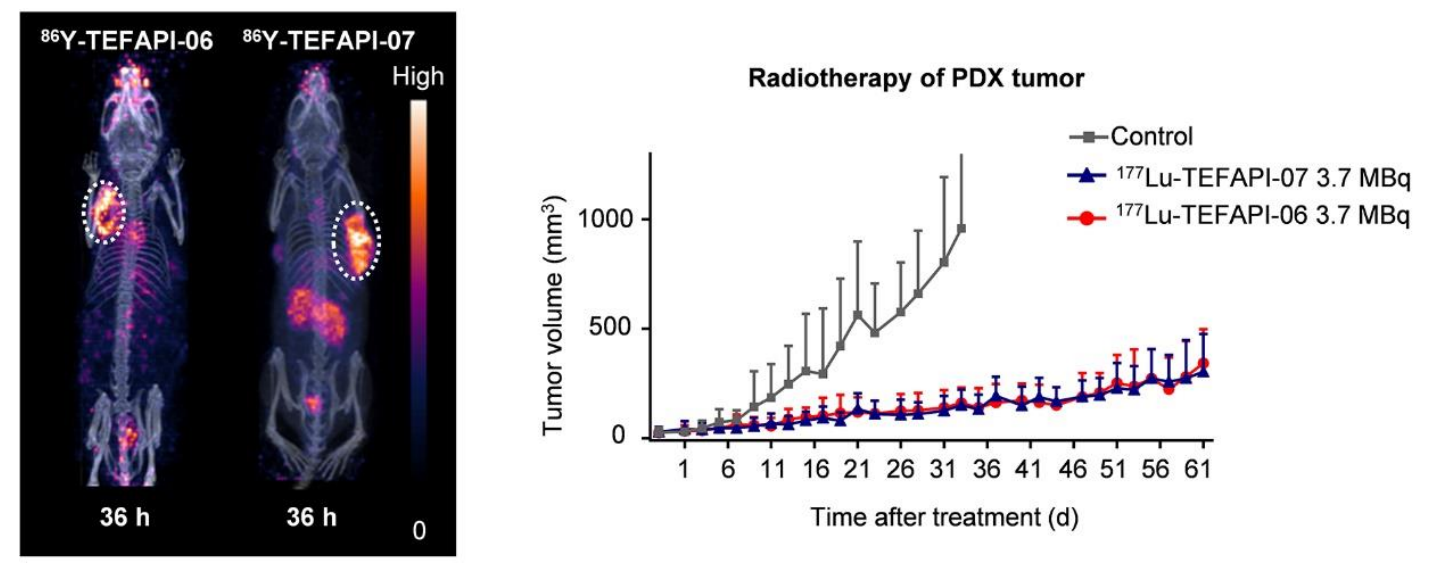
Supplemental Information For

\section{Albumin Binder-Conjugated Fibroblast Activation Protein Inhibitor}

\section{Radiopharmaceuticals for Cancer Therapy}

Mengxin Xu ${ }^{* 1}$, Pu Zhang ${ }^{* 1}$, Jie Ding ${ }^{2}$, Junyi Chen ${ }^{1}$, Li Huo ${ }^{3}$, Zhibo Liu ${ }^{1,3}$

${ }^{1}$ Radiochemistry and Radiation Chemistry Key Laboratory of Fundamental Science, Beijing National Laboratory for Molecular Sciences, College of Chemistry and Molecular Engineering, Peking University, Beijing 100871, China;

${ }^{2}$ Department of Nuclear Medicine, Peking Union Medical College Hospital, Chinese Academy of Medical Science \& Peking Union Medical College, Beijing, 100730, China.

${ }^{3}$ Peking University-Tsinghua University Center for Life Sciences, Beijing 100871, China;

*Contributed equally to this work.

Corresponding author:

Zhibo Liu

Radiochemistry and Radiation Chemistry Key Laboratory of Fundamental Science, Beijing National Laboratory for Molecular Sciences, College of Chemistry and Molecular Engineering

Peking University

Beijing, 100871, China.

Email: zbliu@pku.edu.cn

Phone: +86-15711362486

Fax: $+86-01062751715$

First author:

Mengxin Xu

College of Chemistry and Molecular Engineering

Peking University 
Beijing, 100871, China.

Email: xumengxinbest@pku.edu.cn

Phone: +86-18810991871

Fax: +86-01062751715

Pu Zhang

College of Chemistry and Molecular Engineering

Peking University

Beijing, 100871, China.

Email: zpwawj@pku.edu.cn

Phone: +86-15860752259

Fax: +86-01062751715 


\section{Contents}

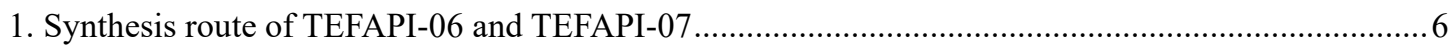

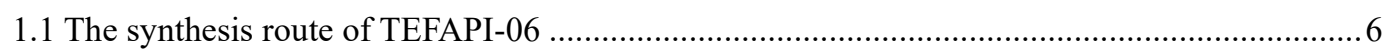

1.1.1 General procedure for preparation of TEFAPI-06_A2 …............................................

1.1.2 General procedure for preparation of TEFAPI-06_A3 ……........................................ 8

1.1.3 General procedure for preparation of TEFAPI-06_A4 ……............................................ 8

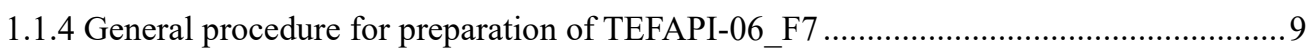

1.1.5 General procedure for preparation of TEFAPI-06_8 ……............................................. 10

1.1.6 General procedure for preparation of TEFAPI-06_9 ………......................................... 11

1.1.7 General procedure for preparation of TEFAPI-06_10 …........................................ 12

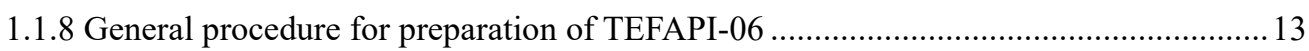

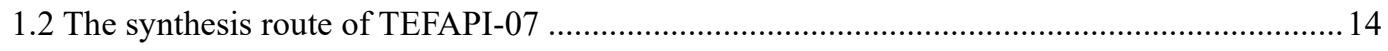

1.2.1 General procedure for preparation of TEFAPI-07_F2 .................................................15

1.2.2 General procedure for preparation of TEFAPI-07_F3 .................................................. 16

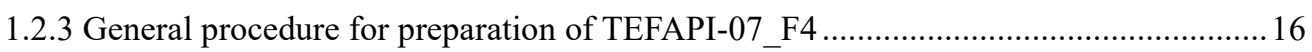

1.2.4 General procedure for preparation of TEFAPI-07_F5 ................................................... 17

1.2.5 General procedure for preparation of TEFAPI-07_F6 .................................................. 18

1.2.6 General procedure for preparation of TEFAPI-07_F7 ................................................ 18

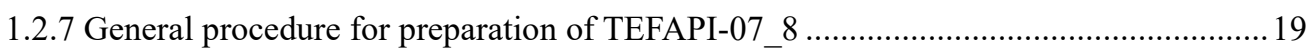

1.2.8 General procedure for preparation of TEFAPI-07_9 ….............................................2 20

1.2.9 General procedure for preparation of TEFAPI-07_10 ..................................................2 20

1.2.10 General procedure for preparation of TEFAPI-07 ..................................................2

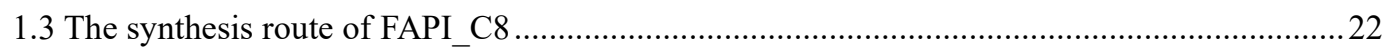

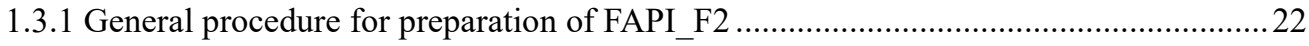

1.3.2 General procedure for preparation of FAPI_C3 ……....................................................2

1.3.3 General procedure for preparation of FAPI_C4 .......................................................... 24

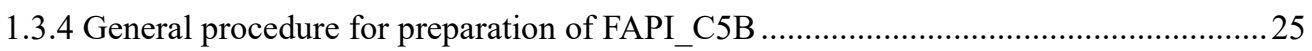




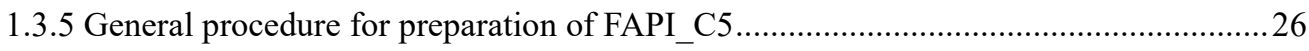

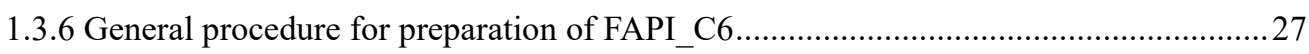

1.3.7 General procedure for preparation of FAPI_C7 ........................................................2 28

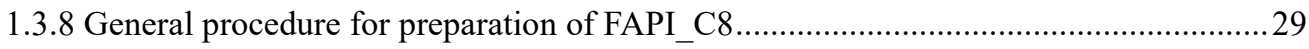

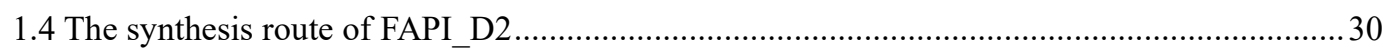

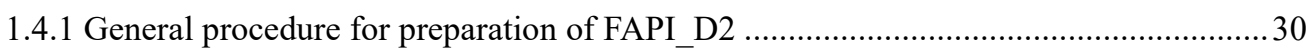

1.5. NMR Spectra and mass spectrum................................................................................. 31

Supplemental Fig 1. LC-MS analysis of TEFAPI-06_F7 ................................................... 31

Supplemental Fig 2. MS analysis of TEFAPI-06_F7 ............................................................ 32

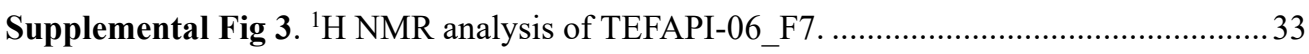

Supplemental Fig 4. LC-MS analysis of TEFAPI-06 .............................................................. 34

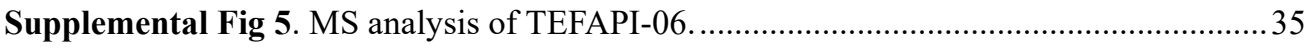

Supplemental Fig 6. ${ }^{1} \mathrm{H}$ NMR (DMSO- $d_{6}$ ) analysis of TEFAPI-06 ......................................... 36

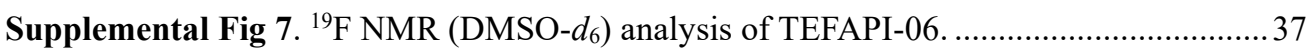

Supplemental Fig 8. ${ }^{1} \mathrm{H}$ NMR $\left(\right.$ methanol- $\left.d_{4}\right)$ analysis of TEFAPI-06 ..................................... 38

Supplemental Fig 9. ${ }^{19} \mathrm{~F}$ NMR (methanol- $d_{4}$ ) analysis of TEFAPI-06.................................. 39

Supplemental Fig 10. ${ }^{1} \mathrm{H}$ NMR analysis of TEFAPI-06................................................ 40

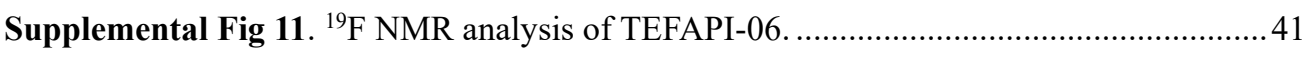

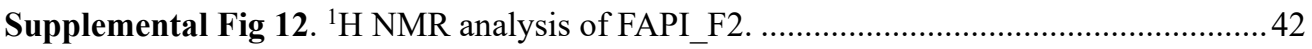

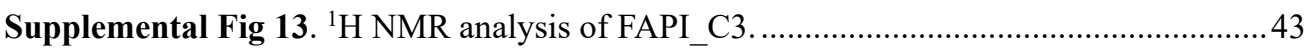

Supplemental Fig 14. ${ }^{1} \mathrm{H}$ NMR analysis of FAPI_C 4 ............................................................. 44

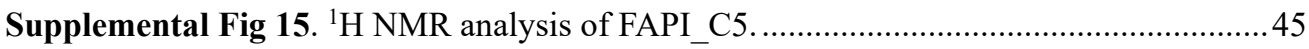

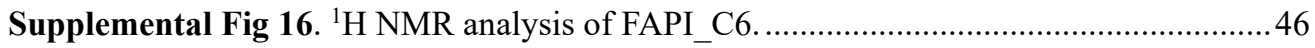

Supplemental Fig 17. ${ }^{1} \mathrm{H}$ NMR analysis of FAPI_C7 ........................................................ 47

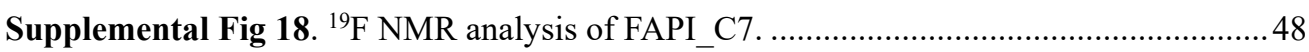

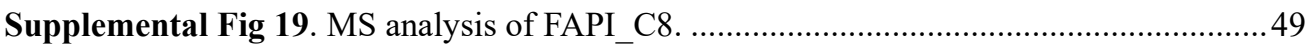

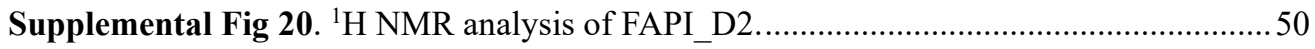


2. ${ }^{68} \mathrm{Ga}-\mathrm{FAPI}-04$ PET imaging and IHC staining results of pancreatic PDX tumor ................................51

3. Radiolabeling and HPLC test procedure and stability results of in vitro stability analysis ................52

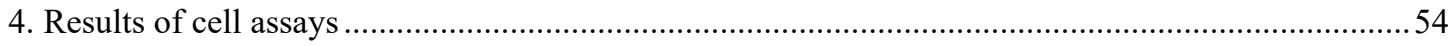

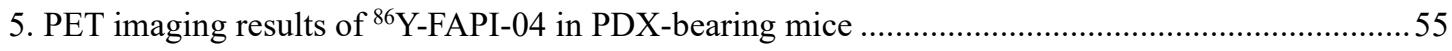

6. PET imaging results of HT-1080-FAP and HT-1080 tumor bearing mice ..........................................56

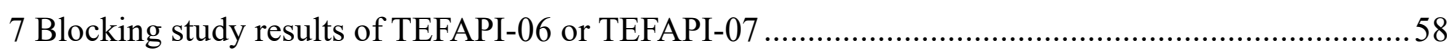

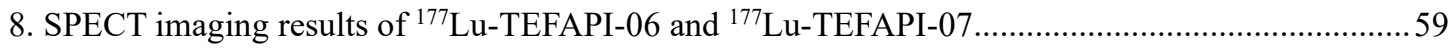

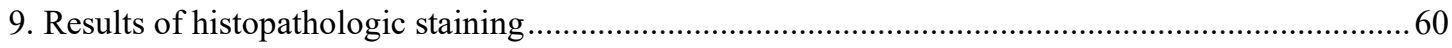




\section{Synthesis route of TEFAPI-06 and TEFAPI-07}

1.1 The synthesis route of TEFAPI-06
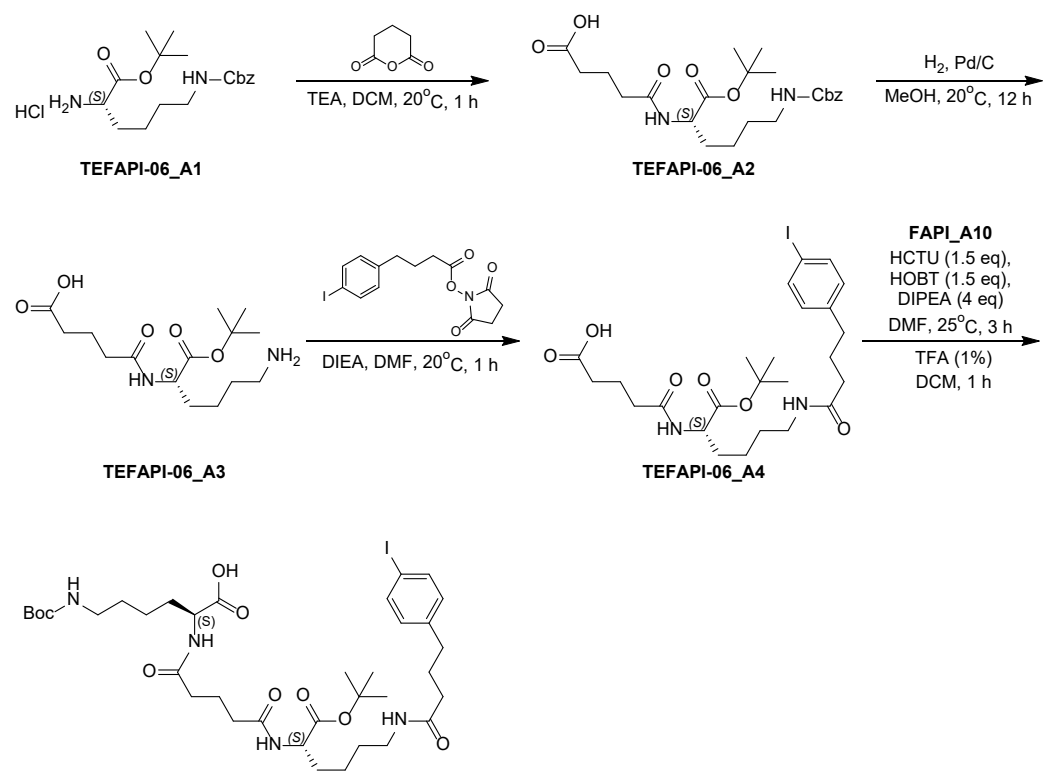

TEFAPI-06_F7
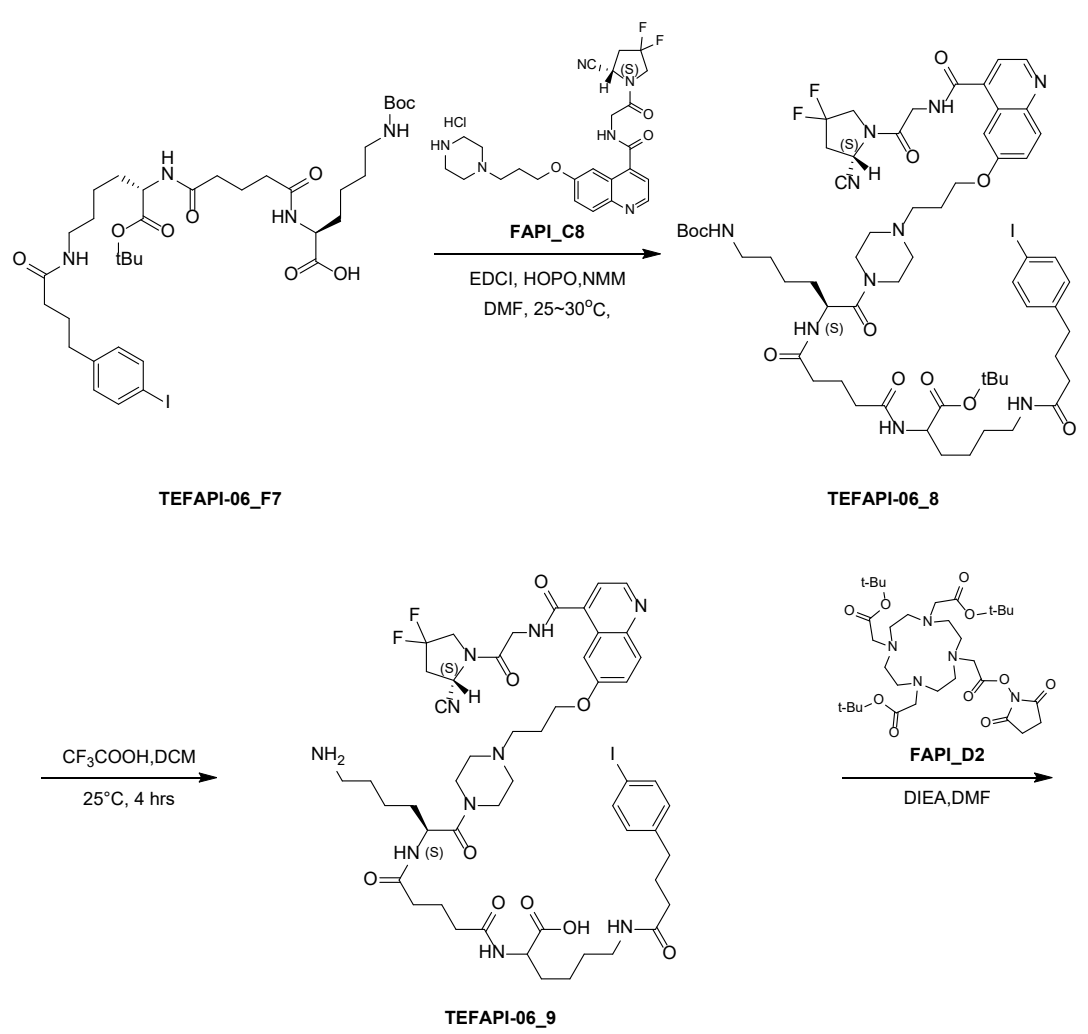


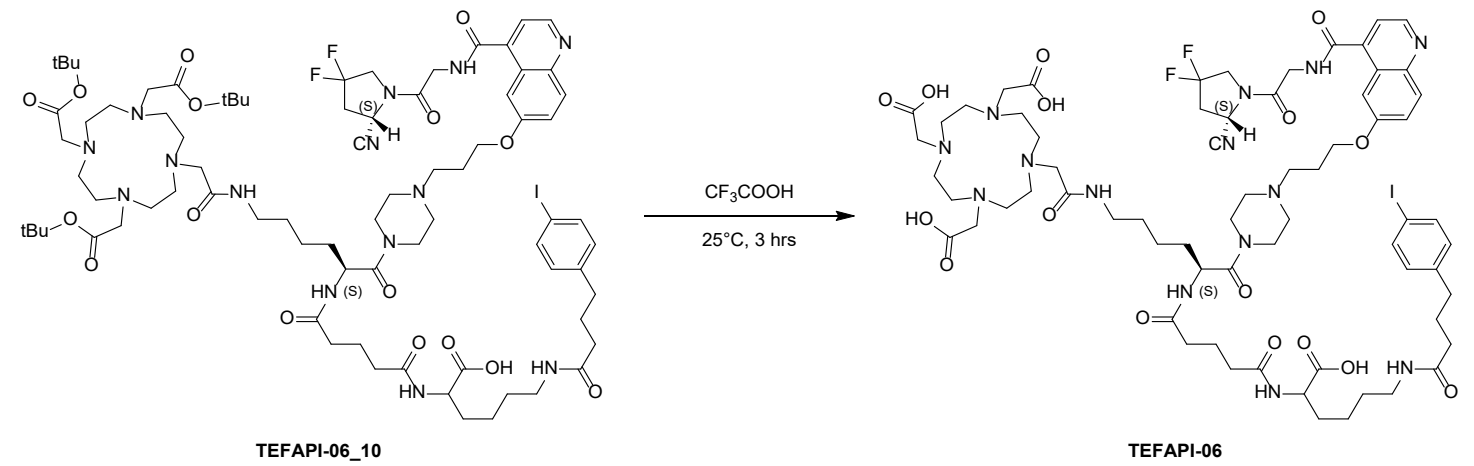

\subsubsection{General procedure for preparation of TEFAPI-06_A2}

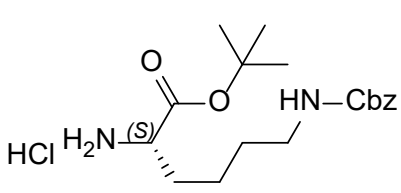

TEFAPI-06_A1

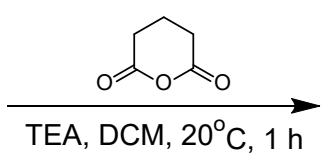

TEA, DCM, $20^{\circ} \mathrm{C}, 1 \mathrm{~h}$

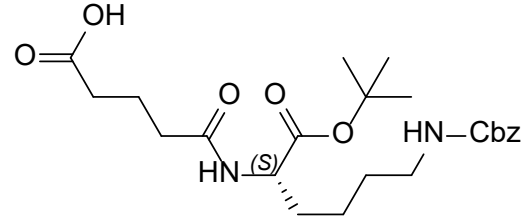

TEFAPI-06_A2

To a solution of TEFAPI-06_A1 $(20 \mathrm{~g}, 53.64 \mathrm{mmol}, 1 \mathrm{eq}, \mathrm{HCl})$ in DCM $(200 \mathrm{~mL})$ was added tetrahydropyran2,6-dione $(9.18 \mathrm{~g}, 80.45 \mathrm{mmol}, 1.5 \mathrm{eq})$, then the solution was cooled to $0{ }^{\circ} \mathrm{C}$. Then TEA $(16.28 \mathrm{~g}, 160.91$ mmol, $22.40 \mathrm{~mL}, 3 \mathrm{eq}$ ) was added drop-wise to the above solution. The mixture was stirred at $20^{\circ} \mathrm{C}$ for $1 \mathrm{~h}$. The solution was concentrated in vacuum, TEFAPI-06_A2 (20 g, crude) was obtained as white oil. LC-MS showed TEFAPI-06_A2 was detected.

LC-MS (ESI $\left.{ }^{+}\right): \mathrm{m} / \mathrm{z} 451.2(\mathrm{M}+\mathrm{H})^{+}$.

The column used for chromatography was a Luna C18 2.0*30 mm (3 um particles). Detection methods are diode array (DAD). MS mode was positive electrospray ionization. MS range was 100-1000. Mobile phase A was $0.037 \%$ trifluoroacetic acid in water, and mobile phase B was $0.018 \%$ trifluoroacetic acid in HPLC grade acetonitrile. The gradient was 5-95\% B in $2.00 \mathrm{~min}, 5 \% \mathrm{~B}$ in $0.01 \mathrm{~min}, 5-95 \% \mathrm{~B}(0.01-1.00 \mathrm{~min}), 95-$ $100 \% \mathrm{~B}(1.00-1.80 \mathrm{~min}), 5 \% \mathrm{~B}$ in $1.81 \mathrm{~min}$ with a hold at $5 \% \mathrm{~B}$ for $0.19 \mathrm{~min}$. The flow rate was $1.0 \mathrm{~mL} / \mathrm{min}$ $(0.00-1.80 \mathrm{~min})$ and $1.2 \mathrm{~mL} / \mathrm{min}(1.81-2.00 \mathrm{~min})$. 


\subsubsection{General procedure for preparation of TEFAPI-06_A3}

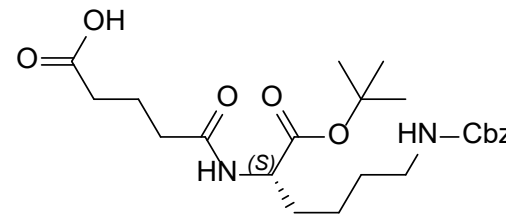

TEFAPI-06_A2

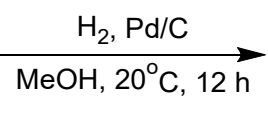

$\underset{\mathrm{MeOH}, 20^{\circ} \mathrm{C}, 12 \mathrm{~h}}{\stackrel{\mathrm{H}_{2}, \mathrm{Pd} / \mathrm{C}}{\longrightarrow}}$

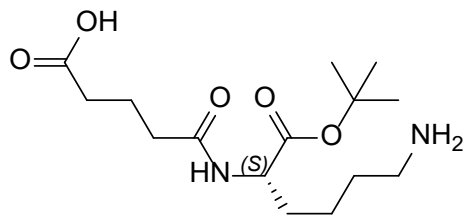

TEFAPI-06_A3

To a solution of TEFAPI-06_A2 (20 g, $44.39 \mathrm{mmol}, 1 \mathrm{eq})$ in $\mathrm{MeOH}(200 \mathrm{~mL})$ was added $\mathrm{Pd} / \mathrm{C}(8 \mathrm{~g}, 10 \%$ purity) at $20{ }^{\circ} \mathrm{C}$, then the mixture was stirred at $20{ }^{\circ} \mathrm{C}$ for $12 \mathrm{~h}$ under $\mathrm{H}_{2}(15 \mathrm{psi})$. The mixture was filtered and the filtrate was concentrated in vacuum. TEFAPI-06_A3 (14 g, crude) was obtained as white oil. LC-MS showed product was detected.

LC-MS (ESI $\left.{ }^{+}\right):$m/z $317.2(\mathrm{M}+\mathrm{H})^{+}$.

The column used for chromatography was a Luna C18 2.0*30 mm (3 um particles). Detection methods are diode array (DAD). MS mode was positive electrospray ionization. MS range was 100-1000. Mobile phase A was $0.037 \%$ trifluoroacetic acid in water, and mobile phase B was $0.018 \%$ trifluoroacetic acid in HPLC grade acetonitrile. The gradient was 5-95\% B in $2.00 \mathrm{~min}, 5 \% \mathrm{~B}$ in $0.01 \mathrm{~min}, 5-95 \% \mathrm{~B}$ (0.01-1.00 min), 95 $100 \% \mathrm{~B}(1.00-1.80 \mathrm{~min}), 5 \% \mathrm{~B}$ in $1.81 \mathrm{~min}$ with a hold at $5 \% \mathrm{~B}$ for $0.19 \mathrm{~min}$. The flow rate was $1.0 \mathrm{~mL} / \mathrm{min}$ $(0.00-1.80 \mathrm{~min})$ and $1.2 \mathrm{~mL} / \mathrm{min}(1.81-2.00 \mathrm{~min})$.

\subsubsection{General procedure for preparation of TEFAPI-06_A4}

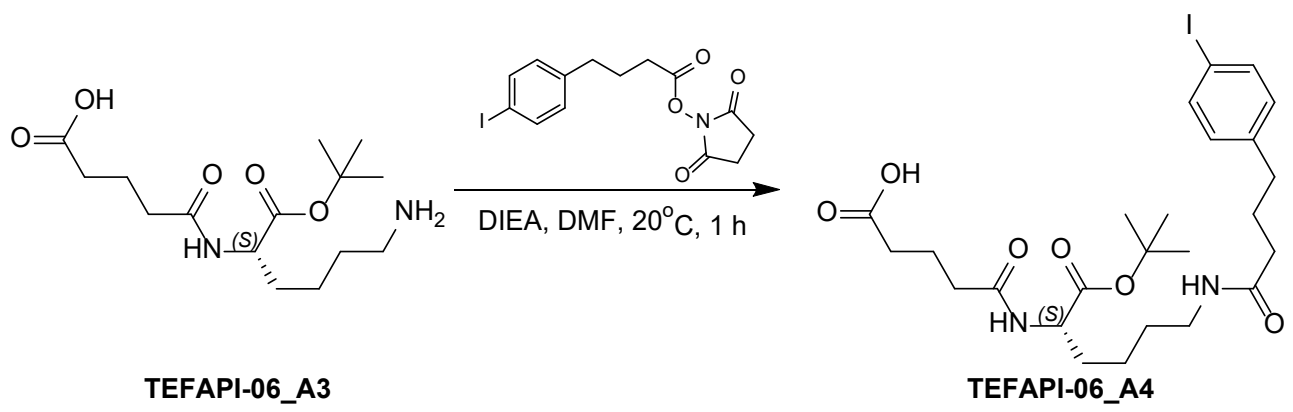

To a solution of 4-(4-iodophenyl) butanoic acid (15 g, $51.71 \mathrm{mmol}, 1 \mathrm{eq})$ in DCM (150 mL) was added 1hydroxypyrrolidine-2,5-dione $(6.55 \mathrm{~g}, 56.88 \mathrm{mmol}, 1.1 \mathrm{eq})$, then the mixture was cooled to $0{ }^{\circ} \mathrm{C}$ and $\mathrm{DCC}$ (12.80 g, $62.05 \mathrm{mmol}, 12.55 \mathrm{~mL}, 1.2 \mathrm{eq})$ was added to the above mixture. The mixture was stirred at $20^{\circ} \mathrm{C}$ 
for $1 \mathrm{~h}$. LC-MS showed the reaction was consumed. The mixture was filtered and the filtrate was concentrated in vacuum. Obtain (2,5-dioxopyrrolidin-1-yl) 4-(4-iodophenyl)butanoate (15 g, crude) as light yellow solid. To a solution of (2,5-dioxopyrrolidin-1-yl) 4-(4-iodophenyl)butanoate (14.68 g, $37.93 \mathrm{mmol}, 1 \mathrm{eq})$ in DMF (120 mL) was added TEFAPI-06_A3 (12 g, $37.93 \mathrm{mmol}, 1 \mathrm{eq})$ and DIEA (14.71 g, $113.78 \mathrm{mmol}, 19.82 \mathrm{~mL}$, 3 eq). The mixture was stirred at $20^{\circ} \mathrm{C}$ for $1 \mathrm{~h}$. LC-MS showed TEFAPI-06_A4 was detected. The mixture was purified by prep-HPLC (column: Phenomenex luna C18 250*100 mm (15 um particles); mobile phase: [water (0.1\%TFA)-ACN]; B\%: 35\%-65\%, 20 min). Obtain TEFAPI-06_A4 (10 g, 16.57 mmol, 43.68\% yield, $97.5 \%$ purity) as colorless oil.

LC-MS (ESI $\left.{ }^{+}\right):$m/z $533.1(\mathrm{M} / 2+\mathrm{H})^{+}$.

The column used for chromatography was Xbridge Shield RP18 2.1*50 mm (5 um particles). Detection methods are diode array (DAD). MS mode was positive electrospray ionization. MS range was 100-1000. Mobile phase A was $10 \mathrm{mM}$ ammonium bicarbonate in water, and mobile phase B was HPLC grade acetonitrile. The gradient was 5-95\% B in $2.05 \mathrm{~min}, 5 \% \mathrm{~B}$ in $0.01 \mathrm{~min}, 5-95 \% \mathrm{~B}(0.01-1.00 \mathrm{~min}), 95-100 \%$ $\mathrm{B}(1.00-1.80 \mathrm{~min}), 5 \% \mathrm{~B}$ in $1.81 \mathrm{~min}$ with a hold at $5 \% \mathrm{~B}$ for $0.24 \mathrm{~min}$. The flow rate was $1.0 \mathrm{~mL} / \mathrm{min}$.

\subsubsection{General procedure for preparation of TEFAPI-06_F7}

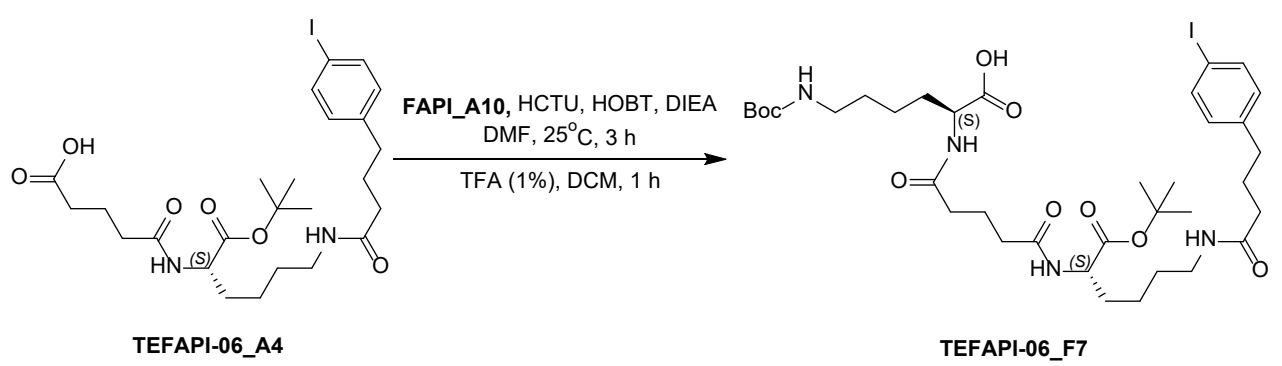

To a solution of TEFAPI-06_A4 (6.14 g, $10.43 \mathrm{mmol}, 1.1 \mathrm{eq})$ in DMF (100 mL) was added HCTU (7.84 g, $18.96 \mathrm{mmol}, 2 \mathrm{eq})$, HOBT (640.47 mg, $4.74 \mathrm{mmol}, 0.5 \mathrm{eq})$ and DIEA (3.68 g, $28.44 \mathrm{mmol}, 4.95 \mathrm{~mL}, 3 \mathrm{eq})$ at $0{ }^{\circ} \mathrm{C}$. The mixture was stirred at $25^{\circ} \mathrm{C}$ for $1 \mathrm{~h}$. And then the mixture was added to a mixture of TEFAPI_A10 $(2.47 \mathrm{~g}, 9.48 \mathrm{mmol}, 1 \mathrm{eq})$ in resin. Then the resin was bubbled with $\mathrm{N}_{2}$ at $25^{\circ} \mathrm{C}$ for $2 \mathrm{~h}$. LC-MS showed starting material was consumed completely and the desired product was detected. The mixture was filtered and the resin was washed with dimethyl formamide $(4 * 400 \mathrm{~mL})$ and dichloromethane $(4 * 400 \mathrm{~mL})$. To the above resin was added a solution of dichloromethane/trifluoroacetic acid $(\mathrm{v} / \mathrm{v}=100: 1,600 \mathrm{~mL})$ to order the 
crude product can be cleavage from resin. The mixture was bubbled with $\mathrm{N}_{2}$ for 20 min and filtered. The operation was repeated for another five times. After cleavage and filter, the filtrate was adjusted to $\mathrm{pH} 7$ with $\mathrm{NaHCO}_{3}(\mathrm{aq})$ and partitioned between dichloromethane $(200 \mathrm{~mL} * 3)$ and water $(200 \mathrm{~mL} * 3)$. The combined organic phases were washed with citric acid $(200 \mathrm{~mL} * 3)$. Then the mixture was concentrated under high vacuum to give TEFAPI-06_F7 (6 g, $7.11 \mathrm{mmol}, 74.99 \%$ yield, 96.77\% purity) as a yellow solid.

LC-MS (ESI $\left.{ }^{+}\right):$m/z 817.2(M+H) ${ }^{+}$, Rt: 2.670 min.

The gradient was $5 \%$ B in $0.40 \mathrm{~min}$ and $5-95 \%$ B at $0.40-3.00 \mathrm{~min}$, hold on $95 \%$ B for $1.00 \mathrm{~min}$, and then $95-5 \% \mathrm{~B}$ in $0.01 \mathrm{~min}$, the flow rate was $1.0 \mathrm{ml} / \mathrm{min}$. Mobile phase A was $0.037 \%$ trifluoroacetic acid in water, mobile phase B was $0.018 \%$ trifluoroacetic acid in acetonitrile. The column used for chromatography was a Kinetex C18 50*2.1 mm column (5 um particles). Detection methods are diode array (DAD) and evaporative light scattering (ELSD) detection as well as positive electrospray ionization.

${ }^{1} \mathbf{H}$ NMR $\left(400 \mathrm{MHz}, \mathrm{CDCl}_{3}\right)$

$\delta=1.30-1.40(\mathrm{~m}, 2 \mathrm{H}), 1.43-1.51(\mathrm{~m}, 24 \mathrm{H}), 1.91-1.93(\mathrm{~m}, 6 \mathrm{H}), 2.16-2.21(\mathrm{~m}, 7 \mathrm{H}), 2.56-2.60(\mathrm{~m}, 3 \mathrm{H}), 3.07-$

$3.11(\mathrm{~m}, 3 \mathrm{H}), 3.47-3.49(\mathrm{~m}, 1 \mathrm{H}), 4.48-4.50(\mathrm{~m}, 1 \mathrm{H}), 4.57-4.60(\mathrm{~m}, 1 \mathrm{H}), 4.76-4.79(\mathrm{~m}, 1 \mathrm{H}), 5.86(\mathrm{br} \mathrm{s}, 1 \mathrm{H})$, 6.90-6.94 (m, 2H), 7.58-7.61 (m, 2H), 7.88-7.91 (m, 1H), 8.09-8.12 (m, 1H).

\subsubsection{General procedure for preparation of TEFAPI-06_8}

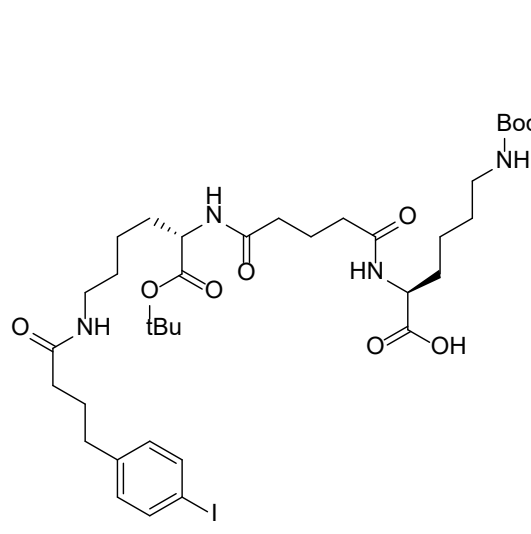

TEFAPI-06_F7

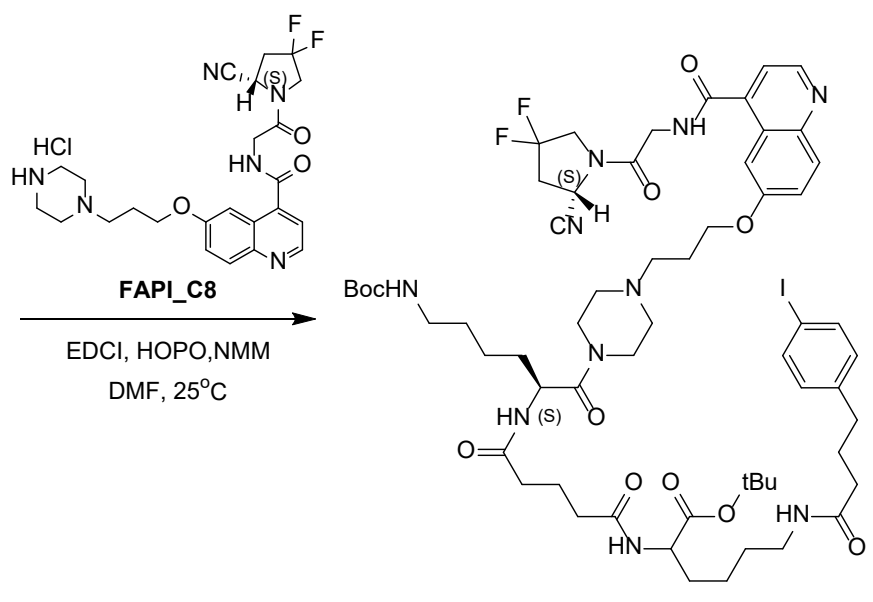

TEFAPI-06_8

To a solution of TEFAPI-06_F7 $(858.97 \mathrm{mg}, 1.05 \mathrm{mmol}, 1.1 \mathrm{eq}), O$-benzotriazol-1-yl-tetramethyluronium hexafluorophosphate (453.23 mg, $1.20 \mathrm{mmol}, 1.25 \mathrm{eq}$ ), 1-hydroxybenzotriazole (167.94 mg, $1.24 \mathrm{mmol}, 1.3$ 
eq), $N, N$-diisopropylethylamine $(617.83 \mathrm{mg}, 4.78 \mathrm{mmol}, 832.65 \mathrm{uL}, 5 \mathrm{eq})$ in dimethyl formamide $(5 \mathrm{~mL})$ was added FAPI_C8 $(500 \mathrm{mg}, 956.07 \mathrm{umol}, 1 \mathrm{eq}, \mathrm{HCl})$, and the reation mixture was stirred at $25^{\circ} \mathrm{C}$ for 12 hrs. LC-MS showed the FAPI_C8 was consumed and the product was detected with the desired MS. The reaction mixture was filtered with a syringe. The mixture was purified by prep-HPLC ( $\mathrm{HCl}$ condition). TEFAPI-06_8 (230 mg, 170.00 umol, 17.78\% yield, 95\% purity) was obtained as a white solid.

LC-MS (ESI $\left.{ }^{+}\right): \mathrm{m} / \mathrm{z} 1285.4(\mathrm{M}+\mathrm{H})^{+}$.

The prep-HPLC method: instrument: Shimadzu LC-8A preparative HPLC; column: Phenomenex luna C18 $80 * 40 \mathrm{~mm}\left(3\right.$ um particles); mobile phase: A for $\mathrm{H}_{2} \mathrm{O}=(0.04 \% \mathrm{HCl})$ and $\mathrm{B}$ for $\mathrm{ACN}$; gradient: $\mathrm{B}$ from $25 \%$ to $50 \%$ in $20 \mathrm{~min}$; flow rate: $40 \mathrm{~mL} / \mathrm{min}$; wavelength: $220 \& 254 \mathrm{~nm}$.

The LC-MS method: the column used for chromatography was a Kinetex C18 2.1*30 mm (5 um particles). Detection methods are diode array (DAD). MS mode was positive electrospray ionization. MS range was 100-1000. Mobile phase A was $0.05 \%$ TFA in water, and mobile phase B was $0.05 \%$ TFA in HPLC grade acetonitrile. The gradient was 5-95\% B in $4.30 \mathrm{~min} .5 \% \mathrm{~B}$ in $0.01 \mathrm{~min}, 5-95 \% \mathrm{~B}(0.01-3.00 \mathrm{~min})$, with a hold at $95 \% \mathrm{~B}$ for $0.50 \mathrm{~min} .95-5 \% \mathrm{~B}(3.50-3.51 \mathrm{~min}), 5 \% \mathrm{~B}$ in $3.51 \mathrm{~min}$, with a hold at $5 \% \mathrm{~B}$ for $0.79 \mathrm{~min}$. The flow rate was $1.0 \mathrm{~mL} / \mathrm{min}$.

\subsubsection{General procedure for preparation of TEFAPI-06_9}

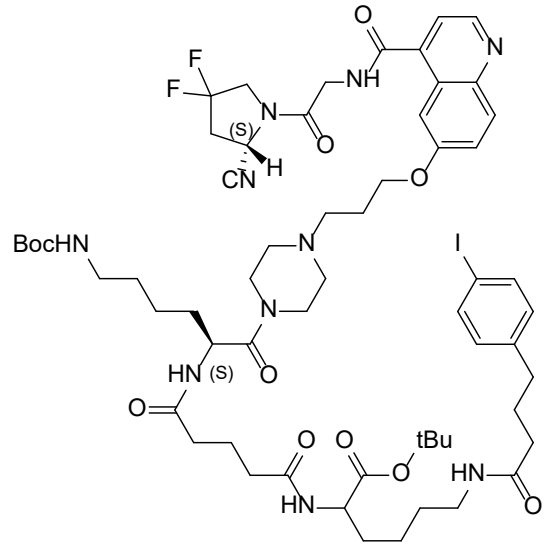

TEFAPI-06_8

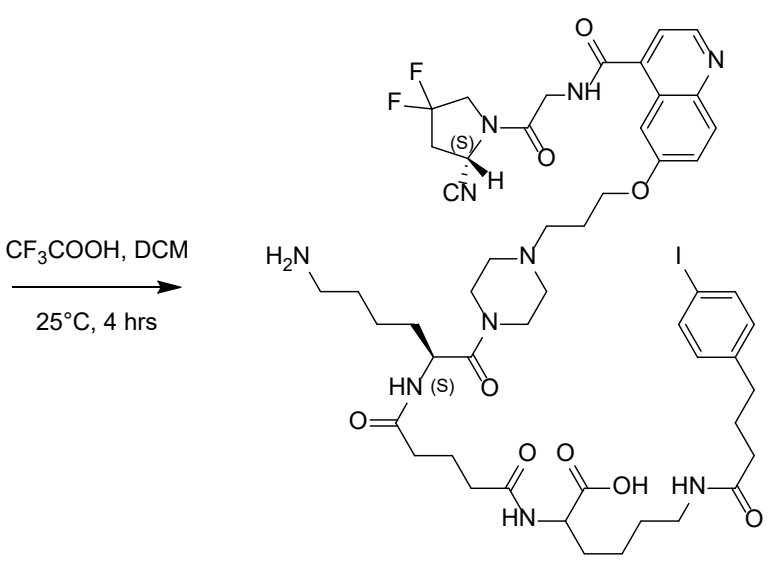

TEFAPI-06_9

To a solution of TEFAPI-06_8 (150 mg, $116.71 \mathrm{umol}, 1 \mathrm{eq})$ in dichloromethane $(10 \mathrm{~mL})$ was added trifluoroacetic acid $(3.08 \mathrm{~g}, 27.01 \mathrm{mmol}, 2 \mathrm{~mL}, 231.45 \mathrm{eq})$, and the reaction mixture was stirred at $25{ }^{\circ} \mathrm{C}$ for 4 hrs. LC-MS showed the TEFAPI-06_8 was consumed, one main peak was shown on LC-MS and $\sim 93.8 \%$ 
of desired compound was detected. The reaction mixture was removed trifluoroacetic acid with $\mathrm{N}_{2}$. The crude product was used for next step directly without further purification. TEFAPI-06_9 (150 mg, crude, TFA) was obtained as a yellow oil.

LC-MS (ESI $\left.{ }^{+}\right): \mathrm{m} / \mathrm{z} 1129.3(\mathrm{M}+\mathrm{H})^{+}$.

The LC-MS method: the column used for chromatography was a Kinetex C18 2.1*30 mm (5 um particles). Detection methods are diode array (DAD). MS mode was positive electrospray ionization. MS range was 100-1000. Mobile phase A was $0.05 \%$ TFA in water, and mobile phase B was $0.05 \%$ TFA in HPLC grade acetonitrile. The gradient was 5-95\% B in $4.30 \mathrm{~min} .5 \% \mathrm{~B}$ in $0.01 \mathrm{~min}, 5-95 \% \mathrm{~B}(0.01-3.00 \mathrm{~min})$, with a hold at $95 \% \mathrm{~B}$ for $0.50 \mathrm{~min} .95-5 \% \mathrm{~B}(3.50-3.51 \mathrm{~min}), 5 \% \mathrm{~B}$ in $3.51 \mathrm{~min}$, with a hold at $5 \% \mathrm{~B}$ for $0.79 \mathrm{~min}$. The flow rate was $1.0 \mathrm{~mL} / \mathrm{min}$.

\subsubsection{General procedure for preparation of TEFAPI-06_10}

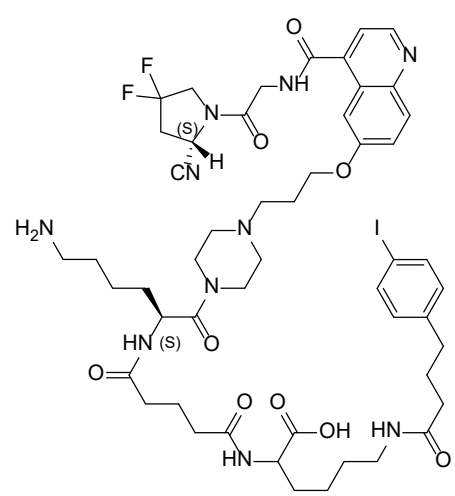

TEFAPI-06_9

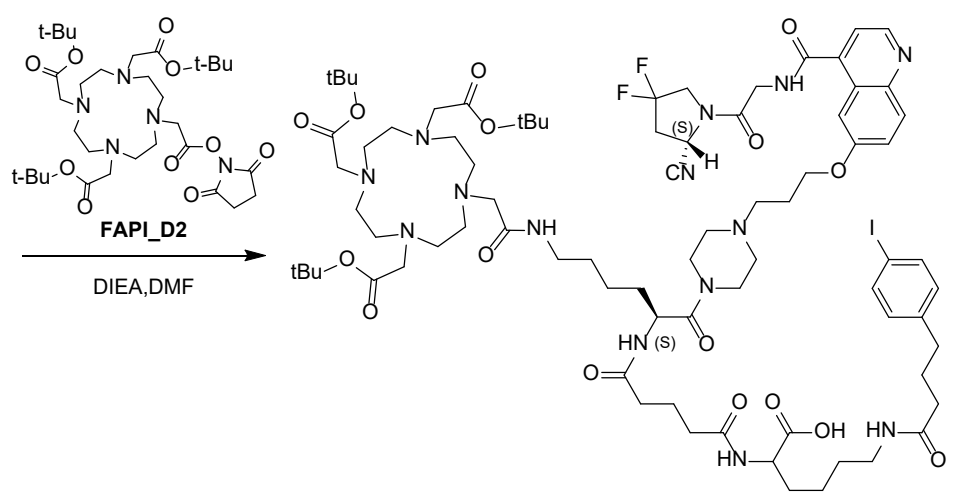

TEFAPI-06_10

To a solution of TEFAPI-06_9 (150 mg, 120.67 umol, 1 eq, TFA) and FAPI_D2 (88.91 mg, 132.74 umol, 1.1 $e q)$ in dimethyl formamide $(1.6 \mathrm{~mL})$ was added $N, N$-diisopropylethylamine $(124.77 \mathrm{mg}, 965.36 \mathrm{umol}$, $168.15 \mathrm{uL}, 8 \mathrm{eq}$ ), and the reaction mixture was stirred at $25^{\circ} \mathrm{C}$ for $12 \mathrm{hrs}$. LC-MS showed TEFAPI-06_9 was consumed, several new peaks were shown on LC-MS and $\sim 53.1 \%$ of desired compound was detected. The reaction mixture was concentrated under reduced pressure to remove dimethyl formamide. The crude product was used for next step directly without further purification. TEFAPI-06_10 (220 mg, crude) was obtained as a yellow oil.

LC-MS (ESI $\left.{ }^{+}\right):$m/z $1684.9(\mathrm{M}+\mathrm{H})^{+}$.

The LC-MS method: the column used for chromatography was Xbridge Shield RP18 2.1*50 mm (5 um 
particles). Detection methods are diode array (DAD). MS mode was positive electrospray ionization. MS range was 100-2000. Mobile phase A was $10 \mathrm{mM}$ ammonium bicarbonate in water, and mobile phase B was HPLC grade acetonitrile. The gradient was 5-95\% B in 2.20 min. 5\% B in $0.01 \mathrm{~min}, 5-95 \% \mathrm{~B}(0.01-1.00$ $\min$ ), $95 \%-100 \%$ B (1.00 min-1.80 min), 100-5\% B (1.80-1.81 min) with a hold at 5\% B for $0.39 \mathrm{~min}$. The flow rate was $1.0 \mathrm{~mL} / \mathrm{min}(0.01-2.20 \mathrm{~min})$.

\subsubsection{General procedure for preparation of TEFAPI-06}

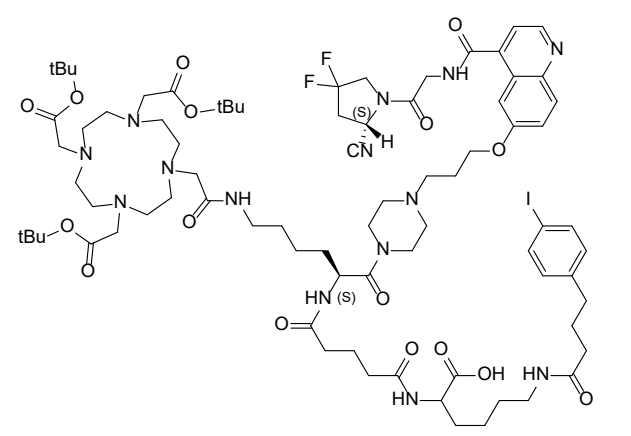

TEFAPI-06_10

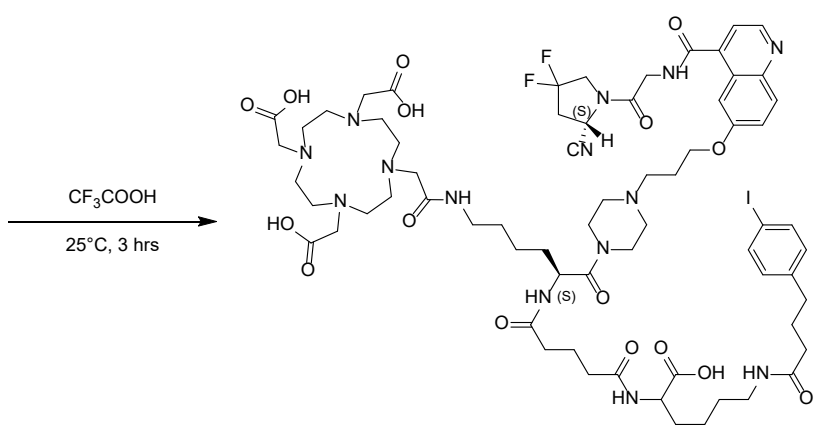

TEFAPI-06

A mixture of TEFAPI-06_10 (210 mg, $124.72 \mathrm{umol}, 1 \mathrm{eq})$ and trifluoroacetic acid (3.23 g, $28.36 \mathrm{mmol}, 2.10$ $\mathrm{mL}, 227.41 \mathrm{eq}$ ) was stirred at $25^{\circ} \mathrm{C}$ for $3 \mathrm{hrs}$. LC-MS showed TEFAPI-06_10 was consumed, several new peaks were shown on LC-MS and $\sim 56 \%$ of desired compound was detected. The reaction mixture was removed trifluoroacetic acid with $\mathrm{N}_{2}$. The mixture was purified by prep-HPLC (TFA condition). TEFAPI-06 (30 mg, 26.40 umol, $21.16 \%$ yield, 100\% purity) was obtained as a white solid.

The prep-HPLC method: instrument: Gilson 281 semi-preparative HPLC system; mobile phase: A: TFA $/ \mathrm{H}_{2} \mathrm{O}$ $=0.075 \% \mathrm{v} / \mathrm{v} ; \mathrm{B}: \mathrm{ACN}$; column: Phenomenex Gemini-NX 150*30 mm (5 um particles); flow rate: 25 $\mathrm{mL} / \mathrm{min}$; monitor wavelength: $220 \& 254 \mathrm{~nm}$.

LC-MS (product) $\left(\mathrm{ESI}^{+}\right): \mathrm{m} / \mathrm{z} 758.4(\mathrm{M} / 2+\mathrm{H})^{+} \mathrm{Rt}: 1.959 \mathrm{~min}$.

The LC-MS method: the gradient was 5\% B in $0.40 \mathrm{~min}$ and 5-95\% B at $0.40-3.00 \mathrm{~min}$, hold on $95 \% \mathrm{~B}$ for $1.00 \mathrm{~min}$, and then $95-5 \% \mathrm{~B}$ in $0.01 \mathrm{~min}$, the flow rate was $1.0 \mathrm{ml} / \mathrm{min}$. Mobile phase A was $0.05 \%$ trifluoroacetic acid in water, mobile phase B was $0.05 \%$ trifluoroacetic acid in acetonitrile. The column used for chromatography was a Kinetex C18 50*2.1 mm column (5 um particles). Detection methods are diode array (DAD) and evaporative light scattering (ELSD) detection as well as positive electrospray ionization. MS range was 100-1500. 


\section{${ }^{1} \mathbf{H}$ NMR (400 MHz, DMSO- $\left.d_{6}\right)$}

$\delta$ ppm 9.18-9.07 (m, 1H), $8.84(\mathrm{~d}, J=4.4 \mathrm{~Hz}, 1 \mathrm{H}), 8.49$ (br s, 1H), 8.18-7.97 (m, 3H), 7.89 (br d, $J=2.4$ Hz, 1H), 7.78 (br t, $J=5.8 \mathrm{~Hz}, 1 \mathrm{H}), 7.62$ (br d, $J=8.1 \mathrm{~Hz}, 2 \mathrm{H}), 7.55$ (d, $J=4.4 \mathrm{~Hz}, 1 \mathrm{H}), 7.46$ (br dd, $J=$ $2.7 \mathrm{~Hz}, 9.1 \mathrm{~Hz}, 1 \mathrm{H}), 7.00$ (br d, $J=8.1 \mathrm{~Hz}, 2 \mathrm{H}), 5.15$ (br dd, $J=3.3,9.0 \mathrm{~Hz}, 1 \mathrm{H}), 4.69$ (br s, 1H), 4.47-4.08 (m, 6H), 4.07-3.69 (m, 13H), 3.64-3.22 (m, 11H), 3.21-2.69 (m, 14H), 2.47 (br s, 2H), 2.33-1.90 (m, 9H), $1.87-1.18(\mathrm{~m}, 18 \mathrm{H})$.

${ }^{\mathbf{1}} \mathbf{H}$ NMR (400 MHz, methanol- $\left.d_{4}\right)$

$\delta$ ppm $8.85(\mathrm{~d}, J=4.6 \mathrm{~Hz}, 1 \mathrm{H}), 8.22-7.97(\mathrm{~m}, 2 \mathrm{H}), 7.71-7.53(\mathrm{~m}, 4 \mathrm{H}), 6.99(\mathrm{~d}, J=8.3 \mathrm{~Hz}, 2 \mathrm{H}), 5.15$ (br d, $J=9.3 \mathrm{~Hz}, 1 \mathrm{H}), 4.83-4.74(\mathrm{~m}, 4 \mathrm{H}), 4.49-4.30(\mathrm{~m}, 6 \mathrm{H}), 4.30-4.08(\mathrm{~m}, 4 \mathrm{H}), 3.90-3.38(\mathrm{~m}, 17 \mathrm{H}), 3.20-2.74$ (m, 16H), $2.58(\mathrm{~s}, 2 \mathrm{H}), 2.40(\mathrm{br} \mathrm{s}, 2 \mathrm{H}), 2.30-2.15(\mathrm{~m}, 6 \mathrm{H}), 2.02-1.82(\mathrm{~m}, 6 \mathrm{H}), 1.77-0.99(\mathrm{~m}, 11 \mathrm{H})$.

\subsection{The synthesis route of TEFAPI-07}
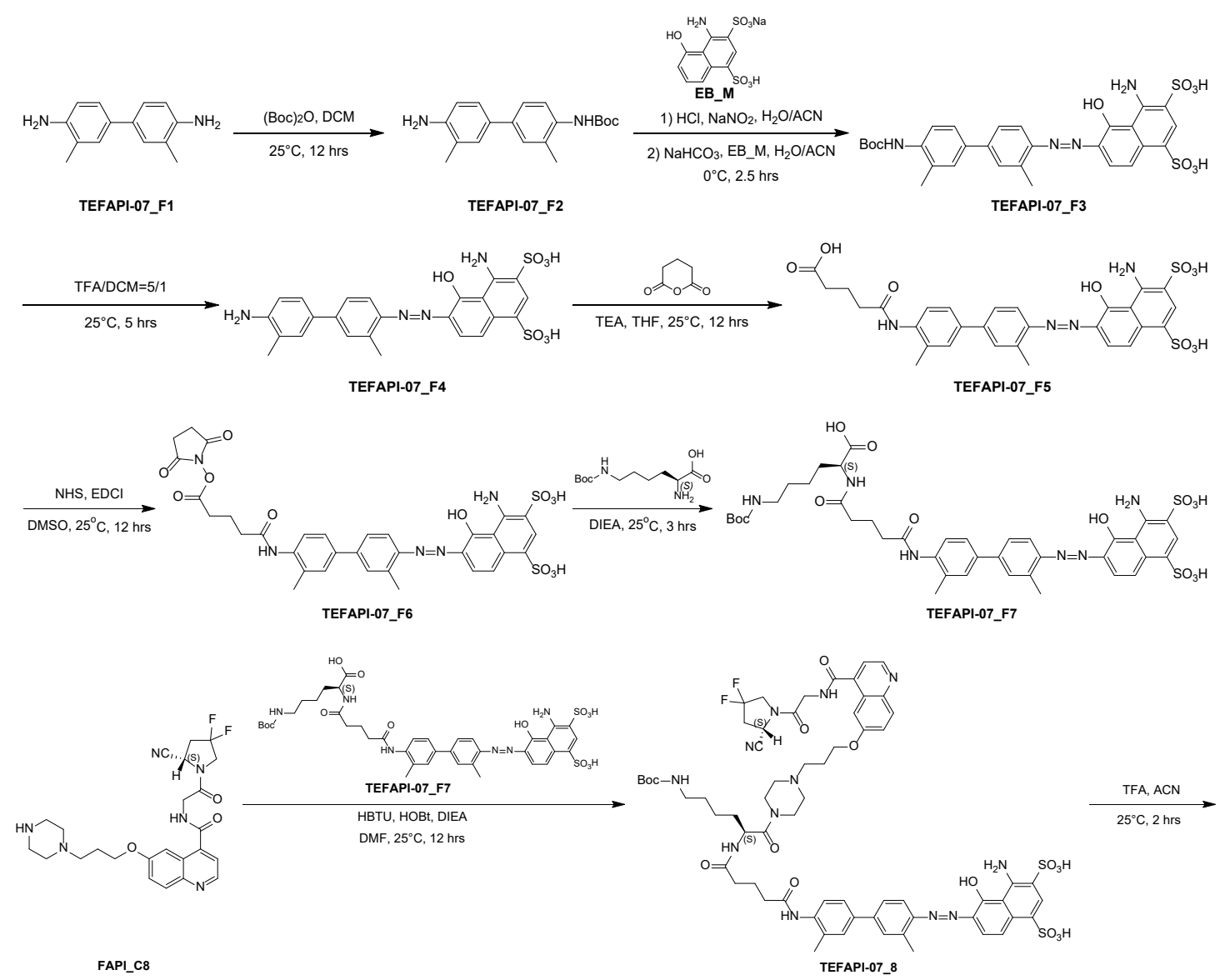

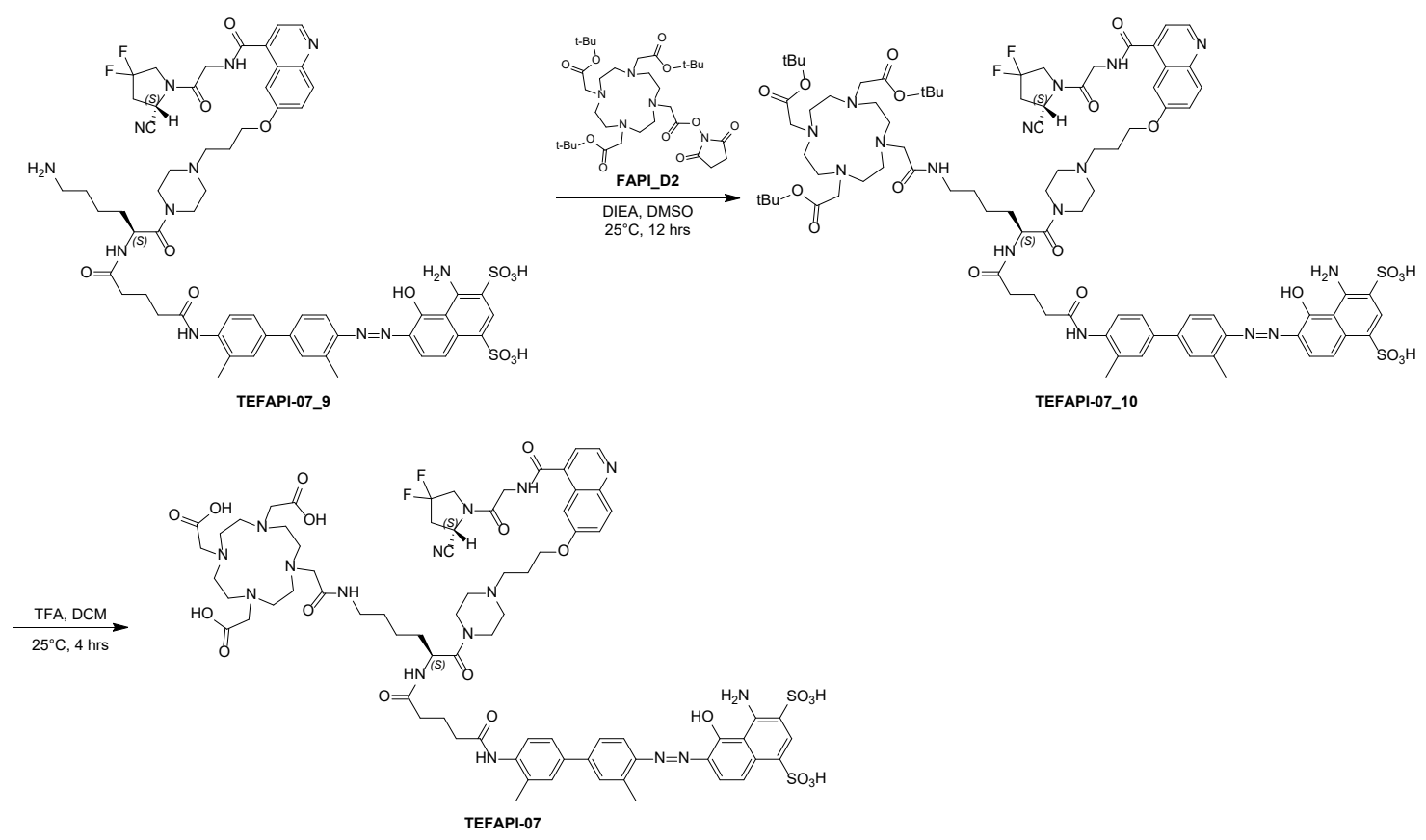

1.2.1 General procedure for preparation of TEFAPI-07_F2

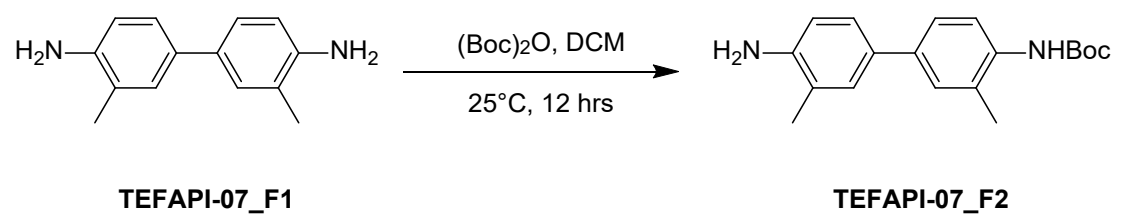

To a solution of TEFAPI-07_F1 (40 g, $188.42 \mathrm{mmol}, 39.60 \mathrm{~mL}, 1 \mathrm{eq})$ in DCM (400 mL) was added dropwise a solution of $\mathrm{Boc}_{2} \mathrm{O}(41.12 \mathrm{~g}, 188.42 \mathrm{mmol}, 43.29 \mathrm{~mL}, 1 \mathrm{eq})$ in $\mathrm{DCM}(200 \mathrm{~mL})$ at $25^{\circ} \mathrm{C}$ over a period of $1 \mathrm{~h}$. The reaction was stirred at $25{ }^{\circ} \mathrm{C}$ for $12 \mathrm{~h}$. TLC (petroleum ether/ethyl acetate $=5 / 1$ ) indicated $\sim 30 \%$ of TEFAPI-07_F1 remaining and one new spot with lower polarity was detected. The solvent was dried to get a residue. The residue was purified on a silica gel column (petroleum ether/ethyl acetate=1/1) to give TEFAPI-07_F2 (17 g, yield 23.39\%) as a light yellow solid.

LC-MS (ESI $\left.{ }^{+}\right): \mathrm{m} / \mathrm{z} 313.2(\mathrm{M}+\mathrm{H})^{+}$.

The column used for chromatography was a Luna C18 2.0*30 mm ( 3 um particles). Detection methods are diode array (DAD). MS mode was positive electrospray ionization. MS range was 100-1000. Mobile phase A was $0.037 \%$ trifluoroacetic acid in water, and mobile phase B was $0.018 \%$ trifluoroacetic acid in HPLC grade acetonitrile. The gradient was 5-95\% B in $2.00 \mathrm{~min}, 5 \% \mathrm{~B}$ in $0.01 \mathrm{~min}, 5-95 \% \mathrm{~B}(0.01-1.00 \mathrm{~min})$, 95 $100 \% \mathrm{~B}(1.00-1.80 \mathrm{~min}), 5 \% \mathrm{~B}$ in $1.81 \mathrm{~min}$ with a hold at $5 \% \mathrm{~B}$ for $0.19 \mathrm{~min}$. The flow rate was $1.0 \mathrm{~mL} / \mathrm{min}$ 
$(0.00-1.80 \mathrm{~min})$ and $1.2 \mathrm{~mL} / \mathrm{min}(1.81-2.00 \mathrm{~min})$.

\subsubsection{General procedure for preparation of TEFAPI-07_F3}

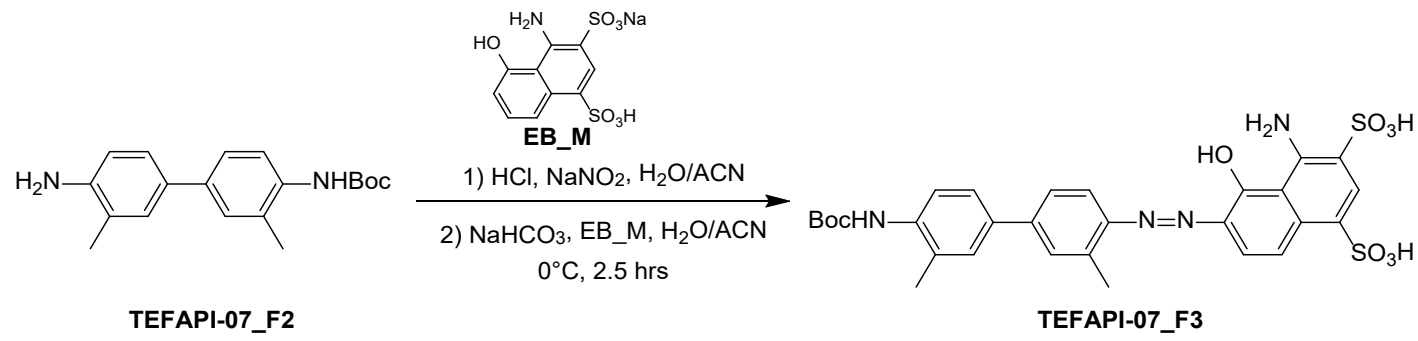

To a solution of TEFAPI-07_F2 $(3.12 \mathrm{~g}, 9.99 \mathrm{mmol}, 1 \mathrm{eq})$ in ACN $(40 \mathrm{~mL})$ was added $\mathrm{HCl}(2 \mathrm{M}, 14.98 \mathrm{~mL}$, $3 e q)$ at $0{ }^{\circ} \mathrm{C}$. Then cold $\mathrm{NaNO}_{2}$ solution $(2.07 \mathrm{~g}, 29.96 \mathrm{mmol}, 3 \mathrm{eq}$, in $20 \mathrm{~mL}$ of water) was added drop-wise to the above mixture. The mixture was stirred for $30 \mathrm{~min}$. This resulting mixture was added drop-wise to another glass vial containing EB_M (3.19 g, $9.35 \mathrm{mmol}, 0.9 \mathrm{eq})$ and $\mathrm{NaHCO}_{3}$ solution $(3.36 \mathrm{~g}, 39.95 \mathrm{mmol}$, $1.55 \mathrm{~mL}, 4 \mathrm{eq}$, in $20 \mathrm{~mL}$ of water) at $0{ }^{\circ} \mathrm{C}$. The reaction was stirred at $0{ }^{\circ} \mathrm{C}$ for $2 \mathrm{~h}$. LC-MS showed TEFAPI07_F2 was consumed completely and one main peak with desired mass was detected. The reaction mixture was lyophilized to give TEFAPI-07_F3 (6 g, yield 93.48\%) as a purple solid. The crude product was purified by prep-HPLC (TFA condition) to give pure product as a purple solid.

LC-MS (ESI'): m/z $641.1(\mathrm{M}-\mathrm{H})^{-}$.

The column used for chromatography was Xbridge Shield RP18 2.1*50 mm (5 um particles). Detection methods are diode array (DAD). MS mode was negative electrospray ionization. MS range was 100-2000. Mobile phase A was $10 \mathrm{mM}$ ammonium bicarbonate in water, and mobile phase B was HPLC grade acetonitrile. The gradient was 5-95\% B in $2.20 \mathrm{~min}, 5 \% \mathrm{~B}$ in $0.01 \mathrm{~min}, 5-95 \% \mathrm{~B}(0.01-1.00 \mathrm{~min}), 95-100 \%$ B (1.00-1.80 min), $100-5 \%$ B $(1.80-1.81 \mathrm{~min})$ with a hold at $5 \% \mathrm{~B}$ for $0.39 \mathrm{~min}$. The flow rate was 1.0 $\mathrm{mL} / \mathrm{min}(0.01-2.20 \mathrm{~min})$.

\subsubsection{General procedure for preparation of TEFAPI-07_F4}

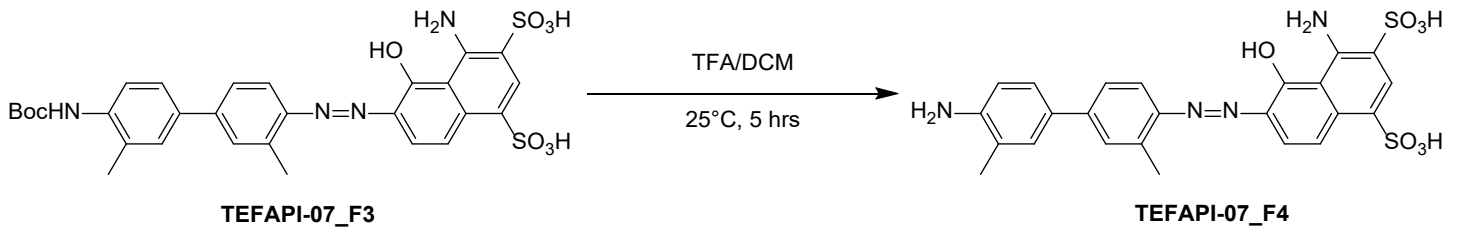


To a solution of TEFAPI-07_F3 $(2.2 \mathrm{~g}, 3.42 \mathrm{mmol}, 1 \mathrm{eq})$ in DCM $(1 \mathrm{~mL})$ was added TFA $(6.78 \mathrm{~g}, 59.43$ mmol, $4.40 \mathrm{~mL}, 17.36 \mathrm{eq}$ ). The mixture was stirred at $25^{\circ} \mathrm{C}$ for $5 \mathrm{~h}$. LC-MS showed $50 \%$ of TEFAPI-07_F3 was consumed and desired MS was detected. The mixture was dried. After lyophilization, the crude product TEFAPI-07_F4 (2.2 g, yield 97.88\%) was obtained as a purple solid which was used to the next step without further purification.

LC-MS (ESI'): m/z $541.0($ M-H)'.

The column used for chromatography was Xbridge Shield RP18 2.1*50 mm (5 um particles). Detection methods are diode array (DAD). MS mode was negative electrospray ionization. MS range was 100-2000. Mobile phase A was $10 \mathrm{mM}$ ammonium bicarbonate in water, and mobile phase B was HPLC grade acetonitrile. The gradient was 5-95\% B in $2.20 \mathrm{~min}, 5 \% \mathrm{~B}$ in $0.01 \mathrm{~min}, 5-95 \% \mathrm{~B}(0.01-1.00 \mathrm{~min}), 95-100 \%$ B (1.00-1.80 $\mathrm{min}), 100-5 \% \mathrm{~B}(1.80-1.81 \mathrm{~min})$ with a hold at $5 \% \mathrm{~B}$ for $0.39 \mathrm{~min}$. The flow rate was 1.0 $\mathrm{mL} / \mathrm{min}(0.01-2.20 \mathrm{~min})$.

\subsubsection{General procedure for preparation of TEFAPI-07_F5}

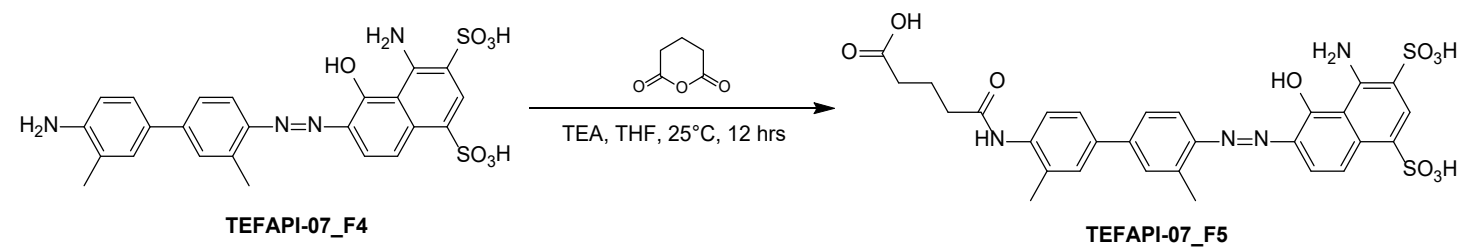

To a solution of TEFAPI-07_F4 $(2.3 \mathrm{~g}, 4.24 \mathrm{mmol}, 990.10 \mathrm{uL}, 1 \mathrm{eq})$ in THF (30 mL) was added tetrahydropyran-2,6-dione (532.03 mg, $4.66 \mathrm{mmol}, 1.1 \mathrm{eq})$ and TEA (1.29 g, $12.72 \mathrm{mmol}, 1.77 \mathrm{~mL}, 3 \mathrm{eq})$. The mixture was stirred at $25{ }^{\circ} \mathrm{C}$ for $12 \mathrm{~h}$. LC-MS showed $42 \%$ of TEFAPI-07_F4 remaining. Several new peaks were shown on LC-MS and $\sim 40 \%$ of desired compound was detected. The mixture was dried under reduced pressure to get a residue. The residue was purified by prep-HPLC (TFA condition). Compound TEFAPI-07_F5 (500 mg, yield 17.96\%) was obtained as a purple solid.

LC-MS (ESI'): m/z $655.1(\mathrm{M}-\mathrm{H})^{-}$.

The column used for chromatography was Xbridge Shield RP18 2.1*50 mm (5 um particles). Detection methods are diode array (DAD). MS mode was negative electrospray ionization. MS range was 100-2000. Mobile phase A was $10 \mathrm{mM}$ ammonium bicarbonate in water, and mobile phase B was HPLC grade 
acetonitrile. The gradient was 5-95\% B in $2.20 \mathrm{~min}, 5 \% \mathrm{~B}$ in $0.01 \mathrm{~min}, 5-95 \% \mathrm{~B}(0.01-1.00 \mathrm{~min}), 95-100 \%$ B (1.00-1.80min), 100-5\% B (1.80-1.81 min) with a hold at 5\% B for $0.39 \mathrm{~min}$. The flow rate was $1.0 \mathrm{~mL} / \mathrm{min}$ (0.01-2.20 min).

\subsubsection{General procedure for preparation of TEFAPI-07_F6}

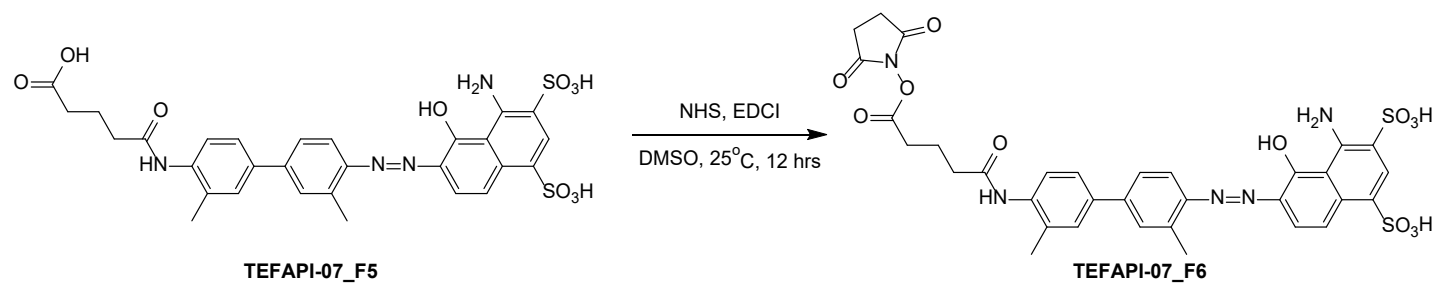

To a solution of TEFAPI-07_F5 (500 mg, $761.40 \mathrm{umol}, 1$ eq) in DMSO (5 mL) was added HOSu $(96.39 \mathrm{mg}$, $837.54 \mathrm{umol}, 1.1 \mathrm{eq})$ and EDCI $(145.96 \mathrm{mg}, 761.40 \mathrm{umol}, 1 \mathrm{eq})$. The mixture was stirred at $25^{\circ} \mathrm{C}$ for $12 \mathrm{~h}$. LC-MS showed $15 \%$ of TEFAPI-07_F5 remaining and $~ 80 \%$ of desired compound. The reaction mixture was used into the next step in situ.

LC-MS (ESI'): m/z $752.0($ M-H)-

The column used for chromatography was Xbridge Shield RP18 2.1*50 mm (5 um particles). Detection methods are diode array (DAD). MS mode was negative electrospray ionization. MS range was 100-2000. Mobile phase A was $10 \mathrm{mM}$ ammonium bicarbonate in water, and mobile phase B was HPLC grade acetonitrile. The gradient was 5-95\% B in $2.20 \mathrm{~min}, 5 \% \mathrm{~B}$ in $0.01 \mathrm{~min}, 5-95 \% \mathrm{~B}(0.01-1.00 \mathrm{~min}), 95-100 \%$ $\mathrm{B}(1.00-1.80 \mathrm{~min}), 100-5 \% \mathrm{~B}(1.80-1.81 \mathrm{~min})$ with a hold at $5 \% \mathrm{~B}$ for $0.39 \mathrm{~min}$. The flow rate was $1.0 \mathrm{~mL} / \mathrm{min}$ (0.01-2.20 $\mathrm{min})$.

\subsubsection{General procedure for preparation of TEFAPI-07_F7}

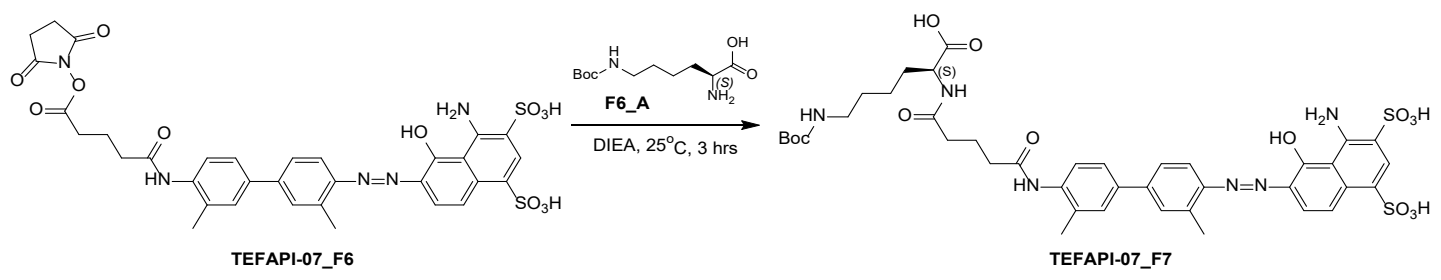

To a solution of F6_A (163.38 mg, 663.35 umol, 1 eq) in DMSO (0.5 mL) was added TEFAPI-07_F6 (500 $\mathrm{mg}, 663.35 \mathrm{umol}, 1 e q)$ and DIEA (171.47 $\mathrm{mg}, 1.33 \mathrm{mmol}, 231.09 \mathrm{uL}, 2 e q)$. The mixture was stirred at 25 
${ }^{\circ} \mathrm{C}$ for 12 h. LC-MS showed 7\% of TEFAPI-07_F6 remaining. Several new peaks were shown on LC-MS and $\sim 20 \%$ of desired compound was detected. The mixture was dried under reduced pressure to get a residue. The residue was purified by prep-HPLC (TFA condition) to give TEFAPI-07_F7 (200 mg, yield 34.07\%) as a dark purple solid.

LC-MS (ESI'): m/z 883.3(M-H)'.

The column used for chromatography was Xbridge Shield RP18 2.1*50 mm (5 um particles). Detection methods are diode array (DAD). MS mode was negative electrospray ionization. MS range was 100-2000. Mobile phase A was $10 \mathrm{mM}$ ammonium bicarbonate in water, and mobile phase B was HPLC grade acetonitrile. The gradient was 5-95\% B in $2.20 \mathrm{~min}, 5 \% \mathrm{~B}$ in $0.01 \mathrm{~min}, 5-95 \% \mathrm{~B}(0.01-1.00 \mathrm{~min}), 95-100 \%$ $\mathrm{B}(1.00-1.80 \mathrm{~min}), 100-5 \% \mathrm{~B}(1.80-1.81 \mathrm{~min})$ with a hold at $5 \% \mathrm{~B}$ for $0.39 \mathrm{~min}$. The flow rate was $1.0 \mathrm{~mL} / \mathrm{min}$ (0.01-2.20 $\mathrm{min})$.

\subsubsection{General procedure for preparation of TEFAPI-07_8}

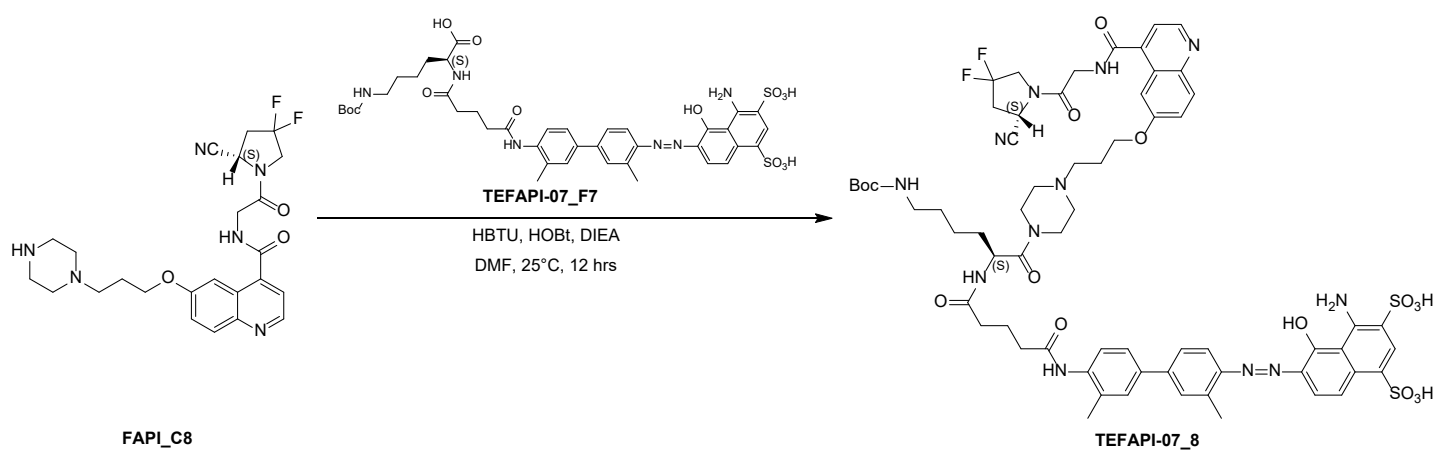

To a solution of FAPI_C8 (100 mg, $113.00 \mathrm{umol}, 1 \mathrm{eq})$ in DMF (1 mL) was added TEFAPI-07_F7 (67.86 mg, 113.00 umol, 1 eq, TFA), HBTU (53.57 mg, 141.25 umol, 1.25 eq), HOBt (19.85 mg, 146.90 umol, 1.3 eq) and DIEA (73.02 mg, $564.99 \mathrm{umol}, 98.41 \mathrm{uL}, 5 \mathrm{eq})$. The mixture was stirred at $25^{\circ} \mathrm{C}$ for $12 \mathrm{~h}$. LC-MS showed TEFAPI-07_F7 was consumed and desired compound was detected. The mixture was dried under reduced pressure to get a residue. The residue was purified by prep-HPLC (TFA condition, column: Phenomenex Gemini-NX C18 75*30 mm (3 um particles); mobile phase: [water (0.1\% TFA)-ACN]; B\%: 15-45\%, $10 \mathrm{~min})$. Compound TEFAPI-07_8 (30 mg, yield 19.62\%) was obtained as a purple solid. LC-MS (ESI $\left.{ }^{+}\right): \mathrm{m} / \mathrm{z} 1354.3(\mathrm{M}+\mathrm{H})^{+}$. 
The column used for chromatography was a Luna C18 2.0*30 mm, (3 um particles). Detection methods are diode array (DAD). MS mode was positive electrospray ionization. MS range was 100-1000. Mobile phase A was $0.037 \%$ trifluoroacetic acid in water, and mobile phase B was $0.018 \%$ trifluoroacetic acid in HPLC grade acetonitrile. The gradient was 5-95\% B in $2.00 \mathrm{~min}, 5 \% \mathrm{~B}$ in $0.01 \mathrm{~min}, 5-95 \% \mathrm{~B}$ (0.01-1.00 min), 95$100 \% \mathrm{~B}(1.00-1.80 \mathrm{~min}), 5 \% \mathrm{~B}$ in $1.81 \mathrm{~min}$ with a hold at $5 \% \mathrm{~B}$ for $0.19 \mathrm{~min}$. The flow rate was $1.0 \mathrm{~mL} / \mathrm{min}$ (0.00-1.80 $\mathrm{min})$ and $1.2 \mathrm{~mL} / \mathrm{min}(1.81-2.00 \mathrm{~min})$.

\subsubsection{General procedure for preparation of TEFAPI-07_9}
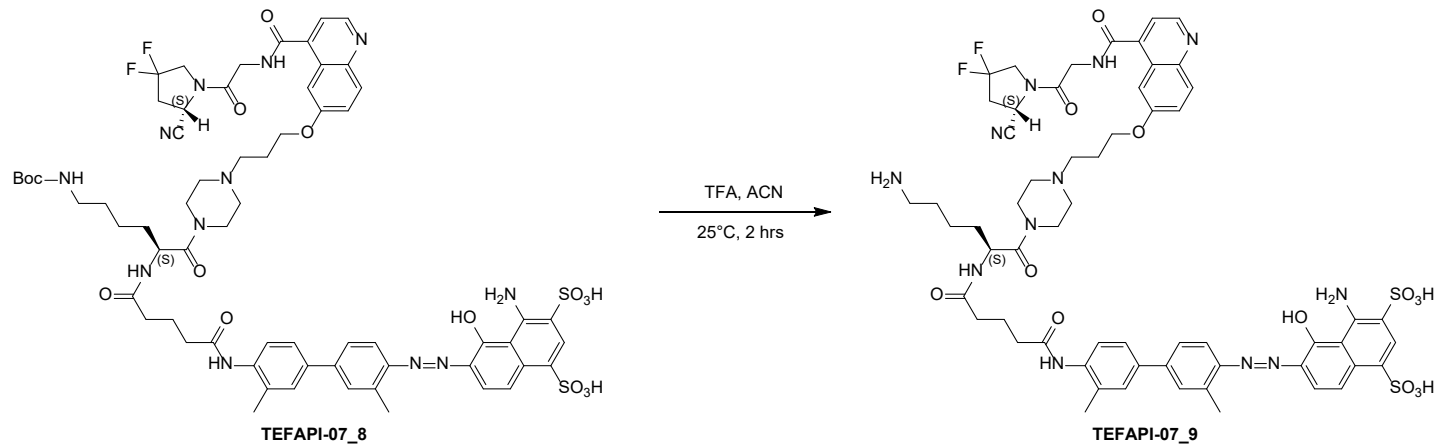

To a solution of TEFAPI-07_8 (30 mg, $22.17 \mathrm{umol}, 1 \mathrm{eq})$ in ACN $(1 \mathrm{~mL})$ was added TFA (308.00 mg, 2.70 mmol, $0.2 \mathrm{~mL}, 121.87 \mathrm{eq}$ ). The mixture was stirred at $25^{\circ} \mathrm{C}$ for $2 \mathrm{~h}$. LC-MS showed reactant 1 was consumed and a main peak with desired compound was detected. The mixture was dried under reduced pressure to get a residue. The crude product TEFAPI-07_9 (30 mg, yield 98.98\%) was obtained as a purple solid which was used for the next step without further purification.

\subsubsection{General procedure for preparation of TEFAPI-07_10}
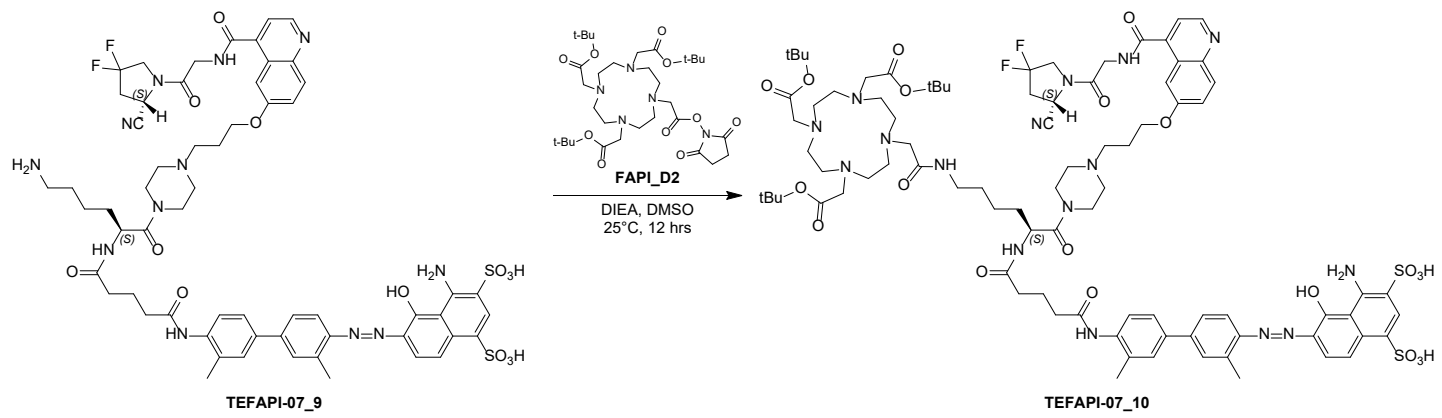

To a solution of TEFAPI-07_9 (15 mg, 10.97 umol, 1 eq, TFA $)$ in DMSO $(1 \mathrm{~mL})$ was added FAPI_D2 (8.82 
$\mathrm{mg}, 13.16 \mathrm{umol}, 1.2 \mathrm{eq})$ and DIEA $(7.09 \mathrm{mg}, 54.85 \mathrm{umol}, 9.55 \mathrm{uL}, 5 \mathrm{eq})$. The mixture was stirred at $25{ }^{\circ} \mathrm{C}$ for $12 \mathrm{~h}$. LC-MS showed reactant 1 was consumed and desired compound was detected. The mixture was dried under reduced pressure to get a residue. Two additional vials were set up as described above. All three reaction mixtures were combined. The residue was purified by prep-HPLC (TFA condition, column: Phenomenex Gemini-NX 150*30 mm (5um particles); mobile phase: [0.1 M TEAB-ACN]; B\%: 10-75\%, 10 min. The product TEFAPI-07_10 (20 mg, yield 75.82\%) was obtained as a purple solid.

LC-MS (ESI $\left.{ }^{+}\right): \mathrm{m} / \mathrm{z} 1847.0(\mathrm{M}+\mathrm{MeCN})^{+}$.

The column used for chromatography was a Luna C18 2.0*30 mm (3 um particles). Detection methods are diode array (DAD). MS mode was positive electrospray ionization. MS range was 100-1000. Mobile phase A was $0.037 \%$ trifluoroacetic acid in water, and mobile phase B was $0.018 \%$ trifluoroacetic acid in HPLC grade acetonitrile. The gradient was 5-95\% B in $2.00 \mathrm{~min} .5 \% \mathrm{~B}$ in $0.01 \mathrm{~min}, 5-95 \% \mathrm{~B}(0.01-1.00 \mathrm{~min}), 95-$ $100 \% \mathrm{~B}(1.00-1.80 \mathrm{~min}), 5 \% \mathrm{~B}$ in $1.81 \mathrm{~min}$ with a hold at $5 \% \mathrm{~B}$ for $0.19 \mathrm{~min}$. The flow rate was $1.0 \mathrm{~mL} / \mathrm{min}$ (0.00-1.80 $\mathrm{min})$ and $1.2 \mathrm{~mL} / \mathrm{min}(1.81-2.00 \mathrm{~min})$.

\subsubsection{General procedure for preparation of TEFAPI-07}
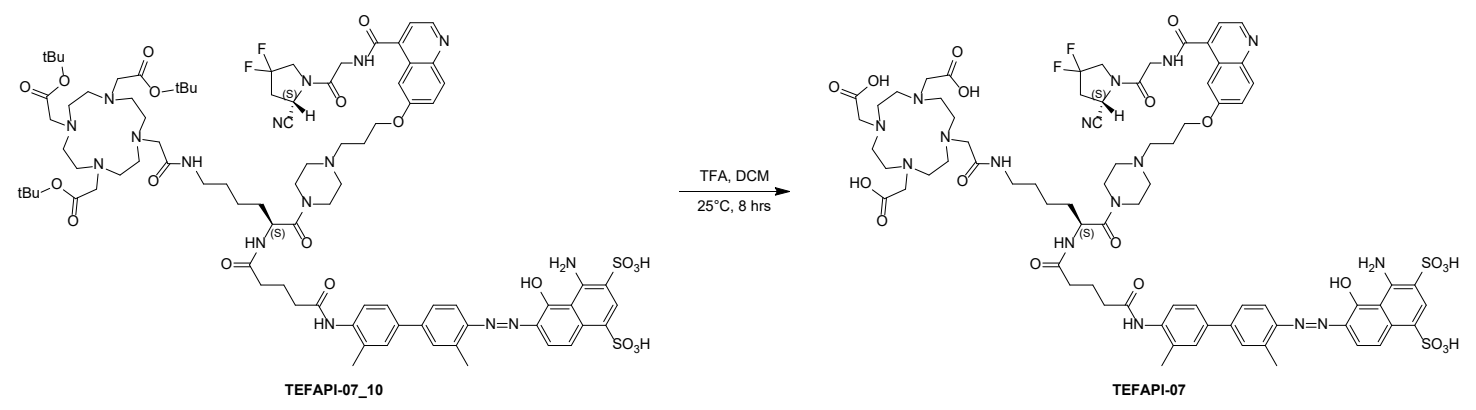

To a solution of TEFAPI-07_10 (20 mg, $11.06 \mathrm{umol}, 1 \mathrm{eq})$ in DCM $(3 \mathrm{~mL})$ was added TFA (18.48 g, 162.07 mmol, $12.00 \mathrm{~mL}, 14651.92 \mathrm{eq}$ ). The mixture was stirred at $25^{\circ} \mathrm{C}$ for $8 \mathrm{~h}$. LC-MS showed reactant 1 was consumed, a main peak with desired compound was detected. The mixture was dried under reduced pressure to get a residue. The residue was purified by prep-HPLC (basic condition, column: Phenomenex Gemini-NX 150*30 mm (5 um particles); mobile phase: [0.1 M TEAB-ACN]; B\%: 10-35\%, $20 \mathrm{~min}$ ). Compound TEFAPI-07 (7.62 mg, yield 41.38\%) was obtained as a purple solid.

${ }^{1}$ H NMR $\left(400 \mathrm{MHz}\right.$, DMSO- $\left.d_{6}\right)$ 
$\delta=1.18-1.30(\mathrm{~m}, 3 \mathrm{H}), 1.33-1.42(\mathrm{~m}, 2 \mathrm{H}), 1.44-1.58(\mathrm{~m}, 2 \mathrm{H}), 1.74-2.13(\mathrm{~m}, 11 \mathrm{H}), 2.17-2.25(\mathrm{~m}, 3 \mathrm{H}), 2.28$

(s, 3H), 2.31-2.40 (m, 5H), 2.57-2.72 (m, 6H), $2.89(\mathrm{br} \mathrm{s}, 22 \mathrm{H}), 4.05-4.40(\mathrm{~m}, 7 \mathrm{H}), 4.60-4.76(\mathrm{~m}, 1 \mathrm{H}), 5.11-$ $5.22(\mathrm{~m}, 1 \mathrm{H}), 6.99$ (br d, $J=9.63 \mathrm{~Hz}, 1 \mathrm{H}), 7.42-7.60$ (m, 5H), 7.64 (br s, 2H), 7.88 (br d, $J=8.38 \mathrm{~Hz}, 2 \mathrm{H}$ ), 7.93-8.07 (m, 2H), 8.28-8.41 (m, 1H), 8.57-8.71 (m, 1H), 8.80 (br d, $J=4.13 \mathrm{~Hz}, 1 \mathrm{H}), 9.15-9.31(\mathrm{~m}, 1 \mathrm{H})$, 9.31-9.47 (m, 1H), 15.84-16.05 (m, 1H).

1.3 The synthesis route of FAPI_C8
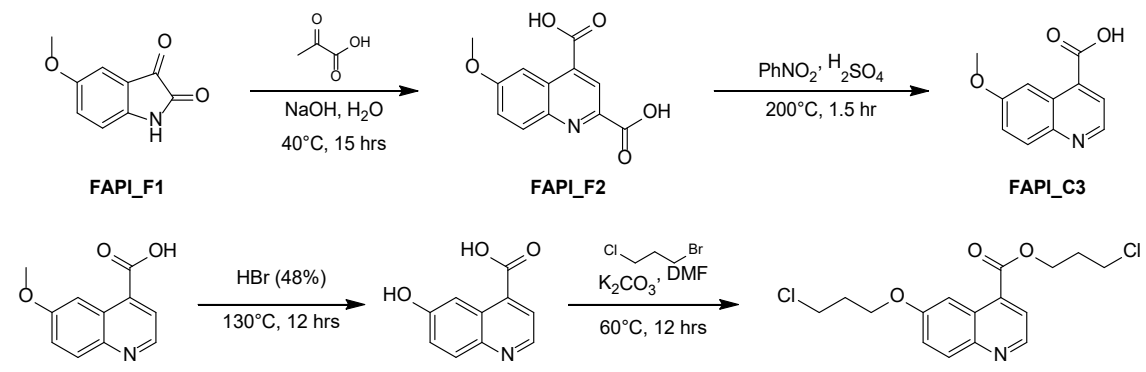

FAPI_F2

FAPI_C3

$\begin{array}{lll}\text { FAPI_C3 } & \text { FAPI_C4 } & \text { FAPI_C5B }\end{array}$

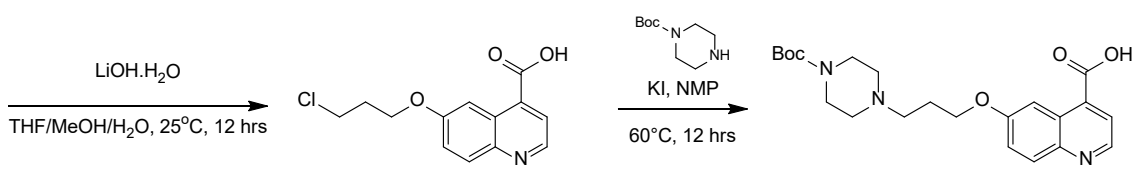

FAPI_C5 $\quad$ FAPI_C6

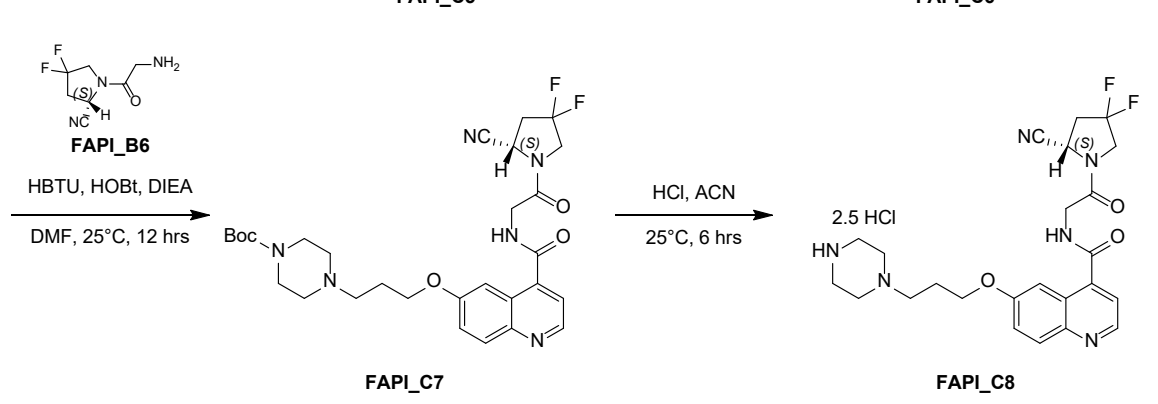

1.3.1 General procedure for preparation of FAPI_F2<smiles>COc1ccc2c(c1)C(=O)C(=O)N2</smiles>

FAPI_F1

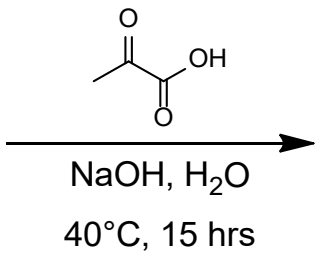

$40^{\circ} \mathrm{C}, 15 \mathrm{hrs}$<smiles>COc1ccc2nc(C(=O)O)cc(C(=O)O)c2c1</smiles>

FAPI_F2

A solution of 5-methoxyindoline-2,3-dione (20 g, $112.89 \mathrm{mmol}, 1 \mathrm{eq})$ and $\mathrm{KOH}(69.68 \mathrm{~g}, 1.24 \mathrm{~mol}, 11 \mathrm{eq})$ 
in $\mathrm{H}_{2} \mathrm{O}(200 \mathrm{~mL})$ was added Pyruvic acid (10.94 g, $\left.124.18 \mathrm{mmol}, 8.75 \mathrm{~mL}, 1.1 \mathrm{eq}\right)$ at $25^{\circ} \mathrm{C}$. The reaction mixture was warmed to $40{ }^{\circ} \mathrm{C}$ and stirred at $40{ }^{\circ} \mathrm{C}$ for 15 hours. LC-MS showed the starting material was consumed completely. The reaction mixture was cooled to $15^{\circ} \mathrm{C}$ and acidified with $\mathrm{HCl}$ to $\mathrm{pH} 3$, the precipitated solid was collected by filtration and washed with deionized water, FAPI_F2 (24 g, 92.23 mmol, $81.70 \%$ yield, $95 \%$ purity) was obtained as grey solid.

${ }^{1}$ H NMR: (400 MHz, DMSO- $\left.d_{6}\right)$

$\delta 3.70-4.24(\mathrm{~m}, 3 \mathrm{H}), 7.58(\mathrm{dd}, J=9.24,2.80 \mathrm{~Hz}, 1 \mathrm{H}), 8.15(\mathrm{~d}, J=9.30 \mathrm{~Hz}, 1 \mathrm{H}), 8.26(\mathrm{~d}, J=2.74 \mathrm{~Hz}, 1 \mathrm{H})$, $8.53(\mathrm{~s}, 1 \mathrm{H}), 13.75$ (br s, 2H).

LC-MS(ESI $\left.{ }^{+}\right):$m/z $248.1(\mathrm{M}+\mathrm{H})^{+}$.

LC-MS method: the column used for chromatography was a ZORBAX Eclipse XDB C18 2.1*30 mm (3.5 um particles). Detection methods are diode array (DAD). MS mode was positive electrospray ionization. MS range was 100-1000. Mobile phase A was 0.037\% trifluoroacetic acid in water, and mobile phase B was $0.018 \%$ trifluoroacetic acid in HPLC grade acetonitrile. The gradient was 5-95\% B in $2.20 \mathrm{~min} .5 \% \mathrm{~B}$ in 0.01 $\min , 5-95 \% \mathrm{~B}(0.01-1.00 \mathrm{~min}), 95-100 \% \mathrm{~B}(1.00-1.80 \mathrm{~min}), 5 \% \mathrm{~B}$ in $1.81 \mathrm{~min}$ with a hold at $5 \% \mathrm{~B}$ for 0.39 min. The flow rate was $1.0 \mathrm{~mL} / \mathrm{min}$.

\subsubsection{General procedure for preparation of FAPI_C3}<smiles>COc1ccc2nc(C(=O)O)cc(C(=O)O)c2c1</smiles>

FAPI_F2

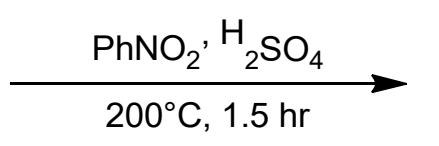

FAPI_C3

A solution of FAPI_F2 $(24 \mathrm{~g}, 97.09 \mathrm{mmol}, 1 \mathrm{eq})$ in nitrobenzene $(150 \mathrm{~mL})$ was stirred at $220^{\circ} \mathrm{C}$ for 1.5 hours. LC-MS showed the starting material was consumed completely. The reaction mixture was cooled to $15^{\circ} \mathrm{C}$ and diluted with PE (150 mL). The precipitated solid was collected by filtration and washed with PE (100 $\mathrm{mL})$ to afford FAPI_C3 $(16.8 \mathrm{~g}, 82.68 \mathrm{mmol}, 85.16 \%$ yield $)$ as grey solid, which was used to the next step without purification. The structure was confirmed by HNMR.

${ }^{1}$ H NMR: (400 MHz DMSO- $\left.d_{6}\right)$ 


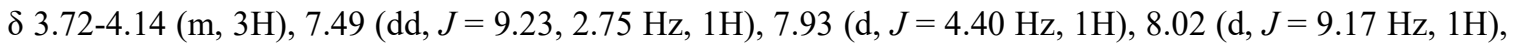
$8.18(\mathrm{~d}, J=2.69 \mathrm{~Hz}, 1 \mathrm{H}), 8.87(\mathrm{~d}, J=4.40 \mathrm{~Hz}, 1 \mathrm{H}), 13.76$ (br s, $1 \mathrm{H})$.

LC-MS(ESI'): m/z $202.1(\mathrm{M}-\mathrm{H})^{-}$.

LC-MS method: the column used for chromatography was a ZORBAX Eclipse XDB C18 2.1*30 mm (3.5 um particles). Detection methods are diode array (DAD). MS mode was positive electrospray ionization. MS range was $100-1000$. Mobile phase A was $0.037 \% \mathrm{NH}_{4} \mathrm{HCO}_{3}$ in water, and mobile phase $\mathrm{B}$ was HPLC grade acetonitrile. The gradient was 5-95\% B in $2.20 \mathrm{~min}, 5 \% \mathrm{~B}$ in $0.01 \mathrm{~min}, 5-95 \% \mathrm{~B}$ ( $0.01-1.00 \mathrm{~min}), 95-100 \%$ B (1.00-1.80 min), 5\% B in $1.81 \mathrm{~min}$ with a hold at $5 \% \mathrm{~B}$ for $0.39 \mathrm{~min}$. The flow rate was $1.0 \mathrm{~mL} / \mathrm{min}$.

\subsubsection{General procedure for preparation of FAPI_C4}

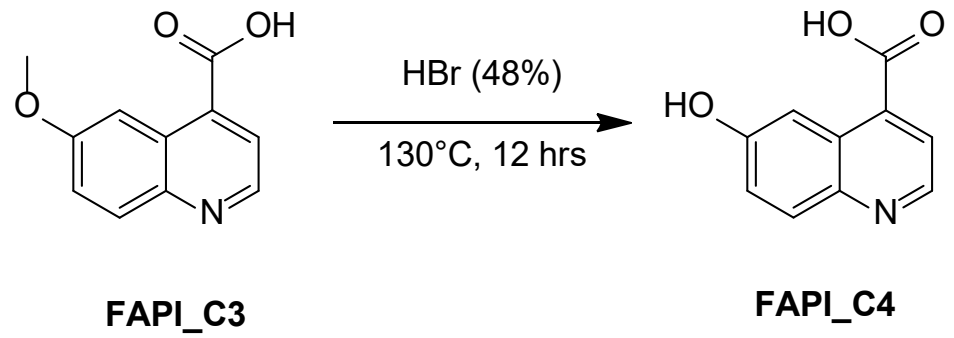

A mixture of FAPI_C3 (40 g, $196.86 \mathrm{mmol}, 1 \mathrm{eq})$ in aqueous solution of hydrogen bromide $(1 \mathrm{~L}, 48 \%$ in water) was stirred at $130^{\circ} \mathrm{C}$ for $12 \mathrm{hrs}$. LC-MS showed FAPI_C3 was consumed, several new peaks were shown on LC-MS and $\sim 81.3 \%$ of desired compound was detected. The reaction mixture was basified by adding $350 \mathrm{ml} \mathrm{30 \%}$ of sodium hydroxide aqueous solution dropwise to $\mathrm{pH} 6$, a large amount of solid were precipitate out, then the solid was collected by filtration, the filter cake was washed with methanol and dried under vacuum to give crude product. The crude product was triturated with methanol $(200 \mathrm{ml})$ and collected by filtration. FAPI_C4 (30 g, $128.93 \mathrm{mmol}, 65.50 \%$ yield, $81.3 \%$ purity) was obtained as a brown soild.

LC-MS (reaction) (ESI): m/z $377.0(2 \mathrm{M}-\mathrm{H})^{-}$.

LC-MS method: the column used for chromatography was Xbridge Shield RP18 2.1* $50 \mathrm{~mm}$ (5 um particles). Detection methods are Diode Array detector (DAD). MS mode was negative electrospray ionization. MS range was 100-1000. Mobile phase A was $10 \mathrm{mM}$ ammonium bicarbonate in water, and mobile phase B was HPLC grade acetonitrile. The gradient was $0-30 \% \mathrm{~B}$ in $4.30 \mathrm{~min}, 0 \% \mathrm{~B}$ in $0.01 \mathrm{~min}, 0-30 \% \mathrm{~B}(0.01-3.50$ min), with a hold at $30 \% \mathrm{~B}$ for $0.3 \mathrm{~min}, 30-0 \% \mathrm{~B}(3.80-3.81 \mathrm{~min})$, with a hold at $0 \% \mathrm{~B}$ for $0.50 \mathrm{~min}$. The 
flow rate was $0.8 \mathrm{~mL} / \mathrm{min}(0.01-3.80 \mathrm{~min})$ and $1.0 \mathrm{~mL} / \mathrm{min}(3.81-4.30 \mathrm{~min})$.

${ }^{\mathbf{1}} \mathbf{H}$ NMR (400 MHz, DMSO- $\left.d_{6}\right)$

$\delta$ ppm 13.66 (br s, 1H), $10.24(\mathrm{~s}, 1 \mathrm{H}), 8.77(\mathrm{~d}, J=4.5 \mathrm{~Hz}, 1 \mathrm{H}), 8.06(\mathrm{~d}, J=2.6 \mathrm{~Hz}, 1 \mathrm{H}), 7.95(\mathrm{~d}, J=9.1 \mathrm{~Hz}$ $1 \mathrm{H}), 7.84(\mathrm{~d}, J=4.4 \mathrm{~Hz}, 1 \mathrm{H}), 7.36(\mathrm{dd}, J=2.7,9.1 \mathrm{~Hz}, 1 \mathrm{H})$.

\subsubsection{General procedure for preparation of FAPI_C5B}<smiles>O=C(O)c1ccnc2ccc(O)cc12</smiles>

FAPI_C4

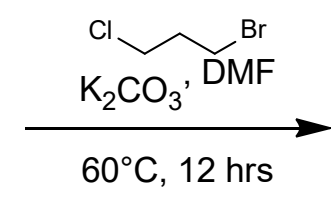

\section{.}<smiles>O=C(OCCCCl)c1ccnc2ccc(OCCCCl)cc12</smiles>

FAPI_C5B

To a stirred solution of FAPI_C4 (30 g, $158.59 \mathrm{mmol}, 1 \mathrm{eq})$ in dimethyl formamide (300 mL) was added potassium carbonate $(87.67 \mathrm{~g}, 634.36 \mathrm{mmol}, 4 \mathrm{eq})$ and 1-bromo-3-chloro-propane (74.90 g, $475.77 \mathrm{mmol}$, $46.81 \mathrm{~mL}, 3 \mathrm{eq})$, then the reaction mixture was stirred at $60{ }^{\circ} \mathrm{C}$ for $12 \mathrm{hrs}$. LC-MS showed the FAPI_C4 was consumed and the product was detected with the desired MS. The reaction mixture was concentrated under reduced pressure and the residue was added water $(200 \mathrm{~mL})$, a large amount of solid were precipitate out, then the resulting mixture was stirred at $25^{\circ} \mathrm{C}$ for $15 \mathrm{mins}$ and filtered in vacuum. The crude product was used for next step directly without further purification. FAPI_C5B (51.69 g, 141.98 mmol, 89.53\% yield, 94\% purity) was obtained as a brown solid (Note: the product is a mixture of $\mathrm{Cl}$ and $\mathrm{Br}$ compound).

LC-MS (reaction) $\left(\mathrm{ESI}^{+}\right): \mathrm{m} / \mathrm{z} 342.8(\mathrm{M}+\mathrm{H})^{+}$.

LC-MS method: the column used for chromatography was a Chromolith RP-18e 25-2 mm. Detection methods are diode array (DAD). MS mode was positive electrospray ionization. MS range was 100-1000. Mobile phase A was $0.04 \%$ trifluoroacetic acid in water, and mobile phase B was $0.02 \%$ trifluoroacetic acid in HPLC grade acetonitrile. The gradient was 5-95\% B in $1.50 \mathrm{~min}, 5 \% \mathrm{~B}$ in $0.01 \mathrm{~min}, 5-95 \% \mathrm{~B}(0.01-0.70$ $\min ), 95-100 \% \mathrm{~B}(0.70-1.15 \mathrm{~min}), 5 \% \mathrm{~B}$ in $1.16 \mathrm{~min}$ with a hold at 5\% B for $0.34 \mathrm{~min}$. The flow rate was 1.5 $\mathrm{mL} / \mathrm{min}$. 


\subsubsection{General procedure for preparation of FAPI_C5}
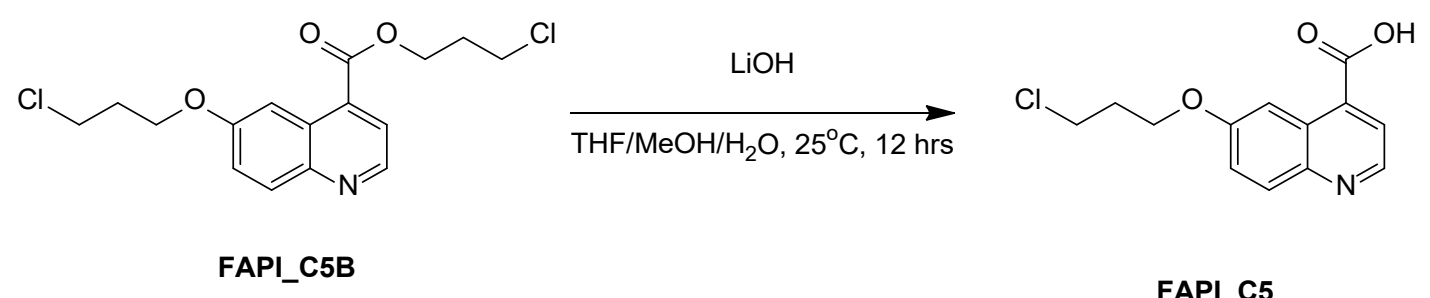

FAPI_C5

To a stirred solution of FAPI_C5B $(51.69 \mathrm{~g}, 151.04 \mathrm{mmol}, 1 \mathrm{eq})$ in water $(270 \mathrm{~mL})$, tetrahydrofuran $(170$ $\mathrm{mL})$, methanol $(170 \mathrm{~mL})$ was added lithium hydroxide $(10.85 \mathrm{~g}, 453.13 \mathrm{mmol}, 3 \mathrm{eq})$ in portions at $25^{\circ} \mathrm{C}$, and the reaction mixture was stirred at $25^{\circ} \mathrm{C}$ for $12 \mathrm{hrs}$. LC-MS showed FAPI_C5B was consumed, one main peak was shown on LC-MS and $\sim 84.47 \%$ of desired compound was detected. The reaction mixture was concentrated under reduced pressure to remove tetrahydrofuran and methanol, then the resulting mixture was acidified by adding $12 \mathrm{~mol} / \mathrm{L}$ hydrochloric acid dropwise at $0{ }^{\circ} \mathrm{C}$ to $\mathrm{pH} 7$, a large amount of solid were precipitate out, the residue was triturated with ethyl acetate $(200 \mathrm{ml} \times 2)$ and collected by filtration under vacuum. FAPI_C5 (37.58 g, $130.13 \mathrm{mmol}, 86.15 \%$ yield, 92\% purity) was obtained as a brown solid (Note: the product is a mixture of $\mathrm{Cl}$ and $\mathrm{Br}$ compound).

LC-MS (reaction) $\left(\mathrm{ESI}^{+}\right): \mathrm{m} / \mathrm{z} 266.1(\mathrm{M}+\mathrm{H})^{+}$.

LC-MS method: the column used for chromatography was a Chromolith RP-18e

25-2 mm. Detection methods are diode array (DAD). MS mode was positive electrospray ionization. MS range was 100-1000. Mobile phase A was 0.04\% trifluoroacetic acid in water, and mobile phase B was $0.02 \%$ trifluoroacetic acid in HPLC grade acetonitrile. The gradient was $5-95 \% \mathrm{~B}$ in $1.50 \mathrm{~min}, 5 \% \mathrm{~B}$ in 0.01 $\min , 5-95 \% \mathrm{~B}(0.01-0.70 \mathrm{~min}), 95-100 \% \mathrm{~B}(0.70-1.15 \mathrm{~min}), 5 \% \mathrm{~B}$ in $1.16 \mathrm{~min}$ with a hold at $5 \% \mathrm{~B}$ for 0.34 min. The flow rate was $1.5 \mathrm{~mL} / \mathrm{min}$.

${ }^{1}$ H NMR (400 MHz, DMSO- $\left.d_{6}\right)$

$\delta$ ppm 2.26-2.98 (m, 2 H), 3.83-3.88 (m, 2 H), 4.22-4.25 (m, 2 H), $7.54(\mathrm{dd}, J=9.19,2.69 \mathrm{~Hz}, 1 \mathrm{H}), 7.96(\mathrm{~d}$, $J=4.38 \mathrm{~Hz}, 1 \mathrm{H}), 8.03-8.11(\mathrm{~m}, 1 \mathrm{H}), 8.19(\mathrm{~d}, J=2.63 \mathrm{~Hz}, 1 \mathrm{H}), 8.90(\mathrm{~d}, J=4.38 \mathrm{~Hz}, 1 \mathrm{H})$. 


\subsubsection{General procedure for preparation of FAPI_C6}<smiles>O=C(O)c1ccnc2ccc(OCCCCl)cc12</smiles>

FAPI_C5

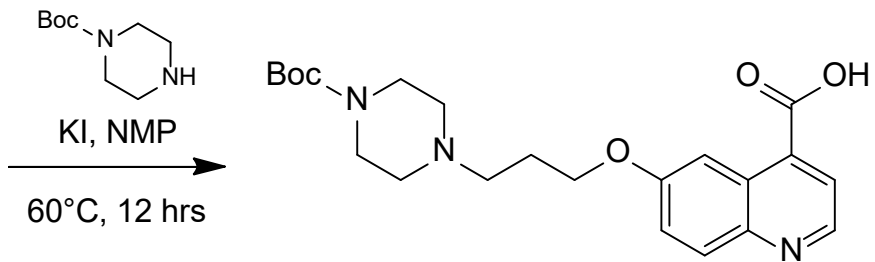

FAPI_C6

A mixture of FAPI_C5 $(30 \mathrm{~g}, 112.91 \mathrm{mmol}, 1 \mathrm{eq})$, tert-butyl piperazine-1-carboxylate $(105.15 \mathrm{~g}, 564.56$ mmol, $5 \mathrm{eq}$ ) and potassium iodide $(9.37 \mathrm{~g}, 56.46 \mathrm{mmol}, 0.5 \mathrm{eq})$ in $N$-methyl-pyrrolidone ( $300 \mathrm{~mL}$ ) was stirred at $60^{\circ} \mathrm{C}$ for $12 \mathrm{hrs}$. LC-MS showed all FAPI_C5 was consumed and the product was detected with the desired MS. The reaction mixture was cooled to room temperature and filtered. The crude product was purified by reversed-phase HPLC (0.1\% FA condition). FAPI_C6 (42.96 g, $96.16 \mathrm{mmol}, 85.16 \%$ yield, 93\% purity) was obtained as yellow solid.

LC-MS (reaction) $\left(\mathrm{ESI}^{+}\right): \mathrm{m} / \mathrm{z} 416.1(\mathrm{M}+\mathrm{H})^{+}$.

LC-MS method: the column used for chromatography was a Kinetex C18 2.1*30 mm (5 um particles). Detection methods are diode array (DAD). MS mode was positive electrospray ionization. MS range was 100-1000. Mobile phase A was $0.04 \%$ TFA in water, and mobile phase B was $0.02 \%$ TFA in HPLC grade acetonitrile. The gradient was 5-95\% B in $4.30 \mathrm{~min}, 5 \% \mathrm{~B}$ in $0.01 \mathrm{~min}, 5-95 \% \mathrm{~B}(0.01-3.00 \mathrm{~min})$, with a hold at $95 \% \mathrm{~B}$ for $0.50 \mathrm{~min}, 95-5 \% \mathrm{~B}(3.50-3.51 \mathrm{~min}), 5 \% \mathrm{~B}$ in $3.51 \mathrm{~min}$, with a hold at $5 \% \mathrm{~B}$ for $0.79 \mathrm{~min}$. The flow rate was $1.0 \mathrm{~mL} / \mathrm{min}$.

${ }^{1}$ H NMR $\left(400 \mathrm{MHz}, \mathrm{DMSO}-d_{6}\right)$

$\delta$ ppm $8.82(\mathrm{~d}, J=4.4 \mathrm{~Hz}, 1 \mathrm{H}), 8.19-8.16(\mathrm{~m}, 1 \mathrm{H}), 7.99(\mathrm{~d}, J=9.3 \mathrm{~Hz}, 1 \mathrm{H}), 7.85(\mathrm{~d}, J=4.4 \mathrm{~Hz}, 1 \mathrm{H}), 7.45$ (dd, $J=2.8,9.1 \mathrm{~Hz}, 1 \mathrm{H}), 4.15$ (br t, $J=6.2 \mathrm{~Hz}, 2 \mathrm{H}), 2.62-2.50$ (m, 6H), 2.42 (br t, $J=4.6 \mathrm{~Hz}, 4 \mathrm{H}), 1.99$ (br d, $J=6.6 \mathrm{~Hz}, 2 \mathrm{H}), 1.39$ (s, 9H). 


\subsubsection{General procedure for preparation of FAPI_C7}

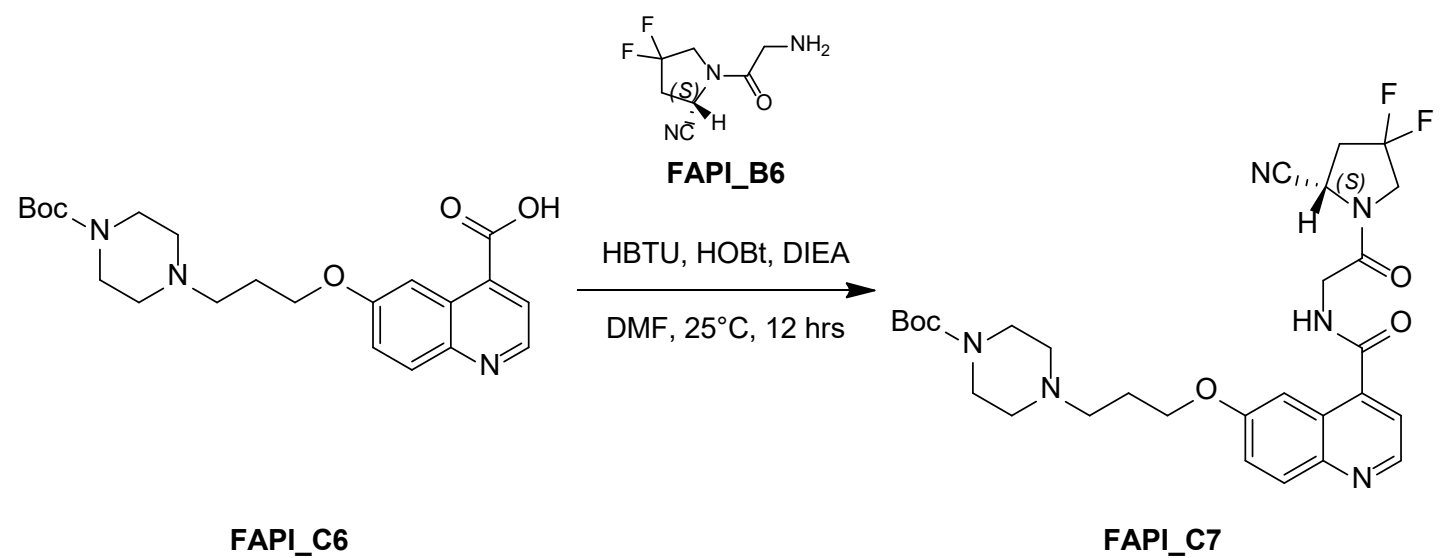

To a stirred solution of FAPI_C6 (12.00 g, $26.57 \mathrm{mmol}$, 92\% purity, $1.02 \mathrm{eq})$, $O$-benzotriazol-1-yltetramethyluronium hexafluorophosphate $(19.76 \mathrm{~g}, 52.10 \mathrm{mmol}, 2 \mathrm{eq})$, 1-hydroxybenzotriazole $(7.04 \mathrm{~g}$, $52.10 \mathrm{mmol}, 2 \mathrm{eq}), N, N$-diisopropylethylamine $(10.10 \mathrm{~g}, 78.15 \mathrm{mmol}, 13.61 \mathrm{~mL}, 3 \mathrm{eq})$ in dimethyl formamide $(120 \mathrm{~mL})$ was added FAPI_B6 $(5.88 \mathrm{~g}, 26.05 \mathrm{mmol}, 1.00 \mathrm{eq}, \mathrm{HCl})$, and the reaction mixture was stirred at $25{ }^{\circ} \mathrm{C}$ for $12 \mathrm{hrs}$. LC-MS showed the FAPI_C6 was consumed, several new peaks were shown on LC-MS and $\sim 50.0 \%$ of desired compound was detected. The reaction mixture was filtered. The filtrate was purified by prep-HPLC ( $\mathrm{HCl}$ condition), column: Phenomenex luna C18 250*70 mm (15 um particles); mobile phase: [water $(0.05 \% \mathrm{HCl})-\mathrm{ACN}$ ]; B\%: 5\%-35\%, 22 min. FAPI_C7 $(11.27 \mathrm{~g}, 17.29$ mmol, 66.37\% yield, $90 \%$ purity) was obtained as a yellow solid.

LC-MS (reaction) $\left(\mathrm{ESI}^{+}\right): \mathrm{m} / \mathrm{z} 587.2(\mathrm{M}+\mathrm{H})^{+}$.

LC-MS method: the column used for chromatography was a Kinetex C18 2.1*30 mm (5 um particles). Detection methods are diode array (DAD). MS mode was positive electrospray ionization. MS range was 100-1000. Mobile phase A was $0.04 \%$ TFA in water, and mobile phase B was $0.02 \%$ TFA in HPLC grade acetonitrile. The gradient was 5-95\% B in $4.30 \mathrm{~min}, 5 \% \mathrm{~B}$ in $0.01 \mathrm{~min}, 5-95 \% \mathrm{~B}(0.01-3.00 \mathrm{~min})$, with a hold at $95 \% \mathrm{~B}$ for $0.50 \mathrm{~min}, 95-5 \% \mathrm{~B}(3.50-3.51 \mathrm{~min}), 5 \% \mathrm{~B}$ in $3.51 \mathrm{~min}$, with a hold at $5 \% \mathrm{~B}$ for $0.79 \mathrm{~min}$. The flow rate was $1.0 \mathrm{~mL} / \mathrm{min}$.

${ }^{1} \mathbf{H}$ NMR $\left(400 \mathrm{MHz}\right.$, DMSO- $\left.d_{6}\right)$

$\delta$ ppm 1.41 (s, 9 H), 2.27-2.33 (m, 2 H), 3.27-3.29 (m, 5 H), 3.43-3.55 (m, 2 H), 3.93-4.21 (m, $10 \mathrm{H}), 5.19$ 
(dd, $J=9.26,2.75 \mathrm{~Hz}, 1 \mathrm{H}), 7.59$ (dd, $J=9.26,2.63 \mathrm{~Hz}, 1 \mathrm{H}), 7.69(\mathrm{~d}, J=4.63 \mathrm{~Hz}, 1 \mathrm{H}), 7.87-8.00(\mathrm{~m}, 1 \mathrm{H})$, $8.14(\mathrm{~d}, J=9.26 \mathrm{~Hz}, 1 \mathrm{H}), 8.95(\mathrm{~d}, J=4.63 \mathrm{~Hz}, 1 \mathrm{H}), 9.24$ (br t, $J=5.82 \mathrm{~Hz}, 1 \mathrm{H}), 11.00$ (br s, $1 \mathrm{H})$.

\subsubsection{General procedure for preparation of FAPI_C8}

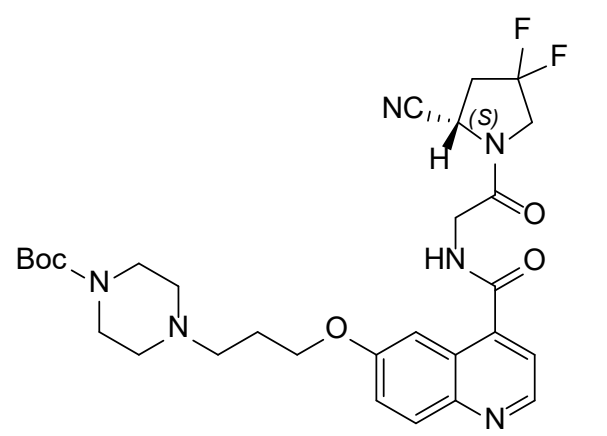

FAPI_C7

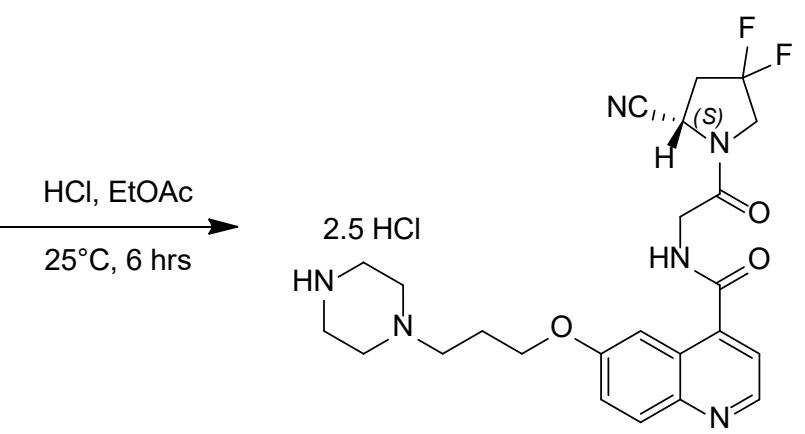

FAPI C8

To a stirred solution of FAPI_C7 $(2 \mathrm{~g}, 3.41 \mathrm{mmol}, 1 \mathrm{eq})$ in ethyl acetate $(40 \mathrm{~mL})$ was added hydrogen chloride in ethyl acetate solution $(4 \mathrm{M}, 4 \mathrm{~mL}, 4.69 \mathrm{eq})$, and the reaction mixture was stirred at $25^{\circ} \mathrm{C}$ for 6 hrs. LC-MS showed FAPI_C7 was consumed, one main peak was shown on LC-MS and $\sim 81.0 \%$ of desired compound was detected. The reaction mixture was concentrated under reduced pressure to remove ethyl acetate. The crude product was used for next step directly without further purification. FAPI_C8 (1.5 g, crude, $\mathrm{HCl}$ ) was obtained as a yellow solid.

LC-MS (reaction) $\left(\mathrm{ESI}^{-}\right): \mathrm{m} / \mathrm{z} 485.1(\mathrm{M}+\mathrm{H})^{+}$.

LC-MS method: the column used for chromatography was Xbridge Shield RP18 2.1*50 mm (5 um particles). Detection methods are diode array (DAD). MS mode was negative electrospray ionization. MS range was 100-1000. Mobile phase A was $10 \mathrm{mM}$ ammonium bicarbonate in water, and mobile phase B was HPLC grade acetonitrile. The gradient was 5-95\% B in $4.30 \mathrm{~min}, 5 \% \mathrm{~B}$ in $0.01 \mathrm{~min}, 5-95 \% \mathrm{~B}(0.01-3.00 \mathrm{~min})$, and hold at $95 \% \mathrm{~B}$ within $0.5 \mathrm{~min}, 95-5 \% \mathrm{~B}(3.50-3.51 \mathrm{~min})$, with a hold at $5 \% \mathrm{~B}$ for $0.79 \mathrm{~min}$. The flow rate was $1.0 \mathrm{~mL} / \mathrm{min}(0.01-4.30 \mathrm{~min})$. 


\subsection{The synthesis route of FAPI_D2}
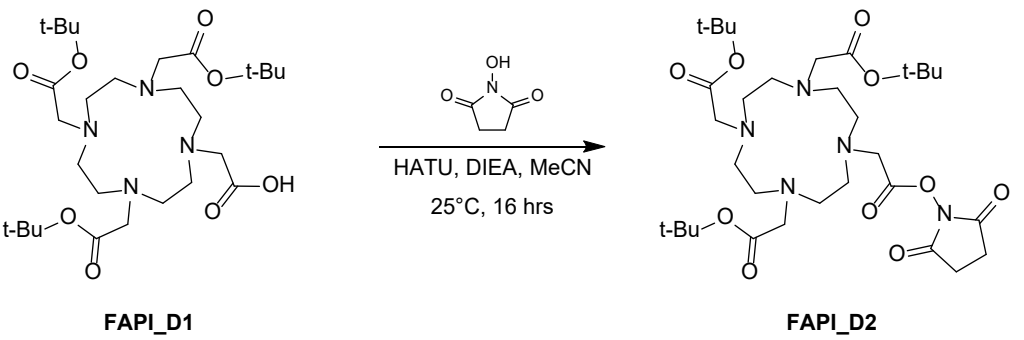

\subsubsection{General procedure for preparation of FAPI_D2}

To a solution of FAPI_D1 $(60 \mathrm{mg}, 104.76 \mathrm{umol}, 1 \mathrm{eq})$ and $O$-benzotriazol-1-yl-tetramethyluronium hexafluorophosphate $(47.68 \mathrm{mg}, 125.71 \mathrm{umol}, 1.2 \mathrm{eq})$ in acetonitrile $(0.6 \mathrm{~mL})$ was added 1hydroxypyrrolidine-2, 5-dione $(14.47 \mathrm{mg}, 125.71 \mathrm{umol}, 1.2 \mathrm{eq})$, and the reaction mixture was stirred at $25^{\circ} \mathrm{C}$ for 12 hrs. TLC (dichloromethane : acetonitrile $=10: 1$ ) showed FAPI_D1 was consumed and desired compound was detected. The reaction mixture was concentrated under reduced pressure to remove acetonitrile. The mixture was purified by prep-TLC $\left(\mathrm{SiO}_{2}\right.$, dichloromethane: acetonitrile $\left.=10: 1\right)$. Compound FAPI_D2 (29 mg, 43.30 umol, $41.33 \%$ yield) was obtained as a white solid. The structure was confirmed by HNMR.

${ }^{1}$ H NMR (400 MHz, chloroform- $d$ )

$\delta$ ppm 1.46 (s, $27 \mathrm{H}), 2.03(\mathrm{~s}, 8 \mathrm{H}), 2.70-2.94(\mathrm{~m}, 16 \mathrm{H}), 3.01-3.13$ (m, $4 \mathrm{H})$. 
1.5. NMR Spectra and mass spectrum

Supplemental Fig 1. LC-MS analysis of TEFAPI-06_F7.

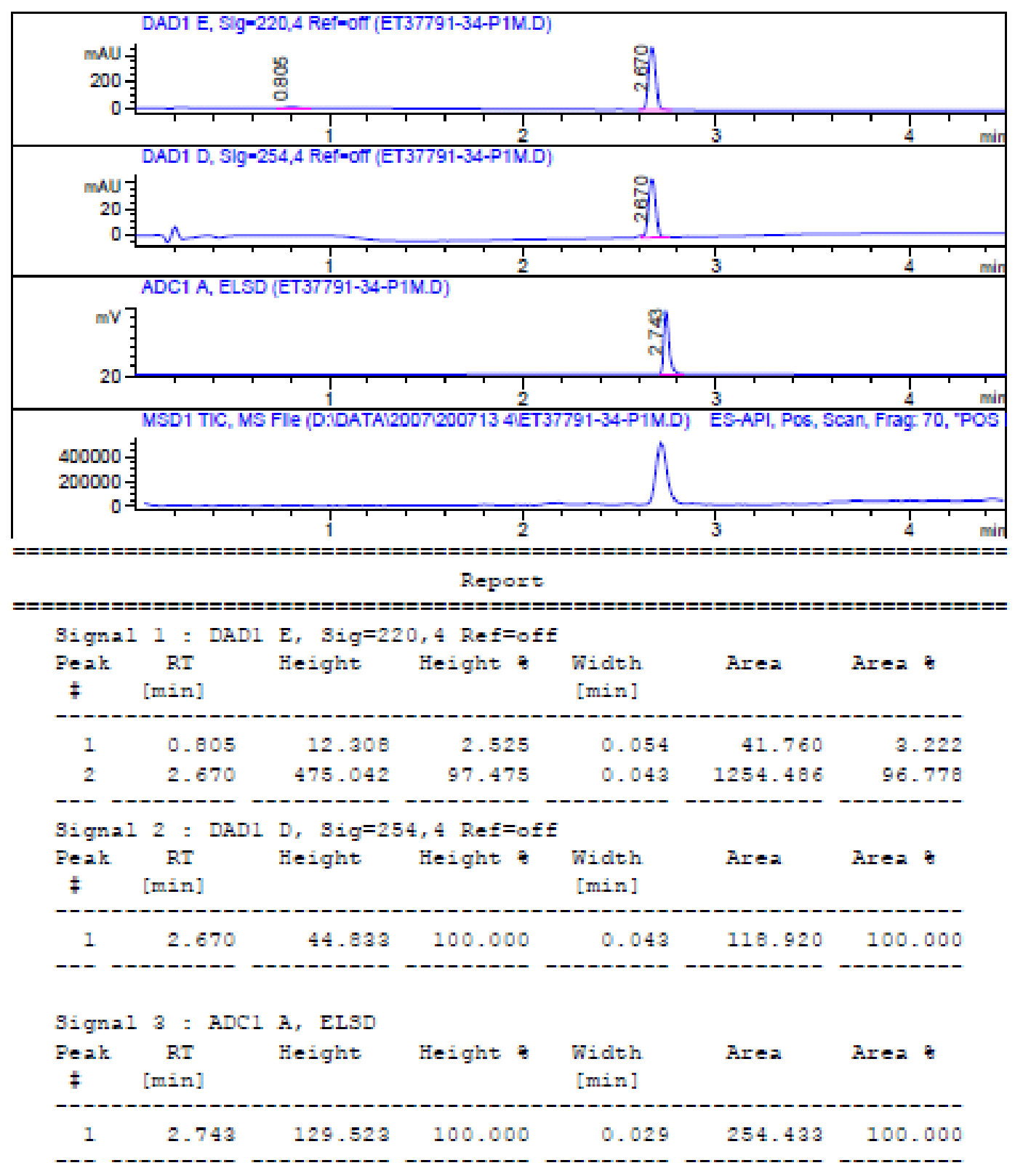


Supplemental Fig 2. MS analysis of TEFAPI-06_F7.

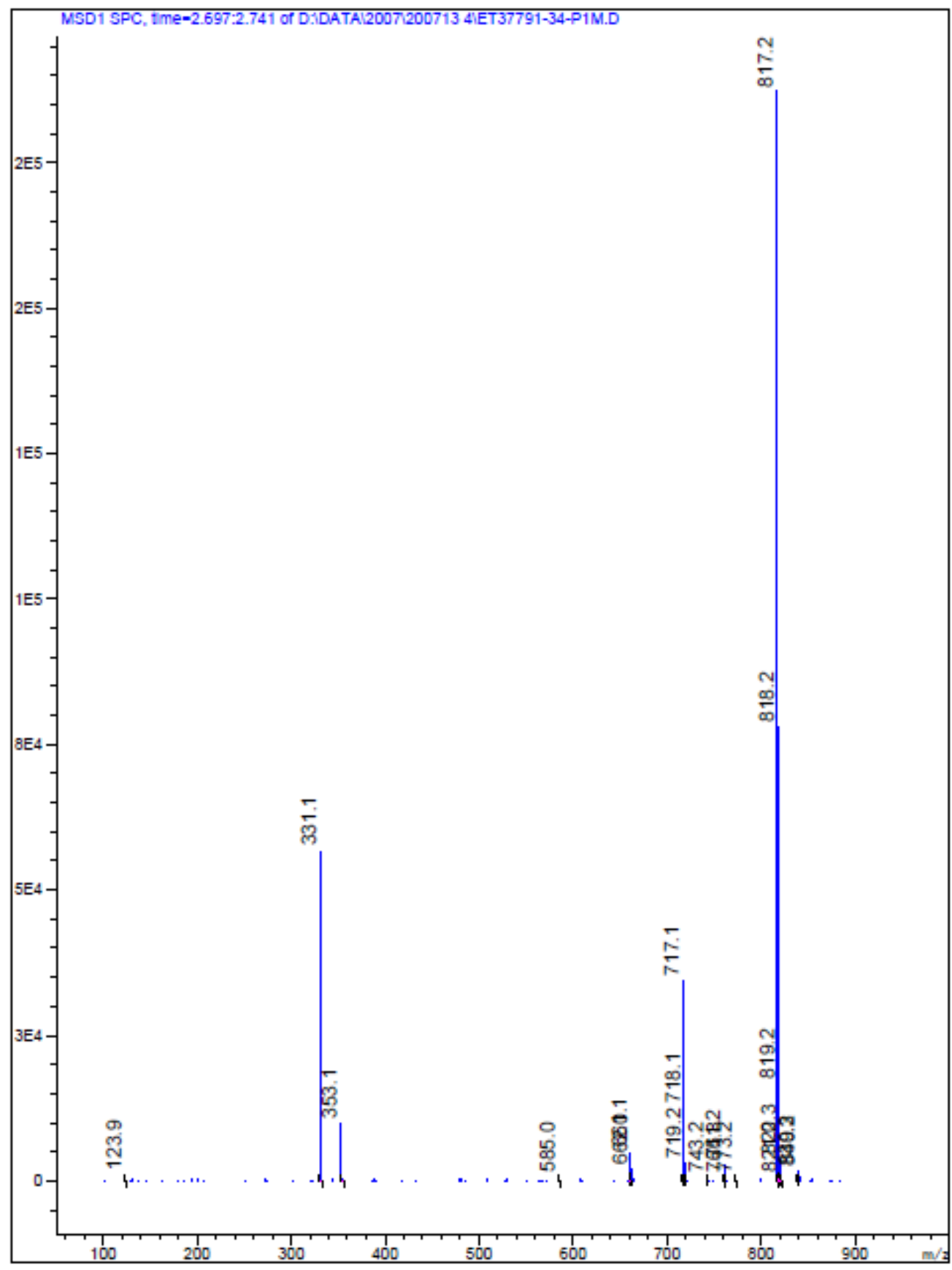


Supplemental Fig 3. ${ }^{1} \mathrm{H}$ NMR analysis of TEFAPI-06_F7.

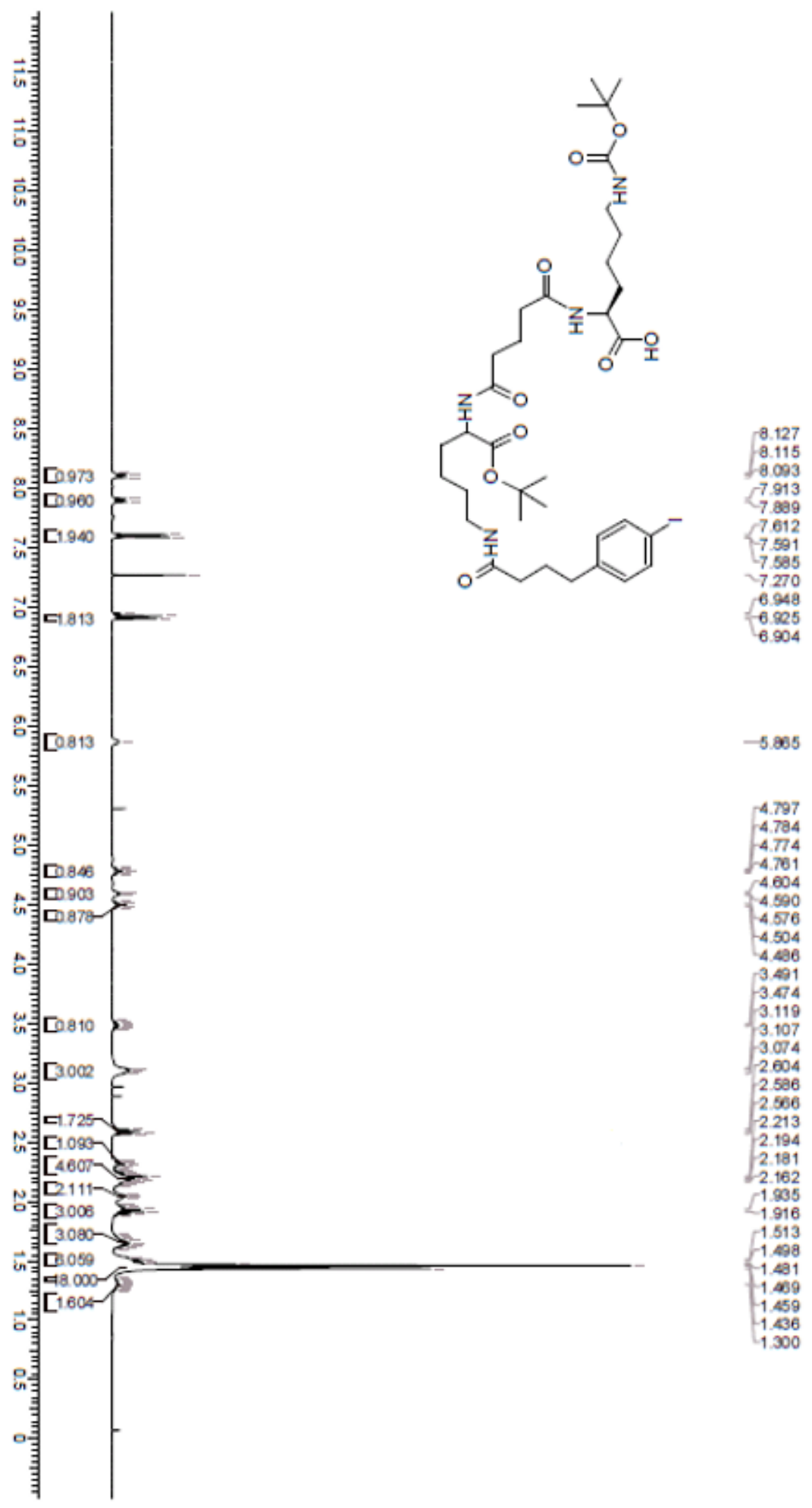


Supplemental Fig 4. LC-MS analysis of TEFAPI-06.

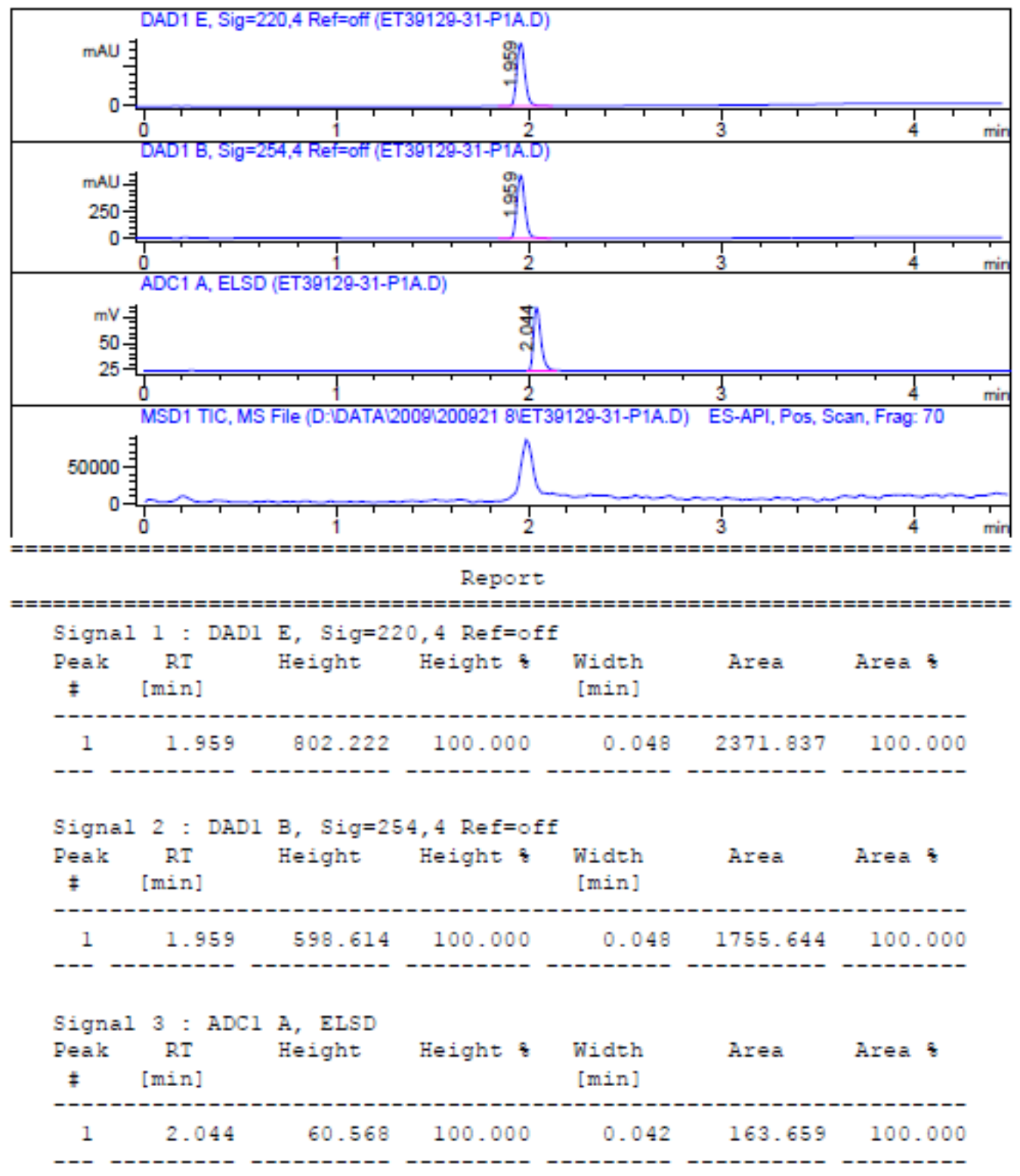


Supplemental Fig 5. MS analysis of TEFAPI-06.

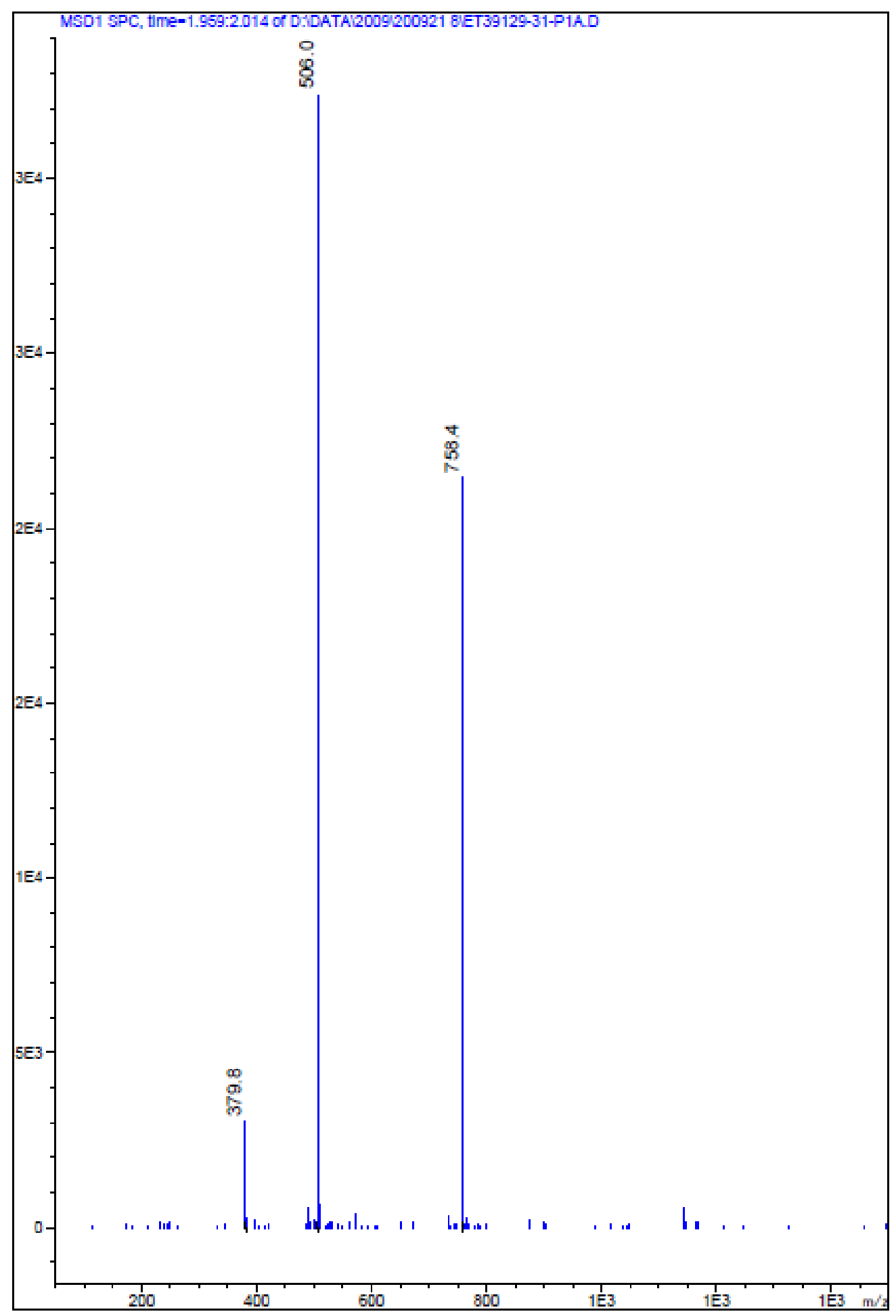

S35 
Supplemental Fig 6. ${ }^{1} \mathrm{H}$ NMR (DMSO- $d_{6}$ ) analysis of TEFAPI-06.

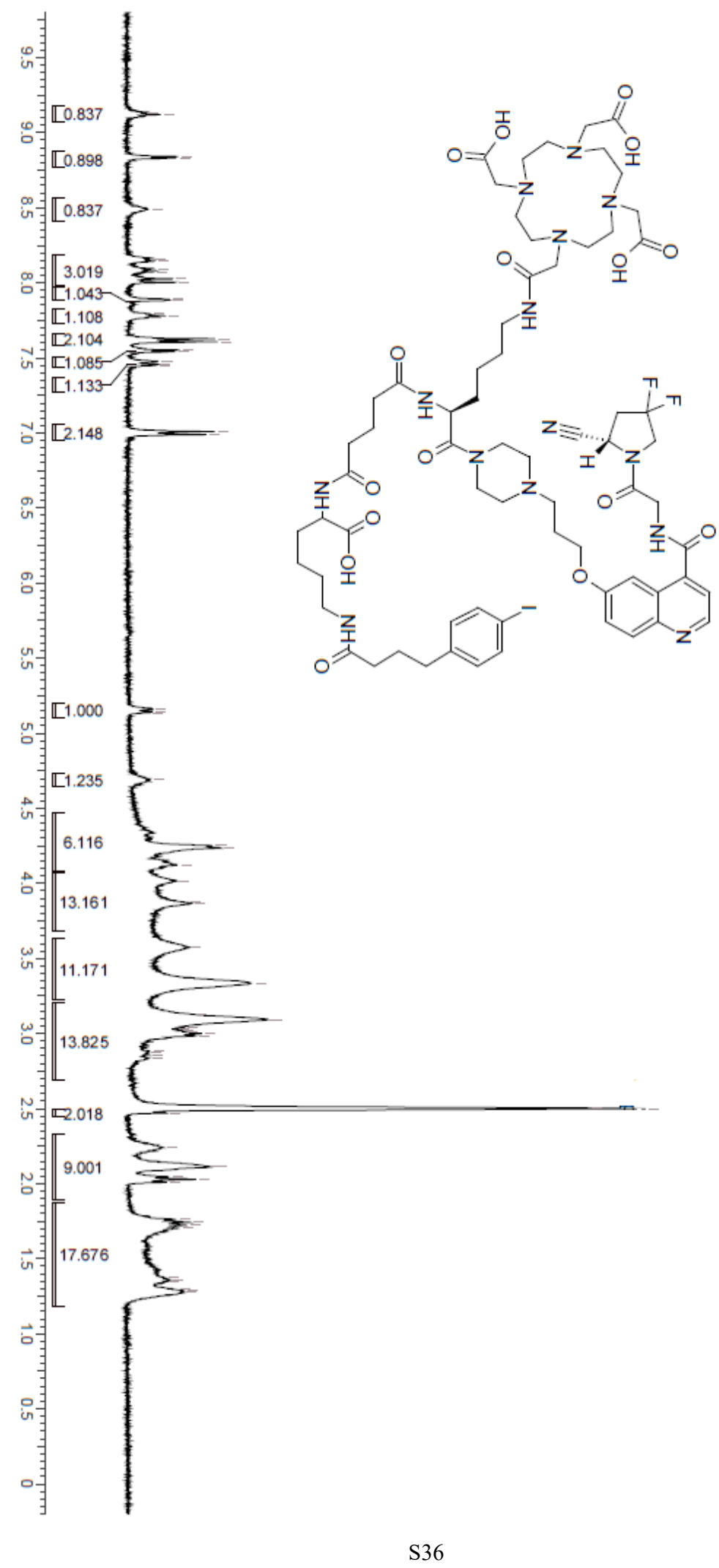

-5.167
-5.159
-5.144
5.136

S36 
Supplemental Fig 7. ${ }^{19}$ F NMR (DMSO- $d_{6}$ ) analysis of TEFAPI-06.

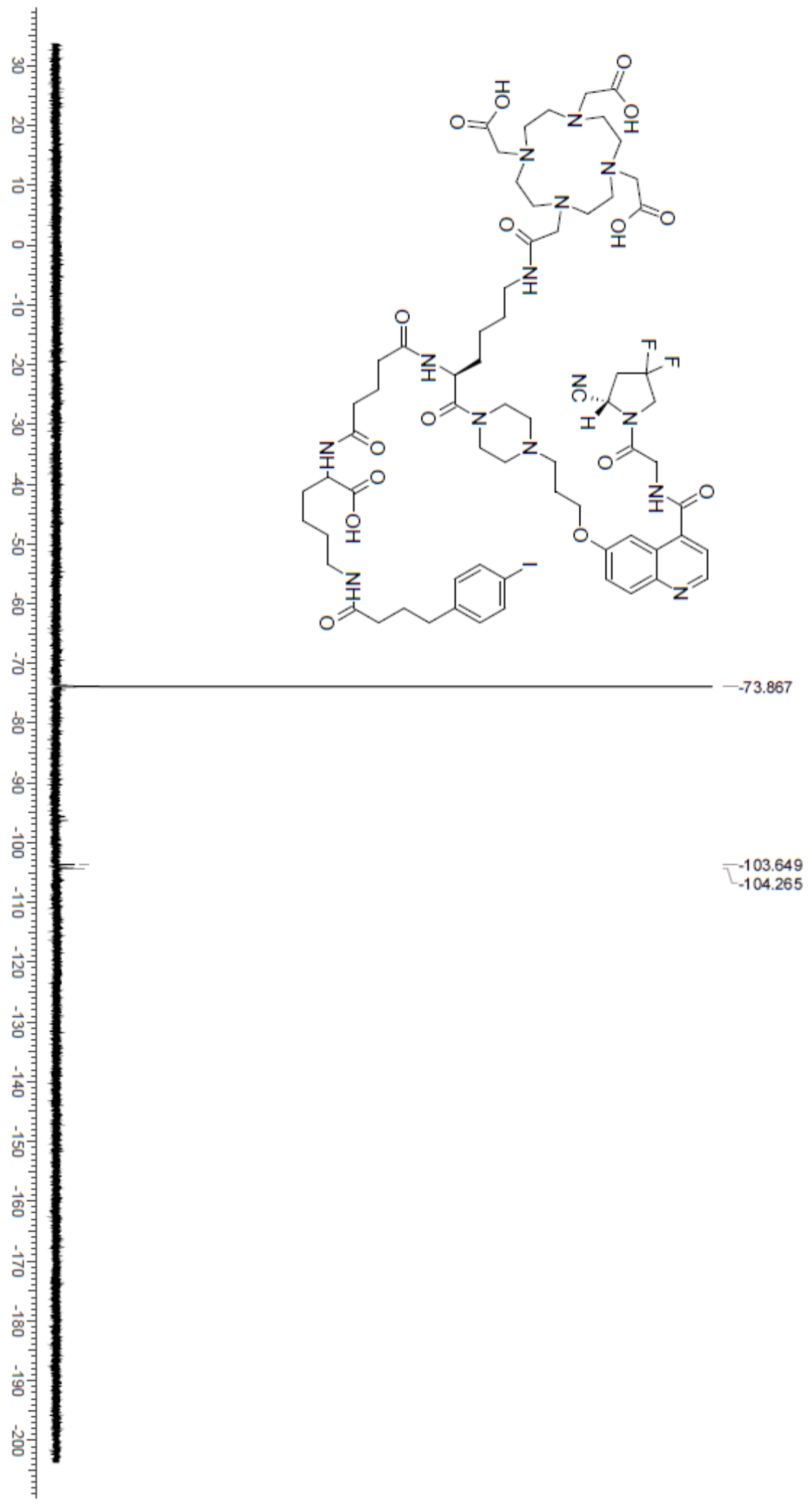


Supplemental Fig 8. ${ }^{1} \mathrm{H}$ NMR (methanol- $d_{4}$ ) analysis of TEFAPI-06.

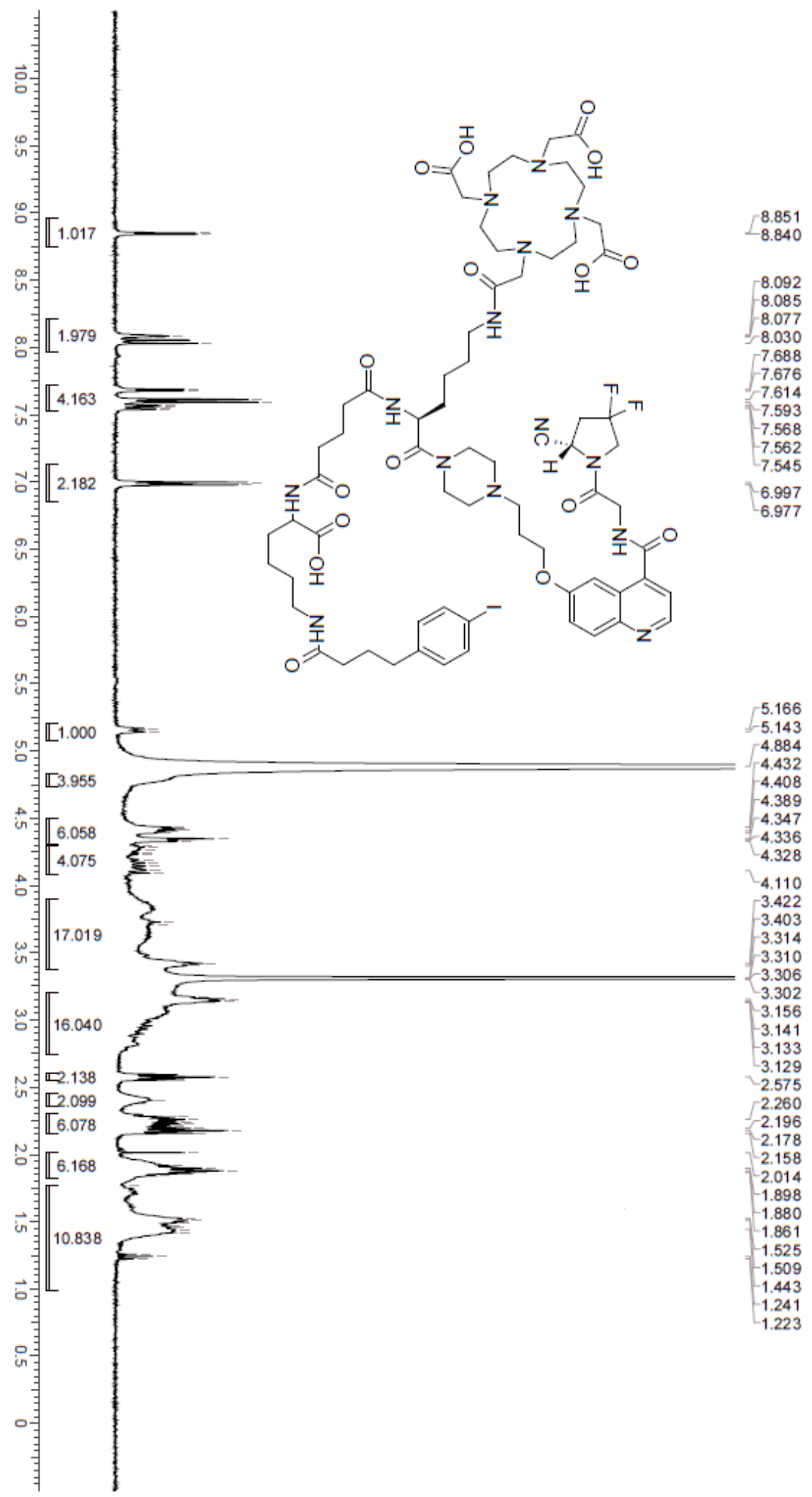


Supplemental Fig 9. ${ }^{19}$ F NMR (methanol- $d_{4}$ ) analysis of TEFAPI-06.

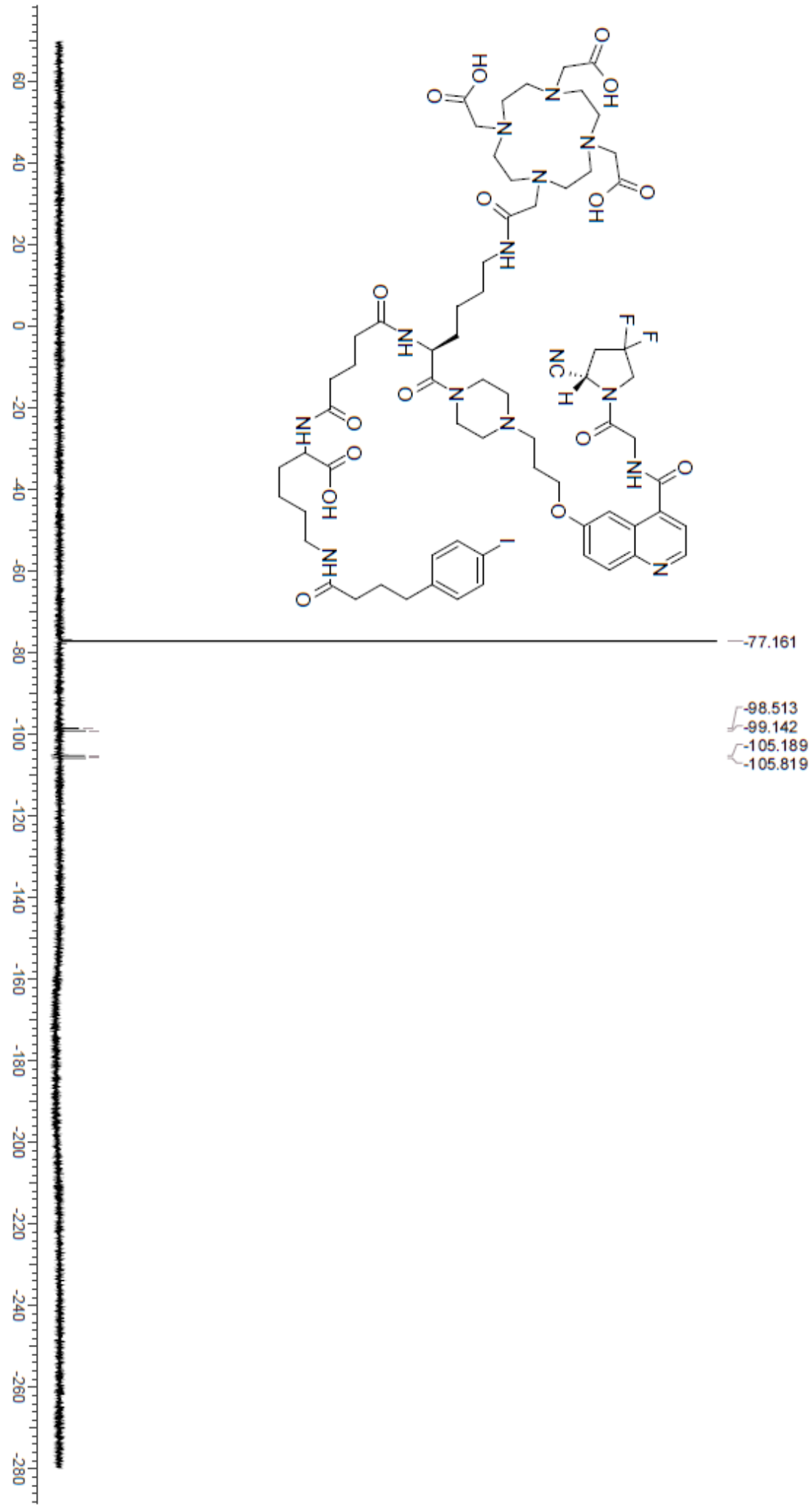


Supplemental Fig 10. ${ }^{1} \mathrm{H}$ NMR analysis of TEFAPI-06.

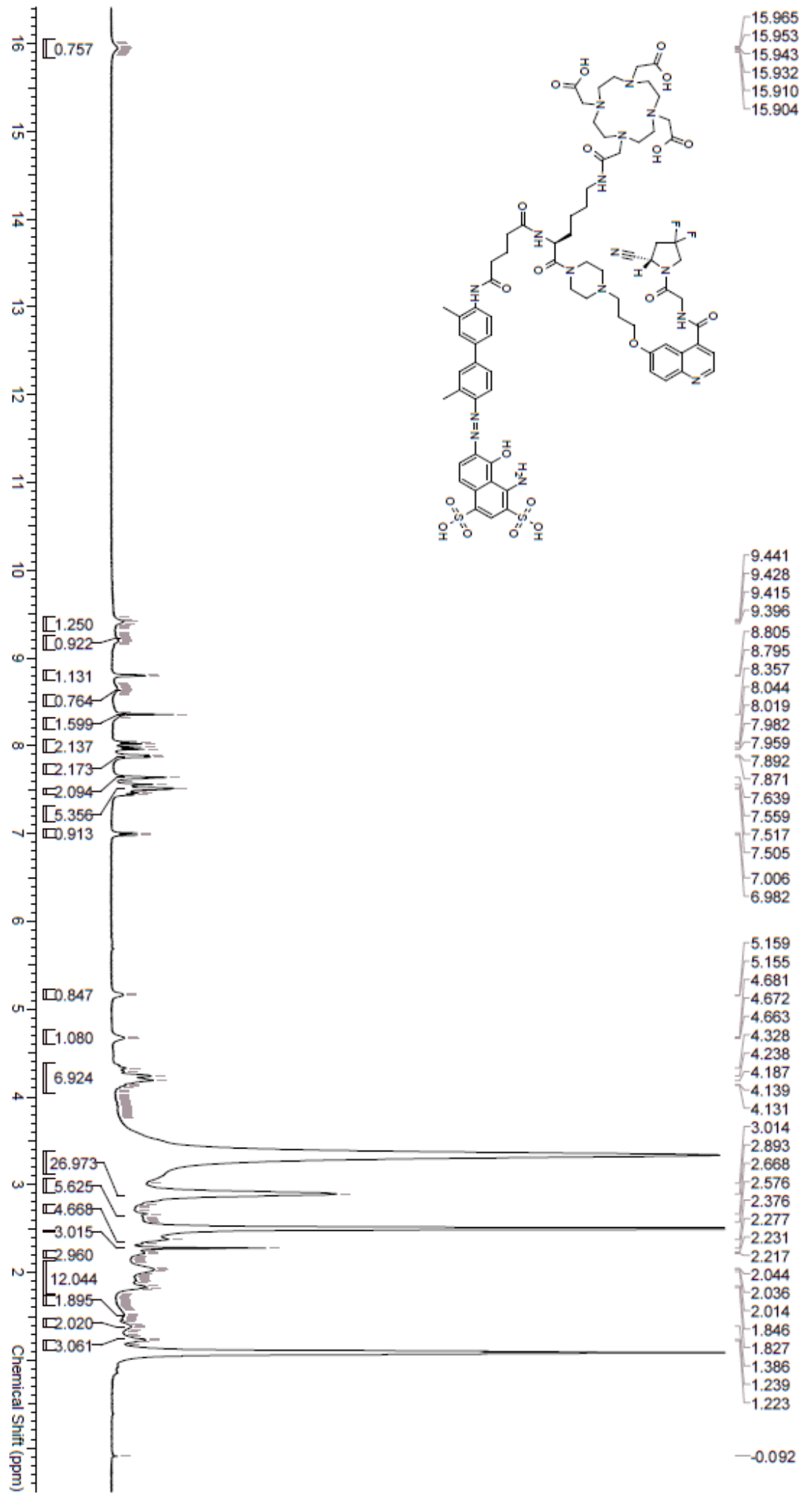


Supplemental Fig 11. ${ }^{19} \mathrm{~F}$ NMR analysis of TEFAPI-06.

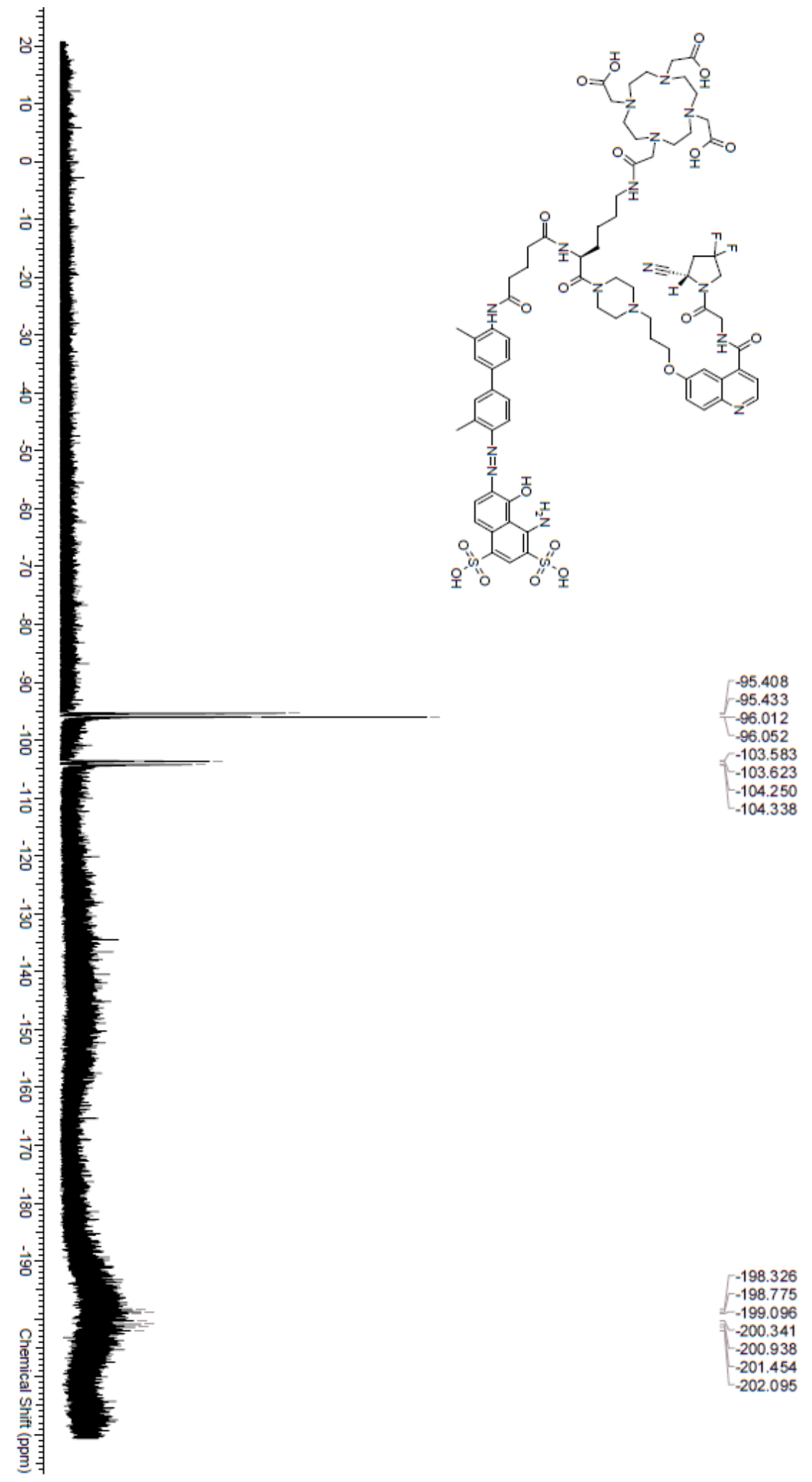


Supplemental Fig 12. ${ }^{1} \mathrm{H}$ NMR analysis of FAPI_F2.

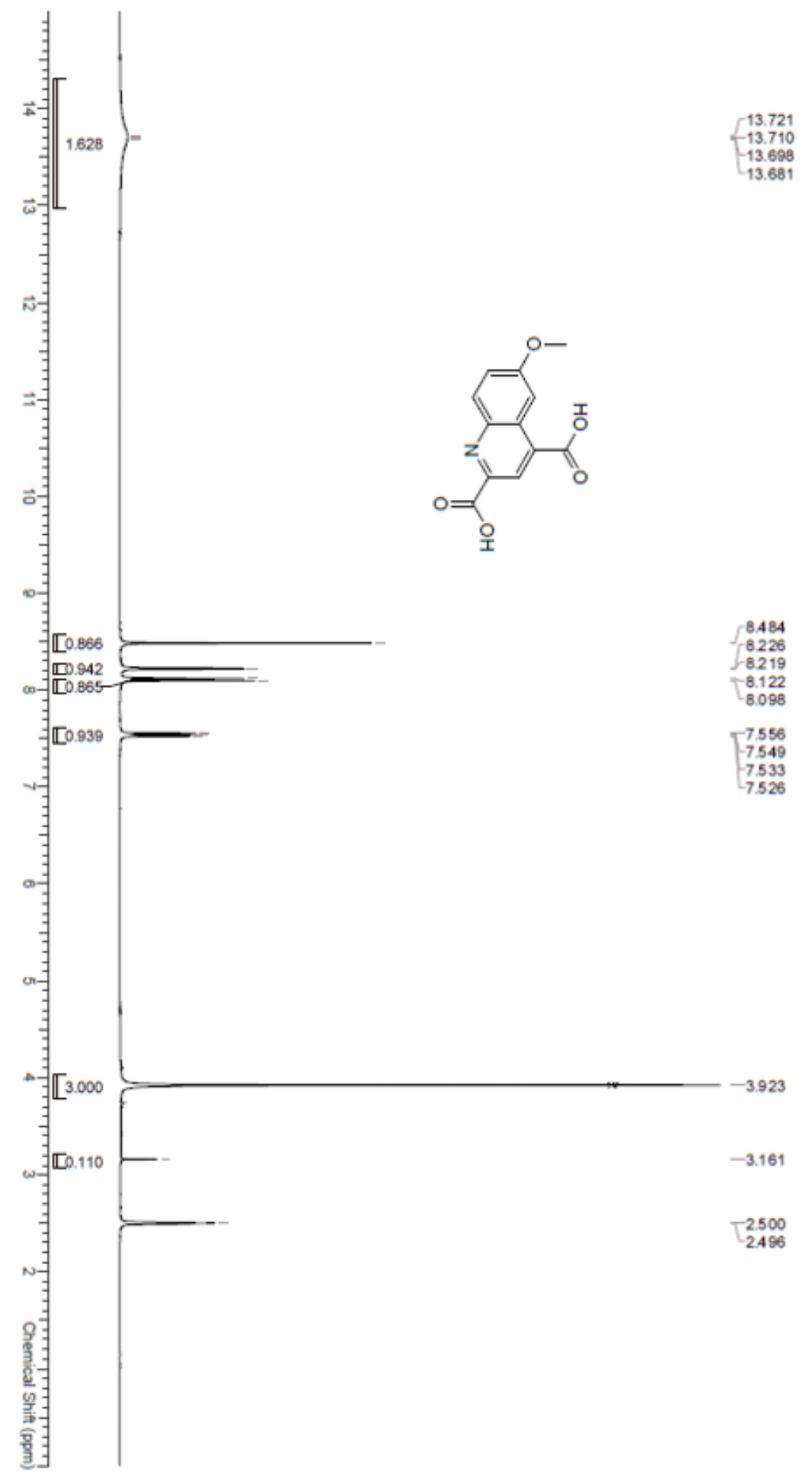


Supplemental Fig 13. ${ }^{1} \mathrm{H}$ NMR analysis of FAPI_C3.

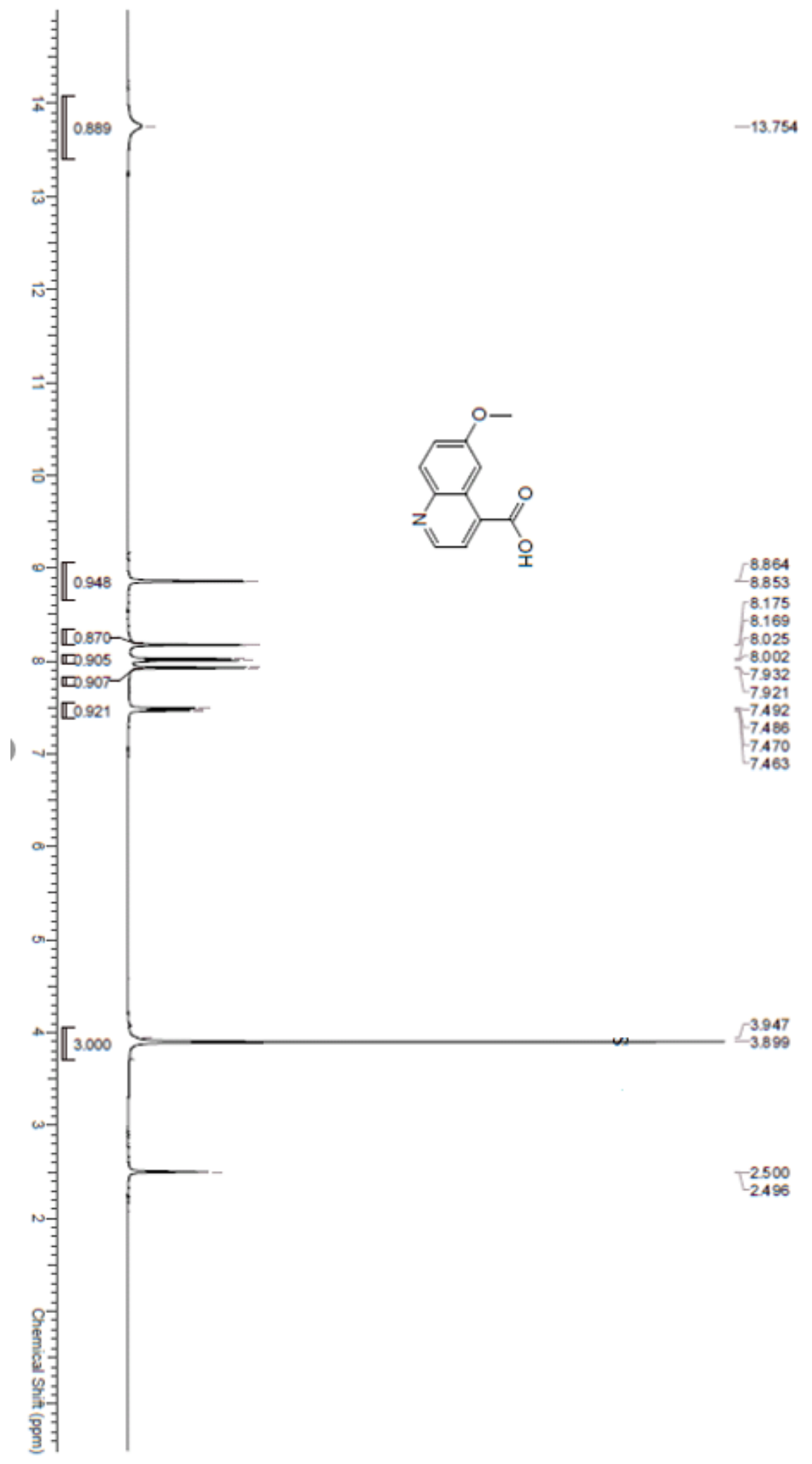


Supplemental Fig 14. ${ }^{1} \mathrm{H}$ NMR analysis of FAPI_C4.

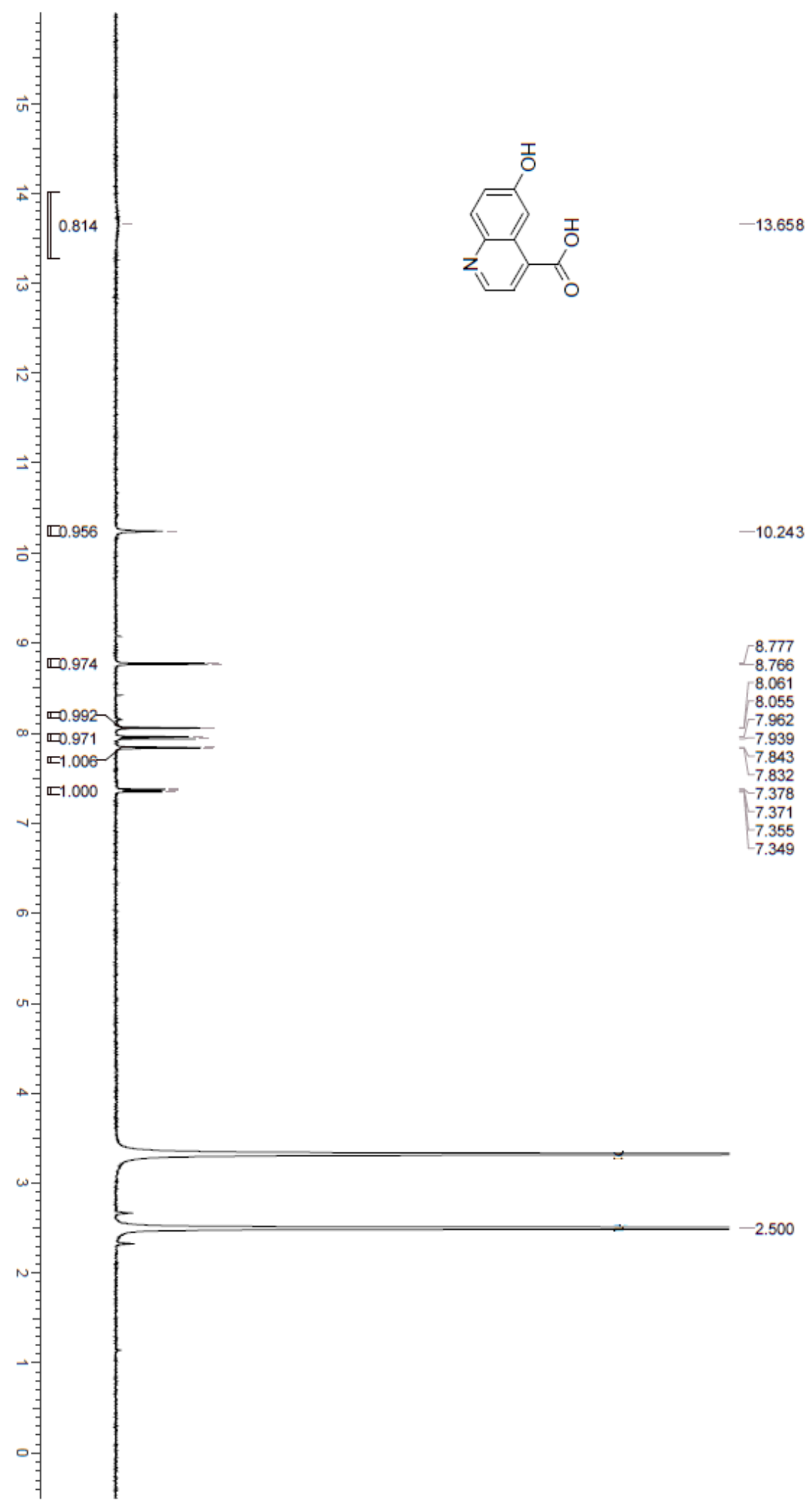


Supplemental Fig 15. ${ }^{1} \mathrm{H}$ NMR analysis of FAPI_C5.

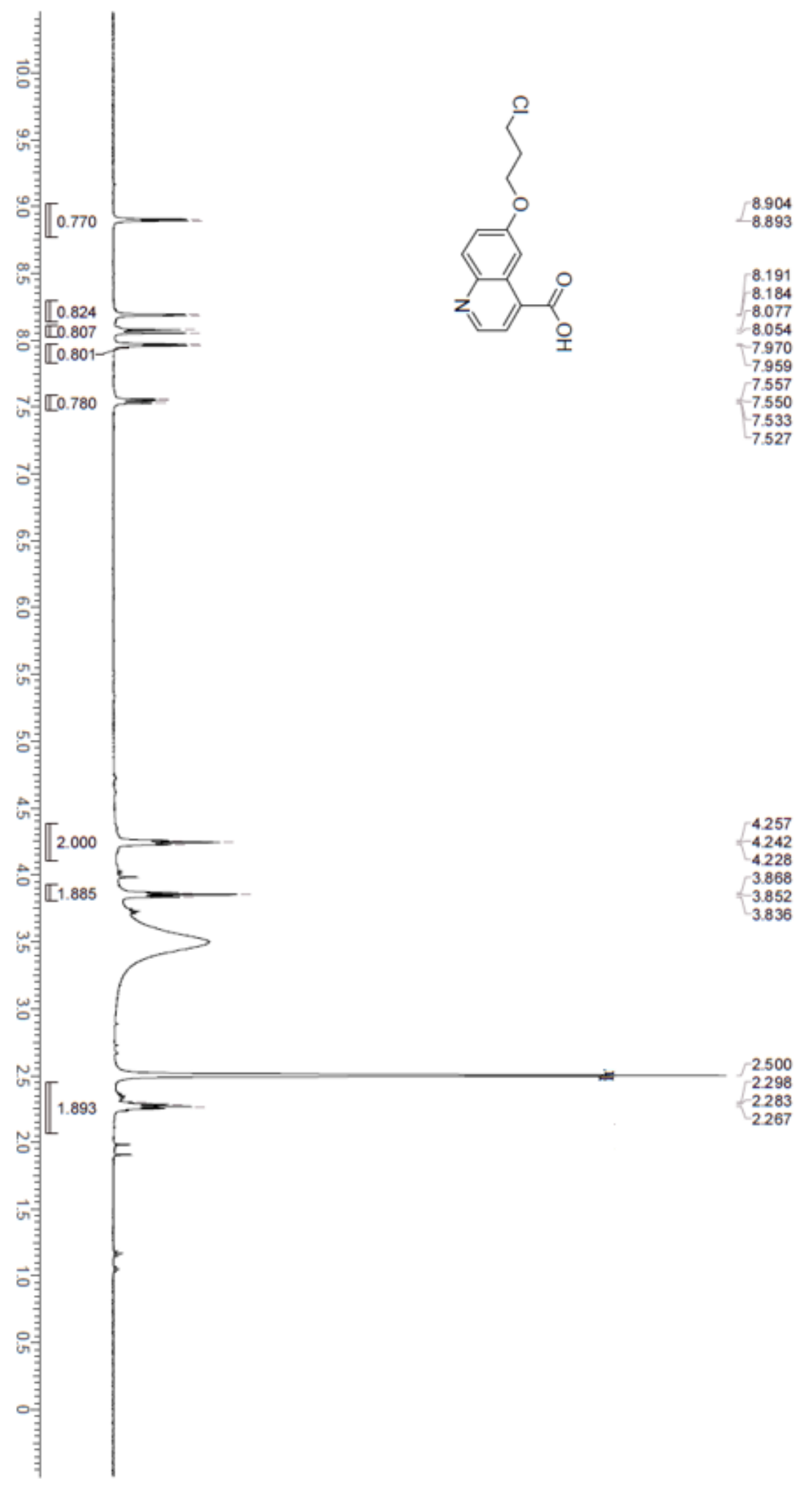


Supplemental Fig 16. ${ }^{1} \mathrm{H}$ NMR analysis of FAPI_C6.

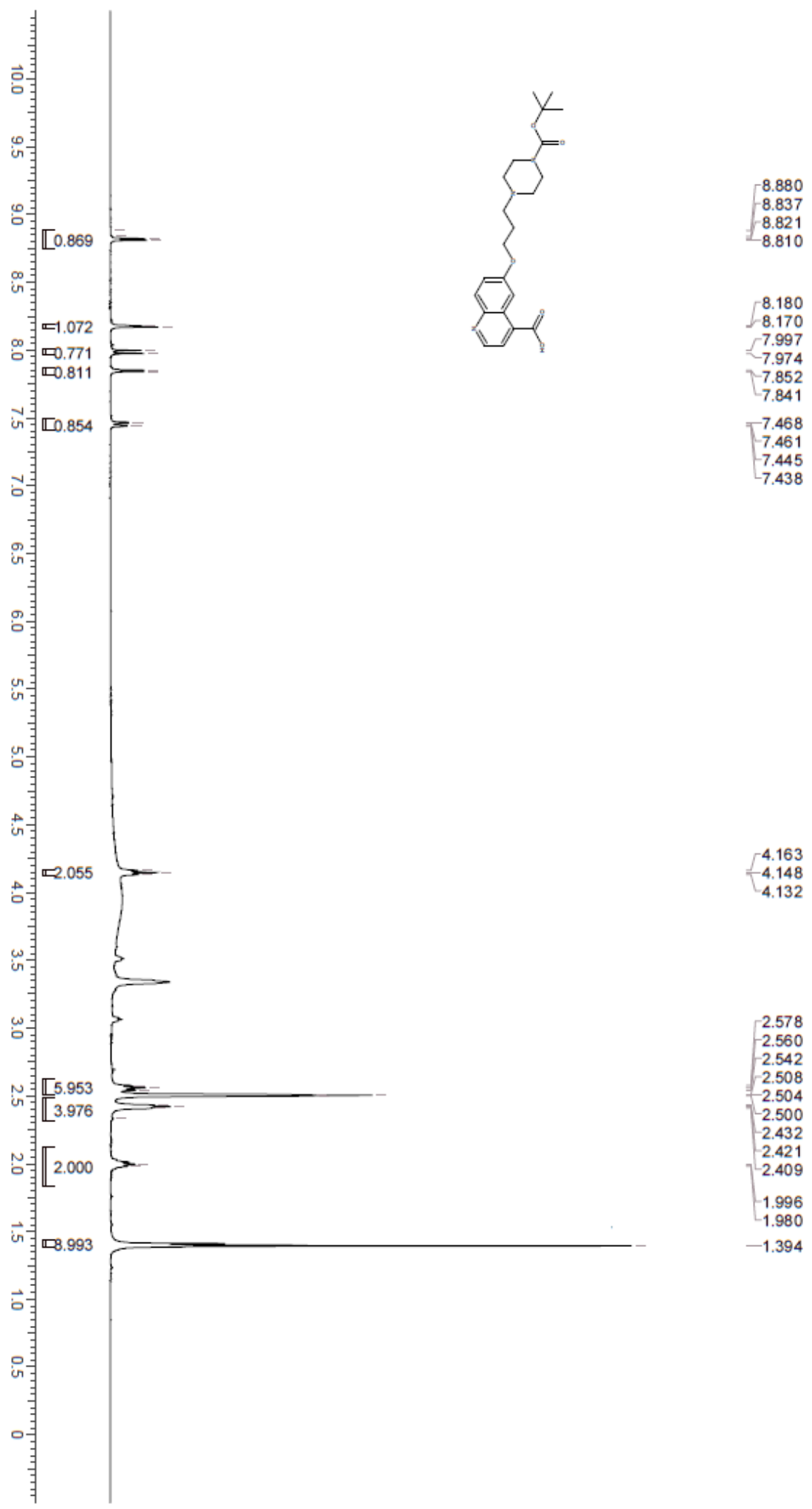


Supplemental Fig 17. ${ }^{1} \mathrm{H}$ NMR analysis of FAPI_C7.

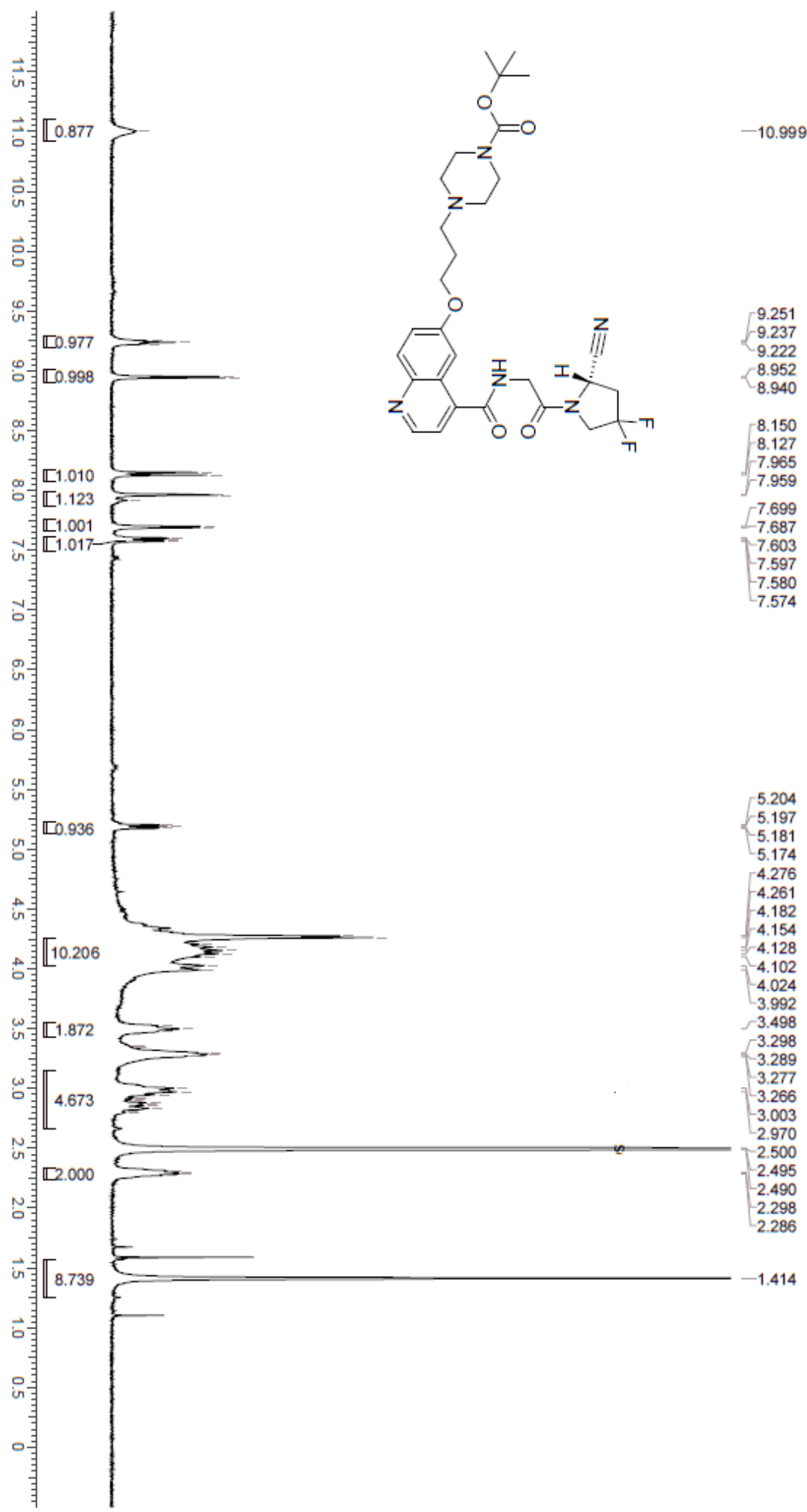


Supplemental Fig 18. ${ }^{19}$ F NMR analysis of FAPI_C7.
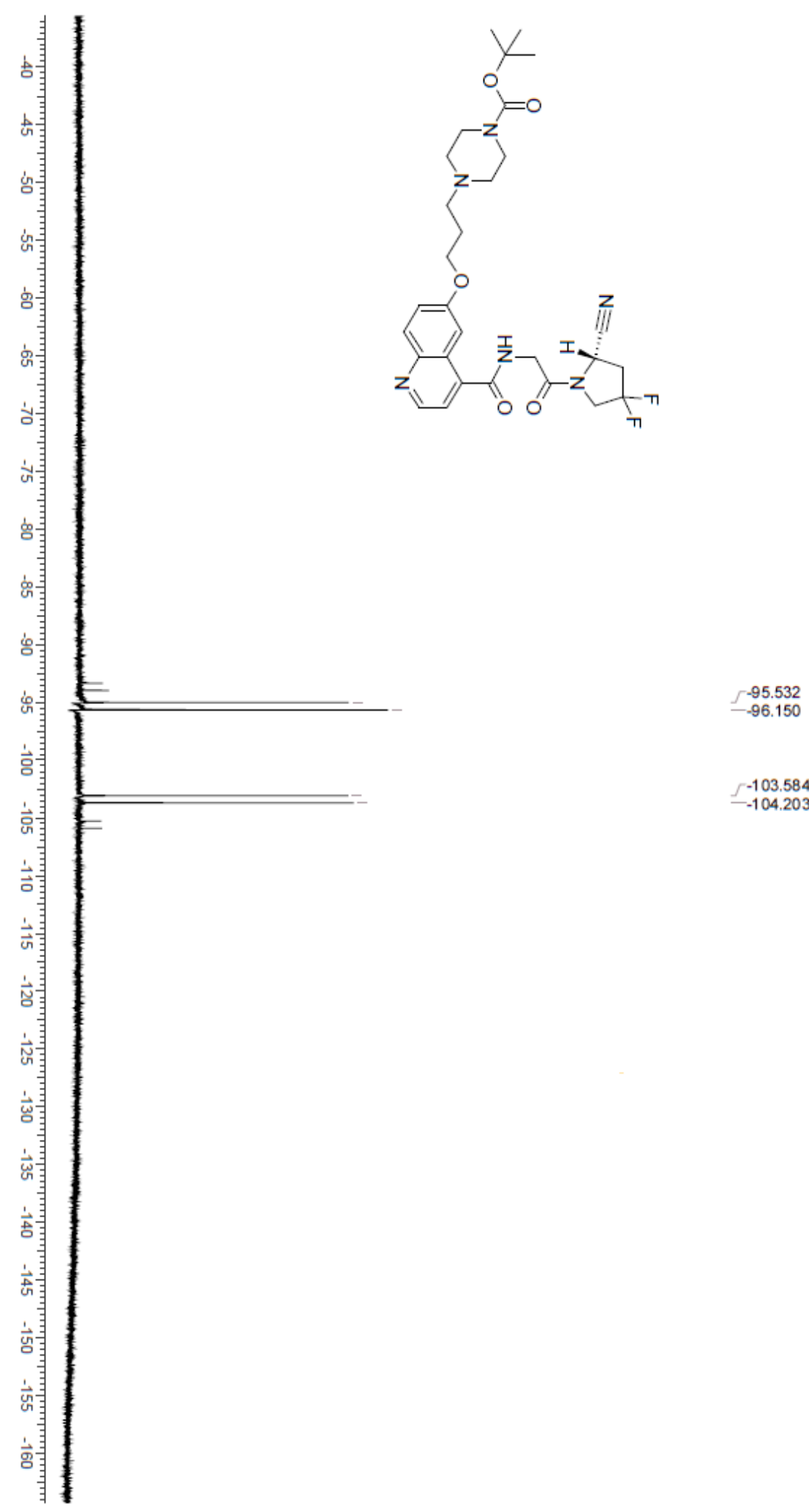

$-103.584$ $-104.203$ 
Supplemental Fig 19. MS analysis of FAPI_C8.

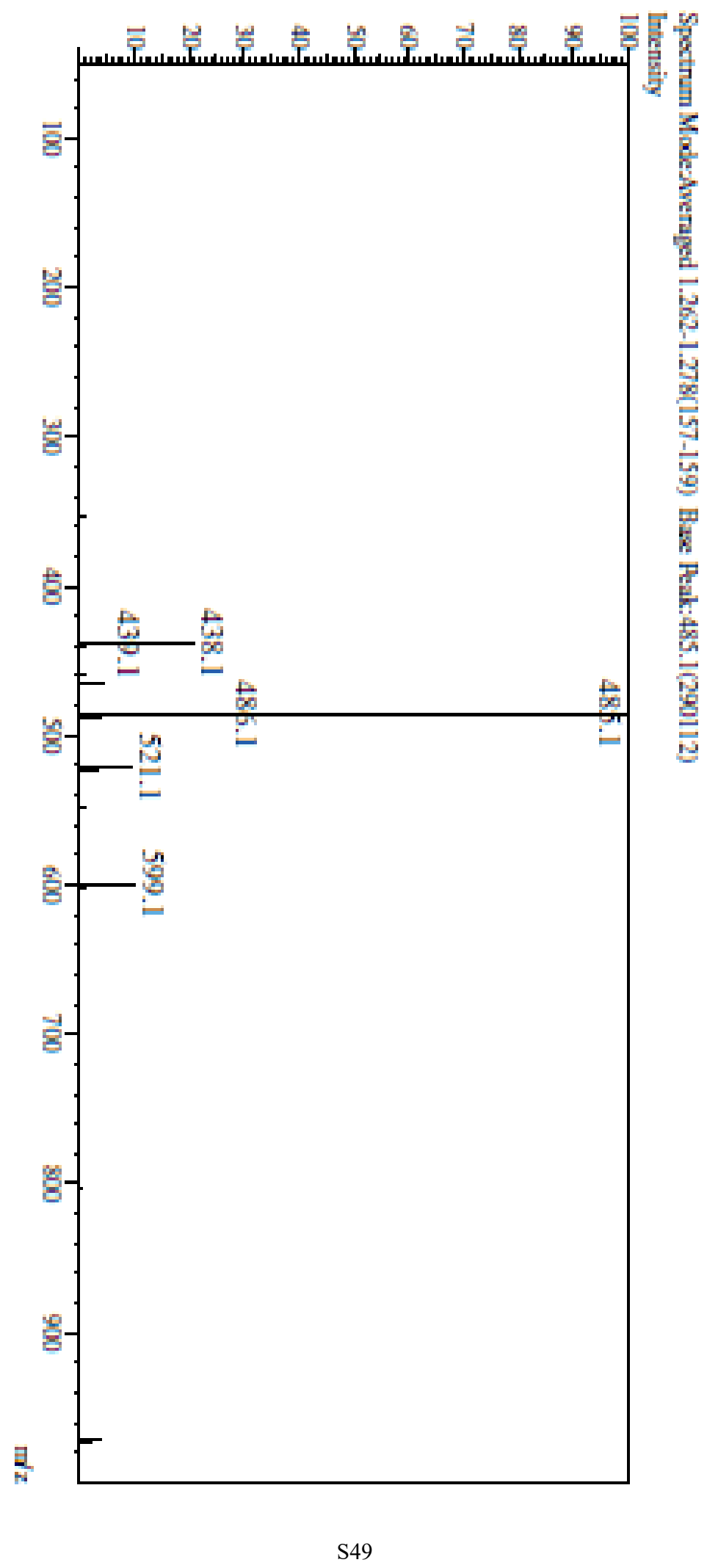


Supplemental Fig 20. ${ }^{1} \mathrm{H}$ NMR analysis of FAPI_D2.

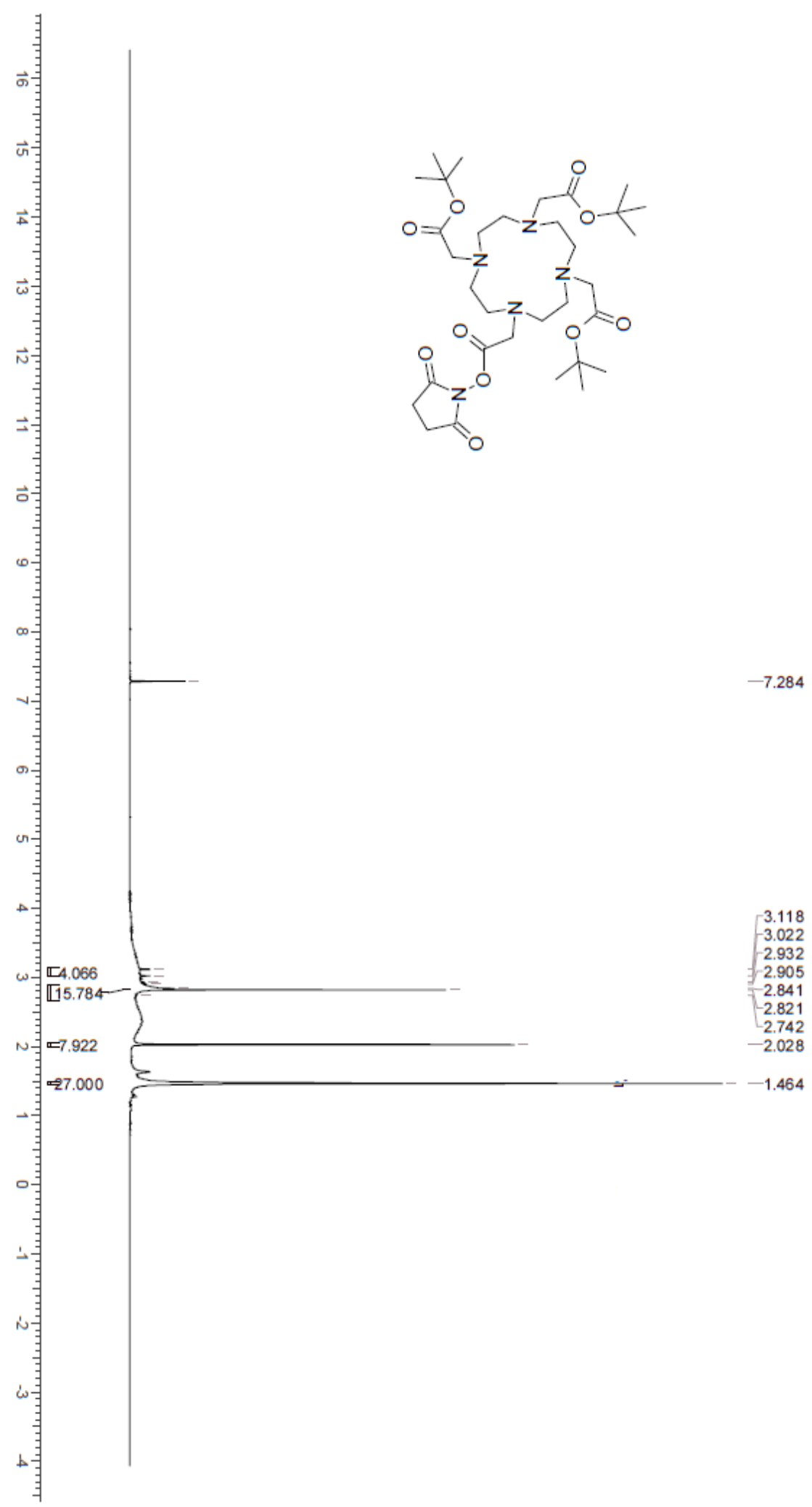




\section{2. ${ }^{68} \mathrm{Ga}-\mathrm{FAPI}-04$ PET imaging and IHC staining results of pancreatic PDX tumor}
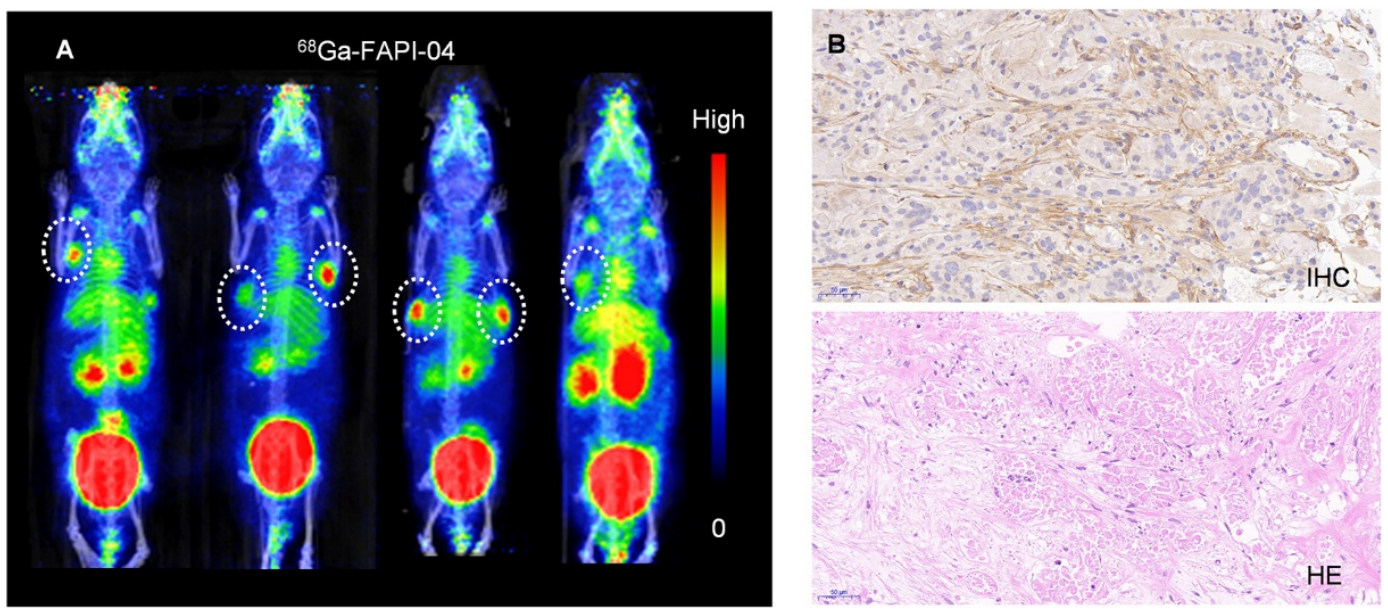

Supplemental Fig 21. (A)PET imaging of four pancreatic PDX tumor bearing mice using ${ }^{68} \mathrm{Ga}$-FAPI-04. (B) IHC staining of FAP expression and HE staining in excised pancreatic PDX tumor. 


\section{Radiolabeling and HPLC test procedure and stability results of in}

\section{vitro stability analysis}

${ }^{68} \mathrm{Ga}$-FAPI-04, ${ }^{68} \mathrm{Ga}$-TEFAPI-06 and ${ }^{68} \mathrm{Ga}$-TEFAPI-07 were prepared using sodium hydroxide $(3 \mathrm{M})$ and sodium acetate $(3 \mathrm{M})$ to adjust the ${ }^{68} \mathrm{GaCl}_{3}$ solution in $0.6 \mathrm{M}$ hydrochloric acid to $\mathrm{pH} 4.5$, the mixture was heated at $90{ }^{\circ} \mathrm{C}$ for $10 \mathrm{~min}$ to obtain the labeling product. ${ }^{86}$ Y-TEFAPI-06 and ${ }^{86}$ Y-TEFAPI-07 were prepared using sodium acetate (3 M) to adjust the ${ }^{86} \mathrm{YCl}_{3}$ solution in $0.1 \mathrm{M}$ hydrochloric acid to $\mathrm{pH} 4.5$, the labeling condition was also incubation at $90{ }^{\circ} \mathrm{C}$ for $10 \mathrm{~min} .{ }^{177} \mathrm{Lu}$-FAPI-04, ${ }^{177} \mathrm{Lu}$-TEFAPI-06 and

${ }^{177} \mathrm{Lu}$-TEFAPI-07 were prepared in sodium acetate buffer ( $\mathrm{pH} 4.5-5.0,0.2 \mathrm{M}$ ), the mixture was heated at $90{ }^{\circ} \mathrm{C}$ for $10 \mathrm{~min}$. The $\mathrm{pH}$ of the labeling mixture was detected using $\mathrm{pH}-$ indicator strips. After heating, the reaction mixture was diluted into $5 \mathrm{~mL}$ saline in a syringe and purified by using a pre-conditioned Sep-Pak Light C18 cartridge (Waters) activated by ethanol $(5 \mathrm{~mL})$ and water $(5 \mathrm{~mL})$. For radiolabeled TEFAPI-06, the product was eluted with about $300 \mu \mathrm{LEtOH}$, and for radiolabeled TEFAPI-07, the product was eluted with about $300 \mu \mathrm{L} \mathrm{EtOH} /$ saline solution containing $20 \%$ saline. The elution of the radiolabeling product was diluted with saline to control the $\mathrm{EtOH}$ content was under $10 \%$ for injection. All the labeling products were purified by solid phase extraction and qualified by high performance liquid chromatography equipped with radioactivity detector (radio-HPLC). Stability of ${ }^{177} \mathrm{Lu}$-TEFAPI-06 and ${ }^{177} \mathrm{Lu}$-TEFAPI-07 in saline and human serum were monitored from $2 \mathrm{~h}$ to $168 \mathrm{~h}$ using radio-HPLC. The chromatograms were collected on a XBridge C18 column $(4.6 \times 150 \mathrm{~mm}, 5 \mu \mathrm{m}$, Waters $)$ at $35^{\circ} \mathrm{C}$. Water with $0.1 \%$ TFA was used as mobile phase A and acetonitrile with $0.1 \%$ TFA was used as mobile phase B, the gradient condition was: 0-2 min, 10\% B; 2-10 min, 10\%-60\% B; 10-12 min, 60\% B; $12-$ $15 \mathrm{~min}, 60 \%-10 \% \mathrm{~B}$, and the flow rate was $1 \mathrm{~mL} / \mathrm{min}$. 

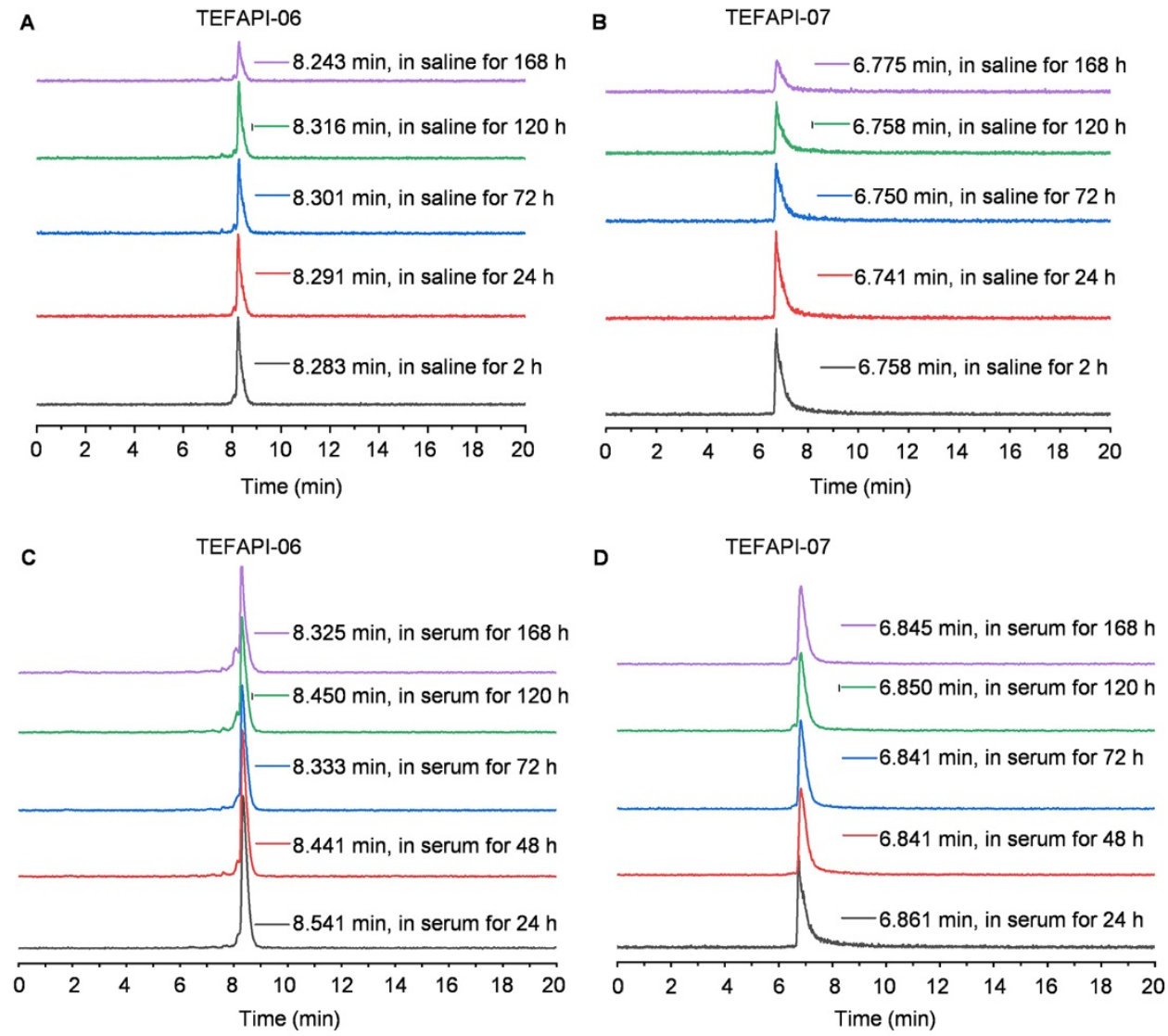

Supplemental Fig 22. In vitro stability analysis of ${ }^{177} \mathrm{Lu}$-TEFAPI-06 and ${ }^{177} \mathrm{Lu}$-TEFAPI07. 


\section{Results of cell assays}
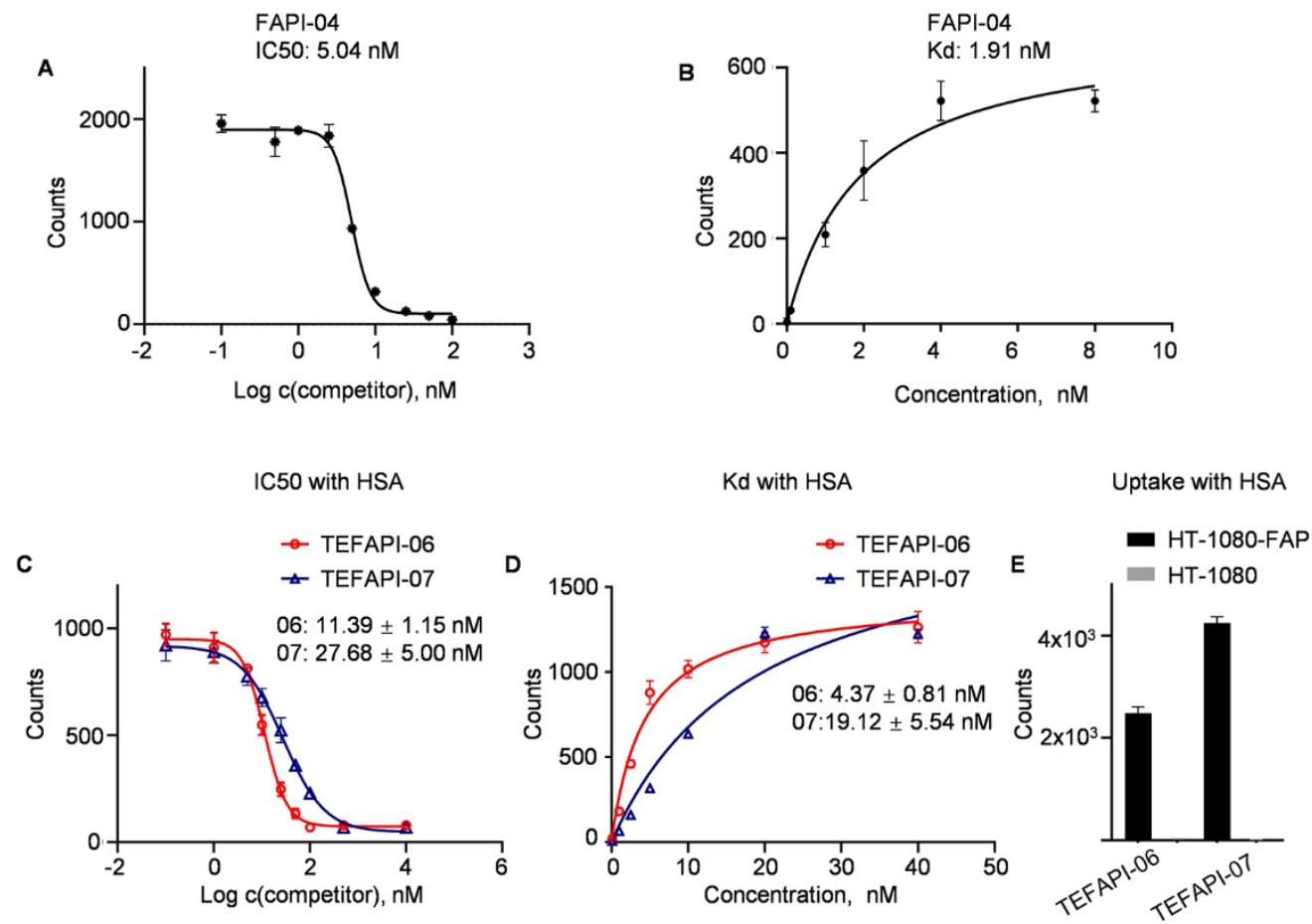

Supplemental Fig 23. (A) Competition assay of FAPI-04; (B) Saturation binding assay of

${ }^{68}$ Ga-FAPI-04. (C) Competition assays of TEFAPI-06 and TEFAPI-07 in the absence of albumin; (D) Saturation binding assays of radiolabeled TEFAPI-06 and TEFAPI-07 in the absence of albumin; (E) Cellular uptake assays of ${ }^{68} \mathrm{Ga}$-TEFAPI-06 and ${ }^{68} \mathrm{Ga}$-TEFAPI-07 in HT-1080-FAP and HT-1080 cells in the presence of albumin. 


\section{PET imaging results of ${ }^{86}$ Y-FAPI-04 in PDX-bearing mice}
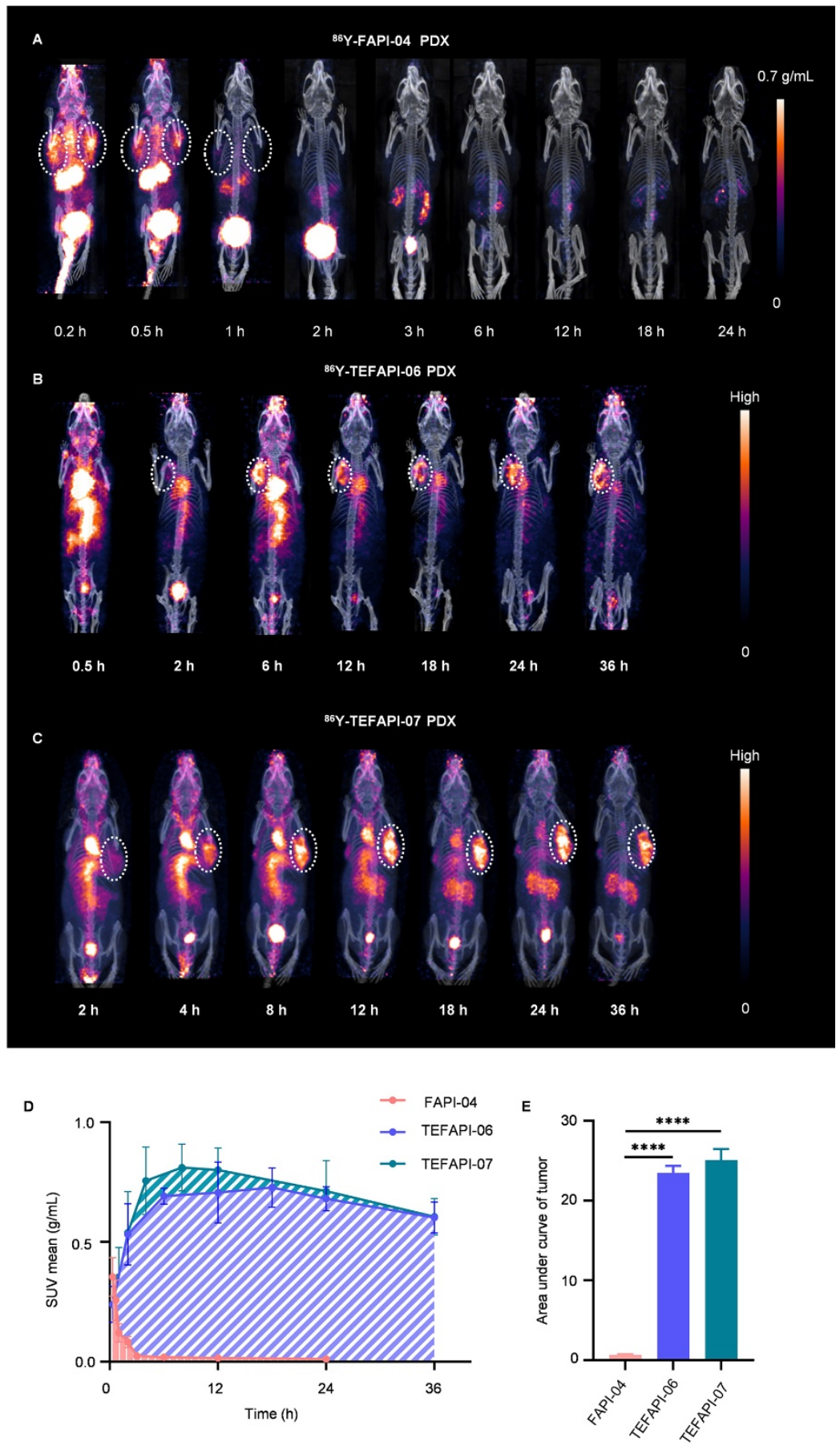

Supplemental Fig 24. (A-C) PET imaging of ${ }^{86}$ Y-FAPI-04 (A), ${ }^{86}$ Y-TEFAPI-06 (B) and ${ }^{86}$ Y-TEFAPI-07 (C) at the indicated time points post injection in PDX-bearing mice. (D) The time-activity curves for tumor of ${ }^{86}$ Y-FAPI-04, ${ }^{86}$ Y-TEFAPI-06 and ${ }^{86}$ Y-TEFAPI-07. 
(E) The area under the curve (AUC) of ${ }^{86}$ Y-TEFAPI-06 and ${ }^{86}$ Y-TEFAPI-07 in tumor is significantly higher than the AUC of ${ }^{86}$ Y-FAPI-04, respectively.

\section{PET imaging results of HT-1080-FAP and HT-1080 tumor bearing mice}

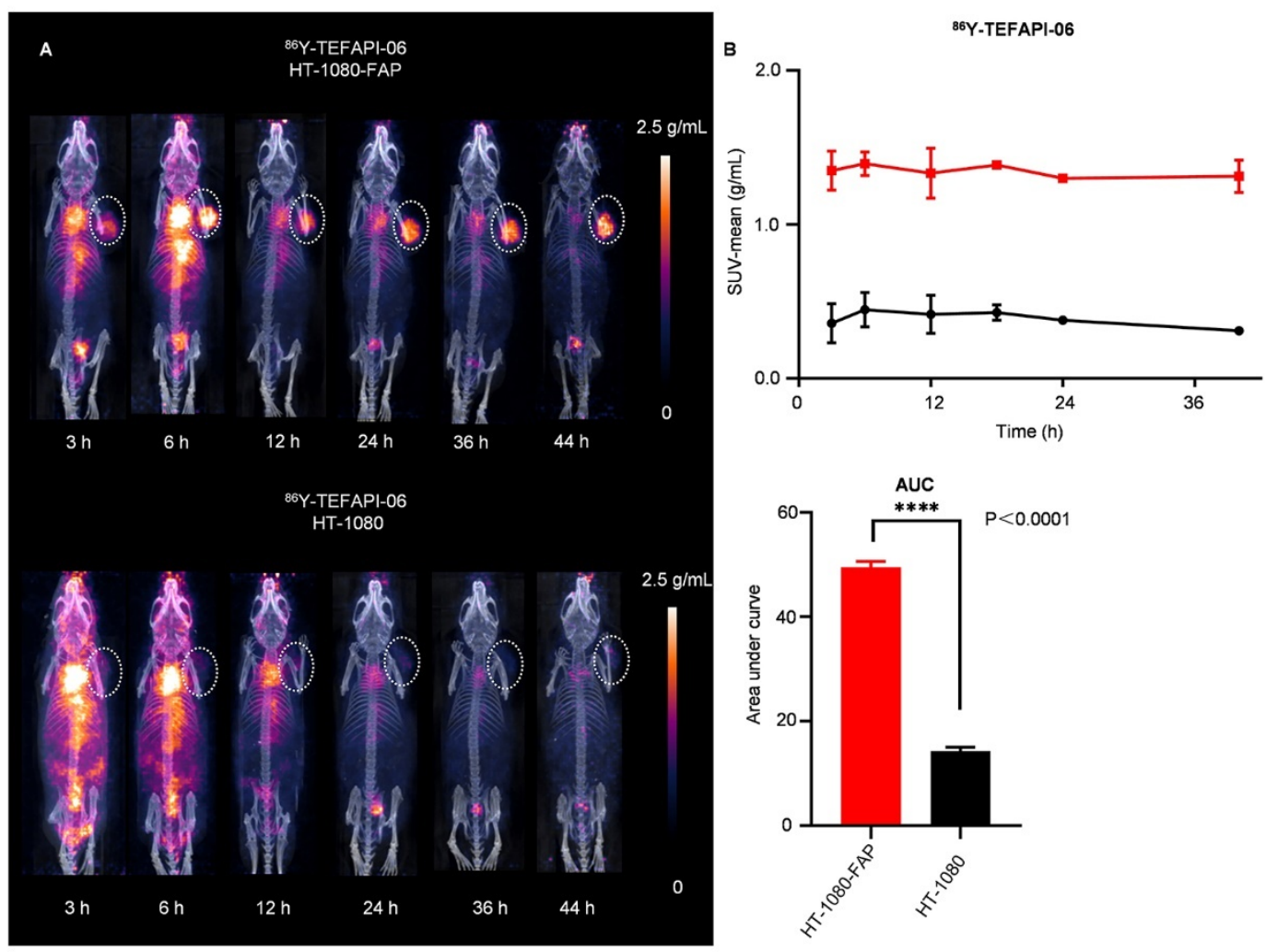

Supplemental Fig 25. (A) PET imaging of ${ }^{86}$ Y-TEFAPI-06 in HT-1080-FAP and HT1080 tumor bearing mice; (B) Time-activity curve and area under the curve for HT-1080FAP and HT-1080 tumor 

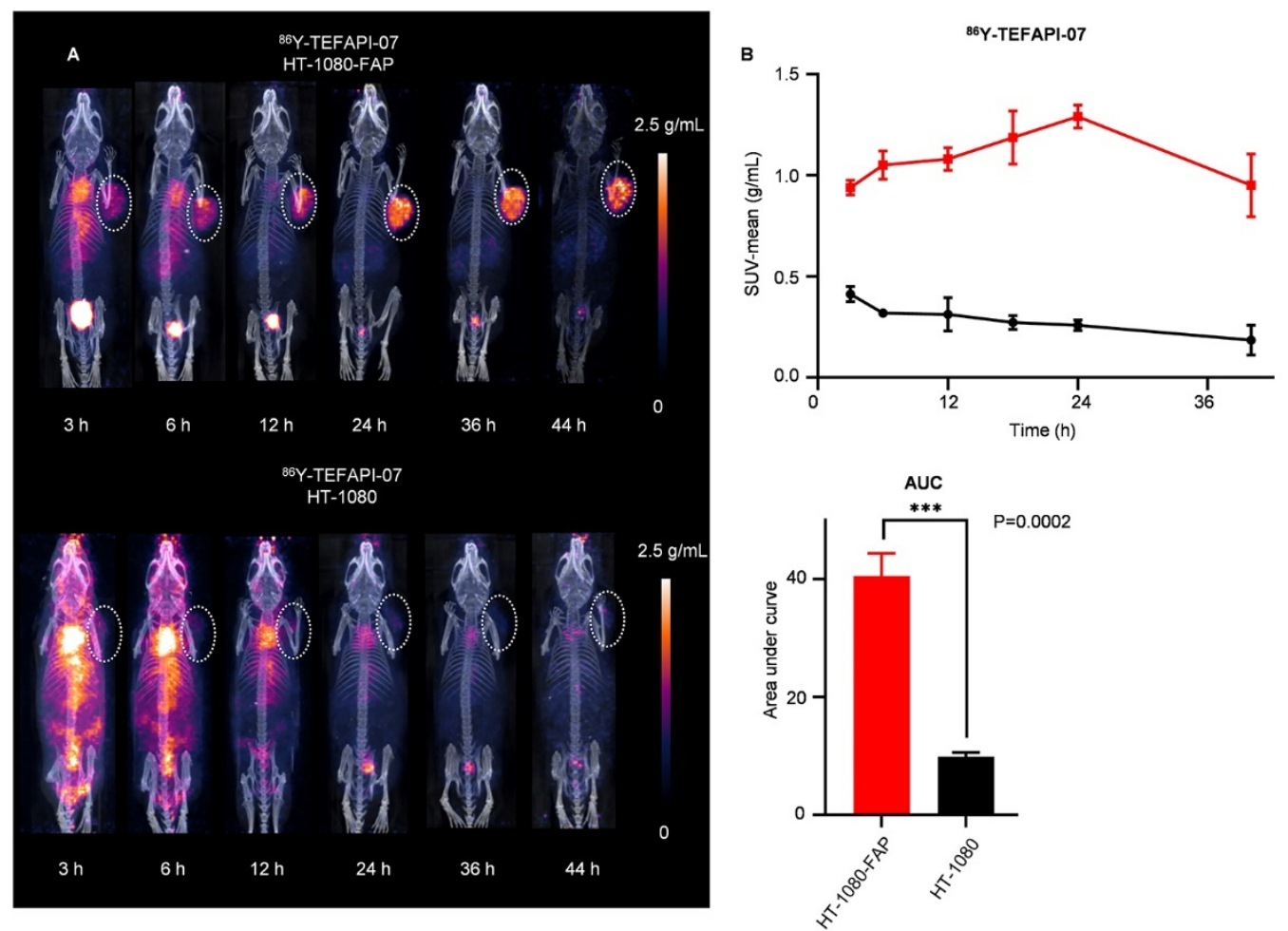

Supplemental Fig 26. (A) PET imaging of ${ }^{86}$ Y-TEFAPI-07 in HT-1080-FAP and HT1080 tumor bearing mice; (B) Time-activity curve and area under the curve for HT-1080FAP and HT-1080 tumor 


\section{Blocking study results of TEFAPI-06 or TEFAPI-07}

A

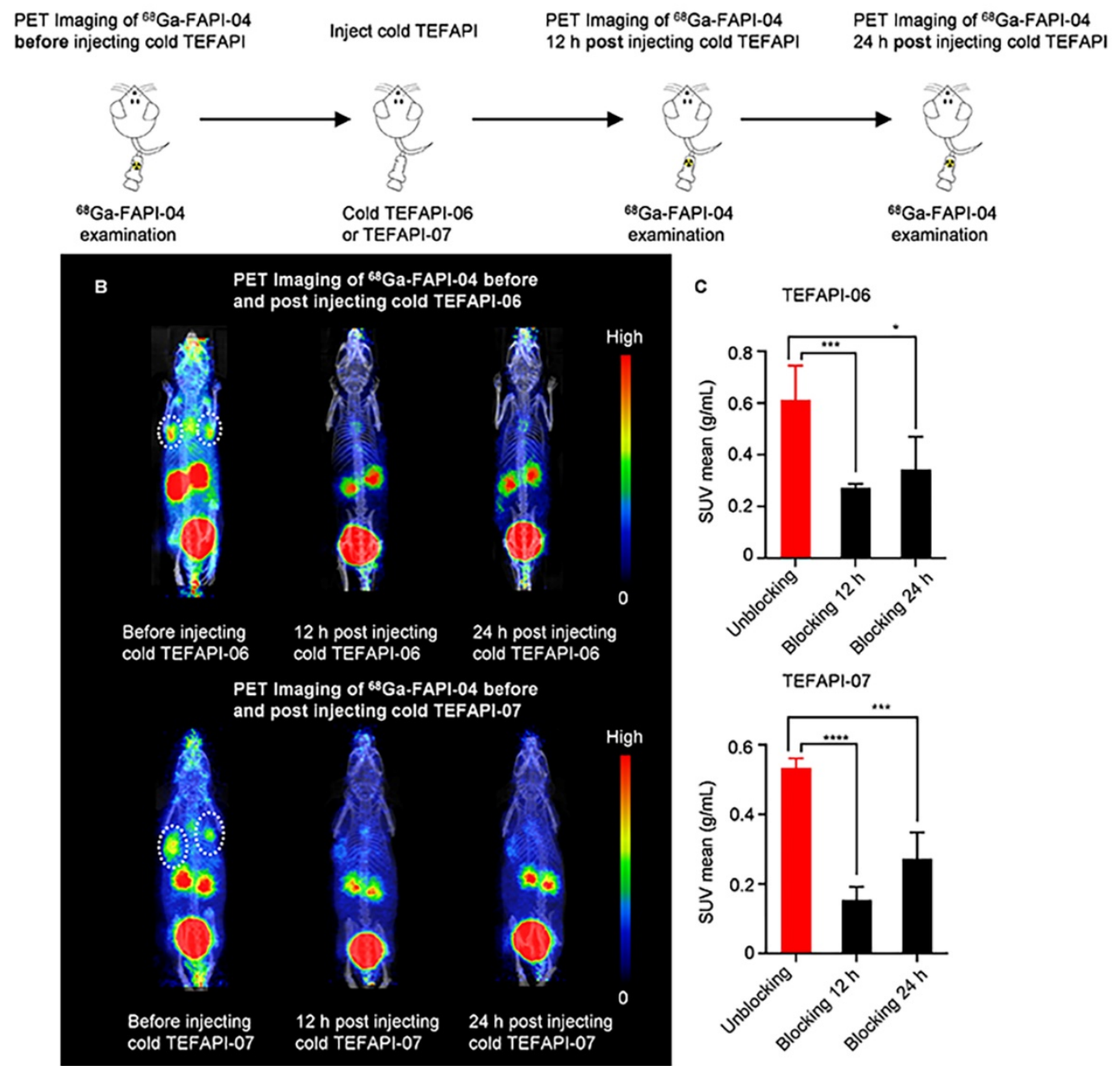

Supplemental Fig 27. (A) Blocking study by pre-treated with non-radiolabeled TEFAPI06 or TEFAPI-07. (B) PET imaging of ${ }^{68}$ Ga-FAPI-04 in PDX-bearing mice at 30 min post injection with or without the treatment of TEFAPI-06 or TEFAPI-07. (C) A series of PET images have been recorded before or at $12 \mathrm{~h}, 24 \mathrm{~h}$ after treatment with TEFAPI; The corresponding ROI analysis of tumor uptake with or without the treatment of TEFAPI-06 or TEFAPI-07. 
8. SPECT imaging results of ${ }^{177} \mathrm{Lu}$-TEFAPI-06 and ${ }^{177} \mathrm{Lu}$-TEFAPI-07

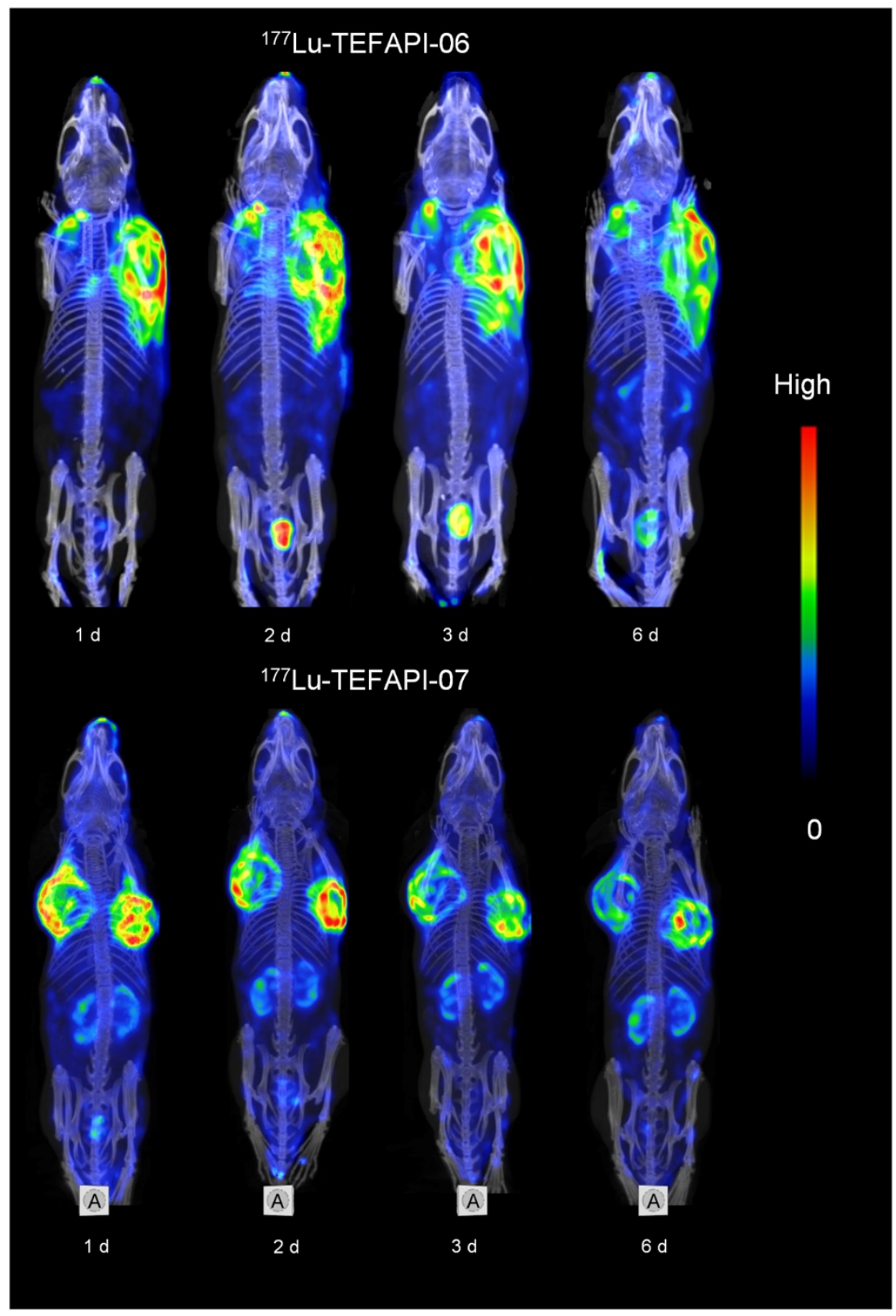

Supplemental Fig 28. SPECT imaging results of ${ }^{177} \mathrm{Lu}$-TEFAPI-06 and ${ }^{177} \mathrm{Lu}$-TEFAPI-07 using pancreatic PDX tumor bearing mice. 


\section{Results of histopathologic staining}

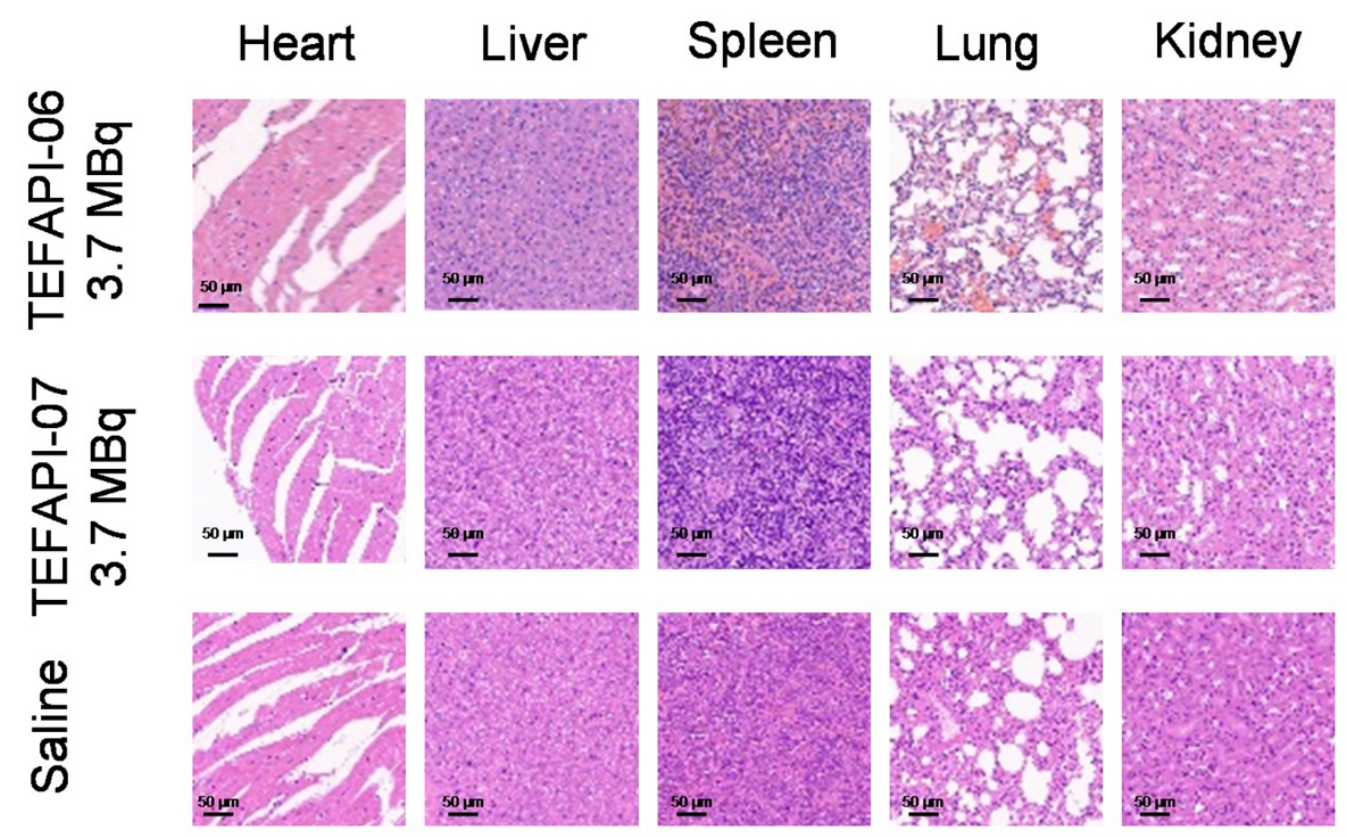

Supplemental Fig 29. H\&E staining of excised main organs including heart, liver, spleen, lung and kidney after treatment with ${ }^{177} \mathrm{Lu}$-TEFAPI-06, ${ }^{177} \mathrm{Lu}$-TEFAPI-07 and saline, respectively. 